\title{
REGULATION AND FUNCTION OF THE FANCONI ANEMIA PATHWAY FOR GENOME MAINTENANCE
}

\author{
Natalie Bucheimer Collins \\ Charlottesville, Virginia
}

Bachelor of Science, University of Maryland at College Park, 2000

A Dissertation presented to the Graduate Faculty of the University of Virginia in Candidacy for the Degree of Doctor of Philosophy

Department of Microbiology

University of Virginia January, 2008

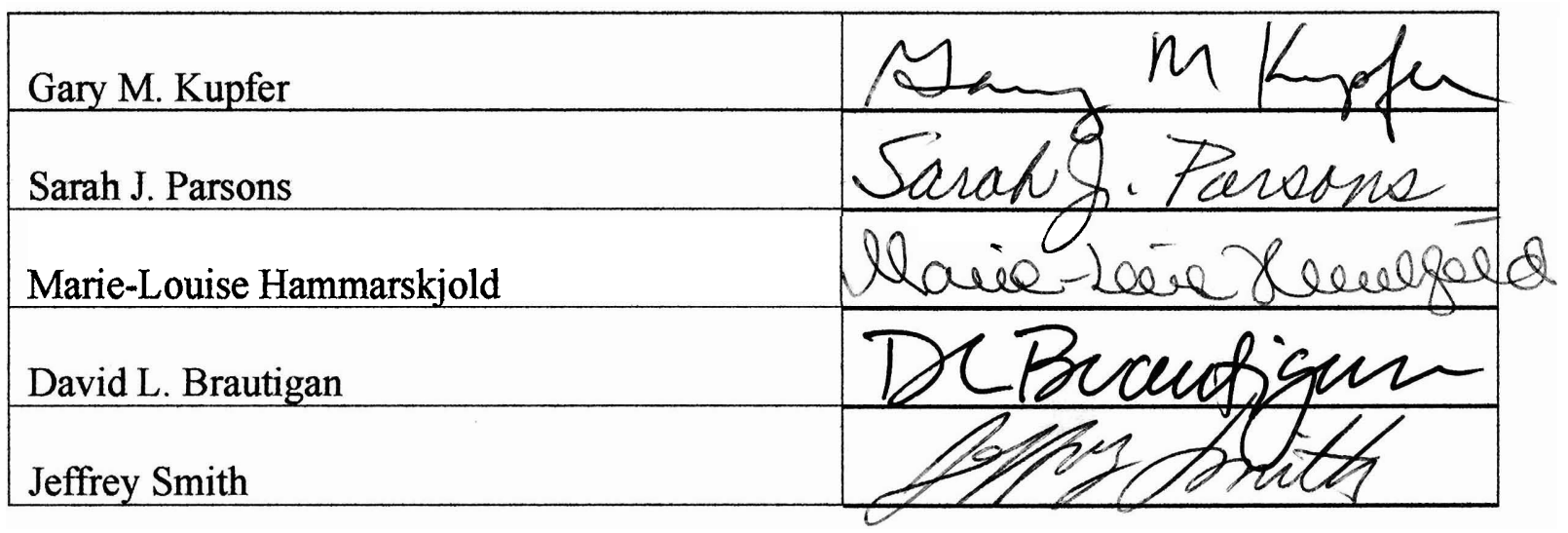




\section{ABSTRACT}

Fanconi anemia (FA) is an inherited disease characterized by a variety of congenital defects, aplastic anemia, and a predisposition to cancer. On a cellular level, cells from FA patients display hypersensitivity to DNA crosslinking agents and an increased level of chromosomal rearrangements, making FA a disease of genome instability. As genome instability is a hallmark of most malignancies, FA offers a unique and valuable system in which to study human carcinogenesis.

At least 13 genes and their corresponding protein products cooperate in the FA pathway, and mutation of any of these genes results in a similar phenotype. Research on FA has been limited by the fact that few of the genes involved have homologues in lower eukaryotes and few of the proteins contain conserved motifs suggestive of function. As such, FA represents a mechanism of genome maintenance restricted to higher eukaryotes.

The ultimate goal of this work was to determine the function of the FA pathway by identifying other interacting proteins with known or discernable function and by determining pathways by which the FA pathway is regulated. We demonstrate that FANCA, a member of the FA pathway, is phosphorylated in response to DNA damage, that this phosphorylation is critical to the function of the pathway, and that this phosphorylation is dependent on ATR kinase, an important kinase in the cellular DNA damage response. Furthermore, we establish an interaction between the FA pathway, RNA transcription, and RNA Polymerase II, an interaction suggestive of a previously unknown function for the FA pathway and a new facet of the DNA damage response. This places FA within the context of the overall cellular response to DNA damage and defines a novel mechanism for human genome maintenance. 


\section{ACKNOWLEDGEMENTS}

First and foremost recognition for this work goes to Gary Kupfer, my scientific mentor. As a physician-scientist in training I was fortunate to work for Gary, who balances his role as both with great success and expertise. I am fortunate to have had the unique opportunity to not only be taught scientifically, but also to attend clinical rounds with him. His enthusiasm and giftedness as a clinician has inspired me in my future career.

To my thesis committee members, I wish to say thank you for expert scientific guidance, for always being available, for seeing me through to the end, for constant encouragment, and for making our meetings always collegial.

Along the way there have been many lab members who have influenced me and shaped my thinking. I thank all the members of the lab over the years for assistance, encouragement, and friendship. Working as a team and interacting with all of them has been a great joy of graduate school. Specifically, Amy Moss and Jen Phillips have blessed me with invaluable friendships. I would do this all over again, just for the opportunity to make these friendships.

Navigating this road along with me has been my sister, Elaine. As we have done for most of our lives, we did this together, and I hope we never stop living our lives together.

Finally, my husband Chris is my companion, love, and greatest blessing. He makes every day joyful, and inspires me to achieve my best. Any success I have found in this work I owe to him and his inspiration. 
TABLE OF CONTENTS

CHAPTER 1: MOLECULAR PATHOGENESIS OF FANCONI ANEMIA............. 1

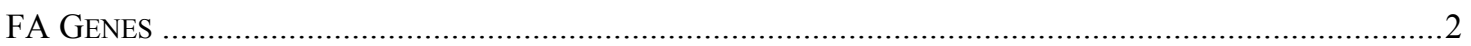

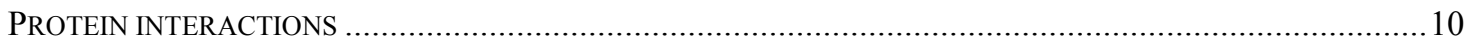

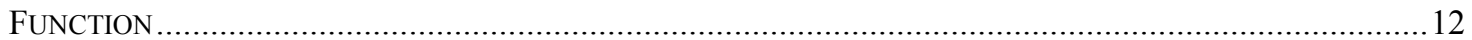

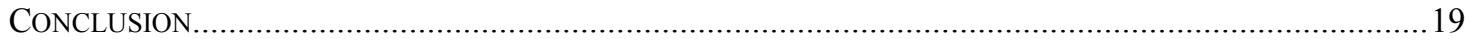

CHAPTER 2: THESIS RATIONALE AND SPECIFIC AIMS ................................. 23

CHAPTER 3: ATR-DEPENDENT PHOSPHORYLATION OF FANCA ON SERINE 1449 AFTER DNA DAMAGE IS IMPORTANT FOR FA PATHWAY

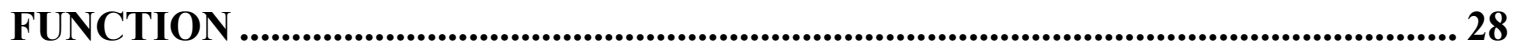

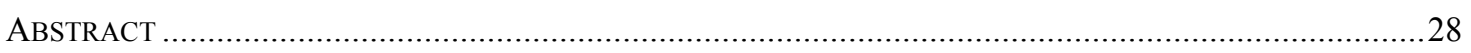

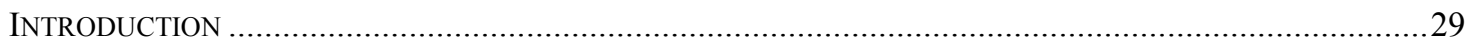

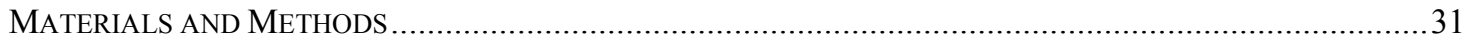

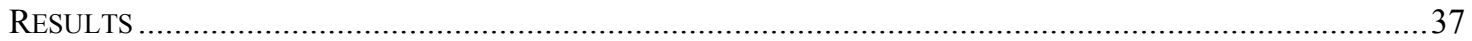

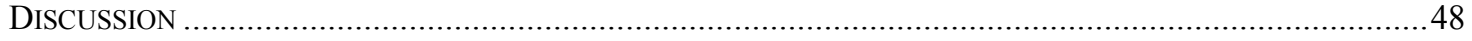

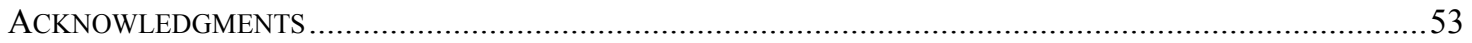

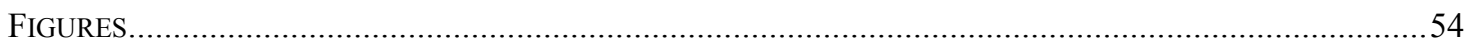

CHAPTER 4: INTERACTION OF THE FA PATHWAY WITH RNA................ 71

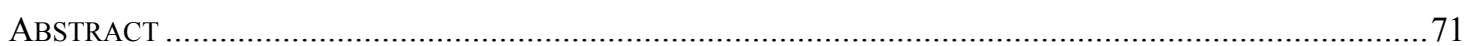

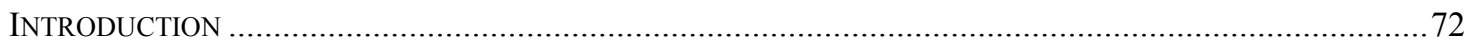

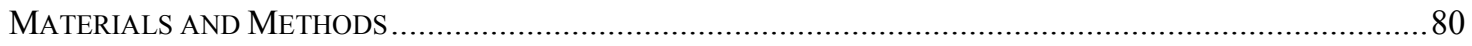

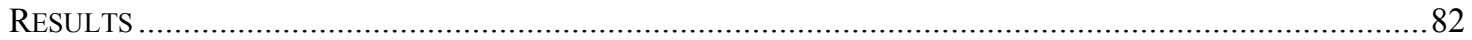

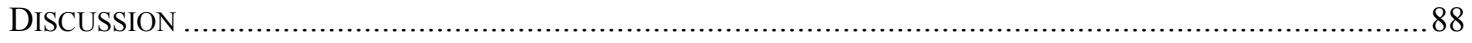

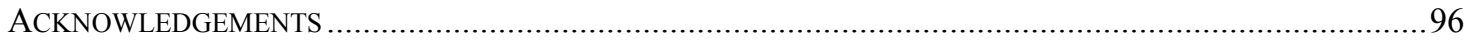

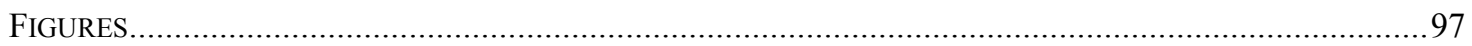

CHAPTER 5: CONCLUSIONS AND FUTURE DIRECTIONS ............................ 109

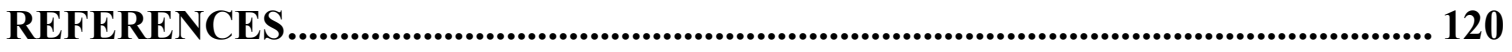


INDEX OF FIGURES AND TABLES

TABLE 1-1: COMPLEMENTATION GROUPS, GENES, AND FEATURES OF PROTEINS RESPONSIBLE FOR FANCONI

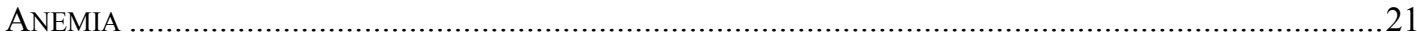

FIGURE 1-1: CURRENT UNDERSTANDING OF FA PROTEIN PATHWAY..................................................22

TABLE 2-1: RARE GENETIC DISORDERS THAT HAVE CONTRIBUTED TO UNDERSTANDING OF CANCER BIOLOGY.

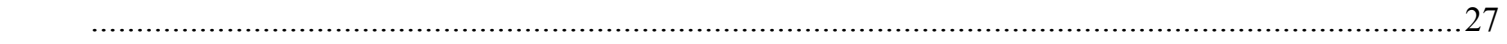

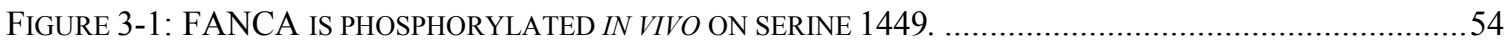

FigURE 3-2: PHOSPHO-FANCA SERINE 1449 IS INDUCED AFTER DNA DAMAGE.....................................56

FIGURE 3-3: FANCA IS NOT PHOSPHORYLATED DURING S PHASE ..................................................5

FIGURE 3-4: PHOSPHO-FANCA S1449 IS INCREASED ON CHROMATIN AFTER DNA DAMAGE AND FANCA

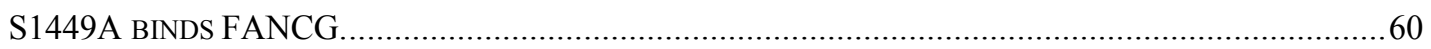

FIGURE 3-5: FANCA S1449A FAILS TO COMPLETELY CORRECT FA-ASSOCIATED PHENOTYPES. .................62

FIGURE 3-6: FANCA SERINE 1449 PHOSPHORYLATION IS DEPENDENT ON ATR IN VIVO. .........................65

FIGURE 3-7: ATR PHOSPHORYLATES SERINE 1449 OF FANCA IN VITRO. ..............................................67

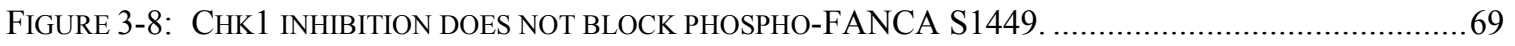

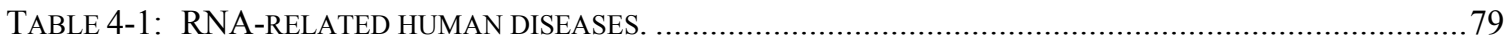

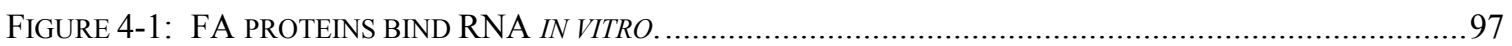

FIGURE 4-2: INHIBITION OF RNAPII INHIBITS FANCD2 MONOUBIQUITINATION....................................99

FIGURE 4-3: RNAPII INHIBITION SENSITIZES WILD TYPE CELLS TO MMC. .......................................... 101

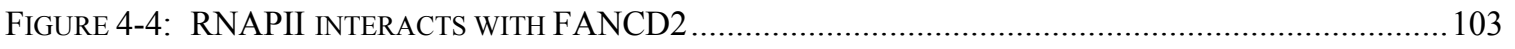

FIGURE 4-5: RNAPII IS NOT POLYUBIQUITINATED IN FA CELLS AFTER DNA DAMAGE. ......................... 105

FIGURE 4-6: MODEL REPRESENTING POTENTIAL ROLES FOR FA PATHWAY AND RNAPII IN PROMOTING

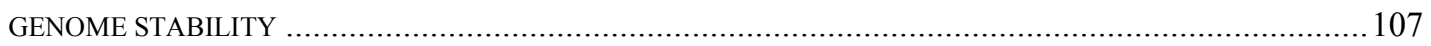




\section{TABLE OF ABBREVIATIONS}

$\begin{array}{ll}\text { AML } & \text { Acute myelogenous leukemia } \\ \text { AT } & \text { Ataxia telangiectasia } \\ \text { CHX } & \text { Cycloheximide } \\ \text { CS } & \text { Cockayne's syndrome } \\ \text { CSR } & \text { Class switch recombination } \\ \text { DBA } & \text { Diamond-Blackfan anemia } \\ \text { DC } & \text { Dyskeratosis congenita } \\ \text { DSB } & \text { Double strand break } \\ \text { FA } & \text { Fanconi anemia } \\ \text { GFP } & \text { Green fluorescent protein } \\ \text { HDR } & \text { Homology-directed repair } \\ \text { IFN- } \gamma & \text { Interferon } \gamma \\ \text { L/S } & \text { Long/short ratio (for FANCD2) } \\ \text { MEF } & \text { Mouse embryonic fibroblast } \\ \text { MMC } & \text { Mitomycin C } \\ \text { NHEJ } & \text { Non-homologous end joining } \\ \text { NBS } & \text { Nijmegen breakage syndrome } \\ \text { RNAPII } & \text { RNA polymerase II } \\ \text { RT } & \text { Reverse transcriptase } \\ \text { SDS } & \text { Schwachman-Diamond syndrome } \\ \text { SSA } & \text { Single-strand annealing } \\ \text { TTD } & \text { Tricothiodystrophy } \\ \text { XP } & \text { Xeroderma pigmentosum }\end{array}$




\section{CHAPTER 1: Molecular Pathogenesis of Fanconi anemia}

Fanconi anemia (FA) is both an inherited bone marrow failure and cancer susceptibility syndrome. As such, the study of the molecular and cell biology of Fanconi anemia represents a unique opportunity to identify potentially novel processes involved in hematopoeisis and maintenance of genome stability. Almost all affected patients will develop aplastic anemia and are susceptible to leukemia (specifically acute myelogenous leukemia) and the development of solid tumors later in life $(4,17,81,148)$. In addition, patients display a variety of congenital defects, most commonly growth retardation, abnormalities of the upper extremity, and skin pigmentation defects (50). Patient-derived cells are hypersensitive to DNA crosslinking agents such as mitomycin $\mathrm{C}(\mathrm{MMC})$ and diepoxybutane and display characteristic chromosome breakage when challenged with these agents, a phenotypic trait used in the clinical diagnosis of FA $(8,9)$.

FA has been traditionally thought of as a genetic disorder affecting children, but recent discovery of sporadic inactivation of genes involved in FA implicates the pathway broadly in oncogenesis. D'Andrea, et.al. first showed inactivation of FANCF by CpG island methylation in a subset of ovarian cancers (175). Similar inactivation by methylation was found in a case of sporadic acute myelogenous leukemia (AML) and in a subset of cervical cancers $(121,180)$. Decreased expression of FANCA from an intact allele was noted in a subset of sporadic AML with monoallelic deletion of FANCA (181). In addition to inactivation by methylation, somatic mutations of FANCC and FANCG have been found in cases of young-onset pancreatic cancer $(26,184)$. Furthermore, genes causative of hereditary breast cancer in the heterozygous state, including 
FANCD1 $=\mathrm{BRCA} 2, \mathrm{FANCJ}=\mathrm{BACH} 1$, and $\mathrm{FANCN}=\mathrm{PALB} 2$, have been identified as FA genes and confer an increased cancer risk $(58,143,156)$. Since crosslinker sensitivity is the hallmark of FA, one would expect tumors harboring FA mutations to be particularly sensitive to crosslinking chemotherapeutic agents, a phenotype that could be exploited therapeutically. Cells derived from AML samples of FA patients have, however, variably demonstrated chemosensitivity or chemoresistance $(64,111,180)$. Acquired chemoresistance could be accounted for by genetic reversion in cells maintained in culture (64).

\section{FA Genes}

FA patients can be divided into at least 13 complementation groups (FA-

A,B,C,D1,D2,E,F,G,I,J,L,M,N) by cell fusion studies (85). Immortalized cell lines from patients in these groups have proven to be invaluable in investigating FA and were used in studies presented here. Only recently has the field seen the successful cloning of each of the genes mutated in these groups (FANCA,B,C,D1,D2,E,F,G,J,L,M,N) (146, 165). The genes are significant because homologues are found only in vertebrates, with the exception of FANCD2 which has homologues in C. elegans, Drosophila, and Arabidopsis, the recently cloned FANCI which is conserved in most eukaryotes with the exception of fission and budding yeast, and FANCM which has orthologues in yeast and archaea $(109,165,179)$. Until recently, none of the identified genes contained motifs suggestive of biochemical function, and thus the functions of the proteins involved in FA remained elusive. Several recently identified genes including FANCL, FANCD1/BRCA2, FANCJ, and FANCM, discussed below, contain motifs suggestive of biochemical function, but a unifying mechanism is still not understood. 
FANCA,B,C,E,F,G, L, and M are known to interact in a protein complex termed the core complex (reviewed in (54)). In the presence of an intact core complex, FANCD2 becomes monoubiquitinated, relocalizes to foci containing BRCA1, and is involved in the response of the cell to DNA crosslinks. Genes involved in FA are discussed below and summarized in Table 1.

FANCA was cloned by both expression and positional cloning $(1,42)$. Like most FA proteins, FANCA does not have any motifs suggestive of function, but it does contain two bipartite nuclear localization signals and a partial leucine zipper. FANCA is phosphorylated, and phosphorylation is required for proper pathway function, but the mechanisms by which phosphorylation is regulated were unknown $(178,200)$.

FANCB represents the first FA gene to display X-linked inheritance (107). All other genes are autosomal recessive. The protein was isolated by biochemical purification and sequencing and was the second FA protein to be identified in such a manner. FANCB is a member of the core complex and is required for FANCD2 monoubiquitination. Previously, the detection of biallelic BRCA2 mutations in FA-B patients led to the proposal that BRCA2 was responsible for complementation group FA$\mathrm{B}$, but identification of FANCB and associated inactivating mutations disproved that conclusion (58). X-linked inheritance implies there may be a carrier risk in females through random $\mathrm{X}$ inactivation, but, interestingly, in all carriers identified so far $\mathrm{X}$ inactivation seems completely skewed to the mutant allele (107).

FANCC was the first FA gene cloned, in a classic expression cloning approach using an FA-C cell line that is sensitive to crosslinkers (169). As has been the case for many of the FA proteins, FANCC does not have any conserved motifs suggestive of 
function. Most FANCC mutations are one of two types, either an intronic mutation that results in deletion of exon 4 (IVS4 $+4 \mathrm{~A}$ to $\mathrm{T}$ ) or a deletion in exon 1 (delG322). Exon 4 deletion results in complete loss of FANCC expression and a severe FA phenotype, whereas exon 1 mutation allows for reinitiation, expression of a partially functional fragment of FANCC, and a less severe phenotype (201). This illustrates a principal of FA genetics, that FA phenotypes exist on a continuum of severity and that genotype dramatically affects the severity of the FA phenotype.

FANCD1 was recently identified as BRCA2, connecting the rare FA to the clinically significant disease of hereditary breast cancer. Direct sequencing identified biallelic mutations in BRCA2 in FA-D1 cell lines, and wild-type BRCA2 complemented the sensitivity of these lines to MMC (58). This discovery is significant also in that it implies increased cancer risk in FA carriers. This increased cancer risk in heterozygotes appears restricted to breast and ovarian cancer, rather than to FA-associated malignancies. FANCD1/BRCA2 cells have characteristic FA associated phenotypes of MMC sensitivity and chromosome instability, but FANCD2 is monoubiquitinated normally in response to DNA damage, leading to the conclusion that FANCD1 acts downstream of FANCD2 (162).

The FANCD2 gene, whose encoded FA protein is one of few with homologues in lower eukaryotes, was cloned positionally (179). It is a large protein, 1451 amino acids, but contains no recognizable motifs. The protein has two isoforms, a long and a short form, with the long form being a monoubiquitinated form of the protein at lysine 561 (K561) that is present following DNA damage and during S phase. FANCD2, usually a dispersed nuclear protein, forms discrete nuclear foci after DNA damage and during $\mathrm{S}$ 
phase and colocalizes with proteins involved in the DNA damage response, including at least BRCA1, Rad51, and $\operatorname{BLM}(47,138,173)$. In addition to ubiquitination, FANCD2 is modified by phosphorylation on serine 222 (S222) by the ATM kinase. Only the K561 site appears to be functionally important in the FA pathway, as mutation of the S222 site does not alter crosslinker sensitivity (174). FANCD2 is further phosphorylated on threonine 691 and serine 717, with ATM and ATR both contributing to these events (57). Mutation of these residues singly has limited functional consequences, but mutation in tandem decreases FANCD2 monoubiquitination and results in crosslinker sensitivity (57). Purified FANCD2 will bind DNA with structure specificity, with highest affinity to double stranded DNA ends and Holliday junctions (135). Interestingly, purified FANCD2 with patient-derived mutations bound DNA with similar affinity.

FANCE was isolated by expression cloning. As is true of most FA proteins, FANCE has no conserved motifs, save two nuclear localization signals, to suggest any function (29). FANCE coprecipitates with members of the FA core complex and FANCD2 and, as the only protein with such behavior, is thought to be a molecular link between the core complex and FANCD2 $(132,172)$. Indeed, FANCE is required for the nuclear accumulation of FANCC and the ubiquitination of FANCD2. FANCE has two Chk1 kinase dependent phosphorylation sites. These sites, while not required for FANCD2 monoubiquitination, are required to complement the MMC sensitivity of FA-E cells (187).

FANCF was cloned by complementation cloning and possesses a region of homology to ROM, a prokaryotic RNA binding protein, although the homology is not in the RNA binding motif region (30). Mutation of critical residues in this region seems to 
have no effect on the function of the protein, however, so the significance of the homology is unknown. FANCF is a member of the core complex and stabilizes the interaction of other core complex members (84).

FANCG is the protein XRCC9, originally identified in a Chinese hamster ovary mutant sensitive to ultraviolet light $(31,93)$. FANCG has no motifs suggestive of function, but does contain several tetratricopeptide (TPR) motifs (11). These sequences are often involved in mediating protein complex interactions, consistent with the presence of FANCG in the FA core complex. FANCG is phosphorylated on at least three serine residues, serines 7, 383, and $387(113,140)$. Two of these phosphorylation events, S383 and S387, occur at mitosis, a time when FA proteins are excluded from condensed chromatin, and may regulate proper localization of the complex $(113,141)$. For at least S387, the likely kinase is the mitotic kinase cdc2, previously shown to physically interact with FANCC (79). Phosphorylation of serine 7 is functionally significant, but the upstream regulation and downstream effects of this phosphorylation are unknown (140). FANCG has also been shown to uniquely interact with FANCD1/BRCA2 in foci after DNA damage and represents the only core complex member to possess such activity (62).

FANCI was only recently identified in a screen for protein targets of the kinases ATM and ATR following ionizing radiation. It was then shown to be mutated in patients from group FA-I, and the wild type gene complements cells from these patients. Interestingly, it shares both sequence and functional homology to FANCD2, including monoubiquitination of a critical lysine (lysine 523) following DNA damage. The functions of FANCI and FANCD2 are dependent on one another, as neither monoubiquitination nor proper localization to foci occurs for either protein in the absence 
of the other. FANCI and FANCD2 also physically interact, suggesting the presence of a dimeric or multimeric complex between the two that is essential for maintaining genome stability $(163,165)$.

FANCJ is the $B$ RCA1 associated $C$-terminal helicase, BACH1, also known as BRIP1, identified as an FA gene by two groups simultaneously. One group used positional cloning, and one group initiated a search specifically for FA patients deficient in BACH1 based on phenotypic similarity between FA cells and BACH1 deficient cells $(86,92)$. BACH1, as the name suggests, is a DEAH-box containing helicase that interacts with BRCA1 and unwinds DNA in a 5' to 3' direction (19). Other DEAHfamily helicases, including BLM, WRN, and RecQL4 are also associated with disorders of DNA repair (147). FANCJ is not required for FANCD2 monoubiquitination and is, therefore, thought to act downstream of the core complex and FANCD2 (92).

FANCL was the first FA protein identified by biochemical purification of proteins involved in FA and sequencing by mass spectroscopy (106). FANCL is the ubiquitin ligase PHF9. This protein is mutated in patients from complementation group FA-L and is required for FANCD2 monoubiquitination in vivo. The protein has a PHD finger-type E3 ubiquitin ligase motif characteristic of ubiquitin ligases and has enzymatic activity in vitro by polyubiquitinating itself. While FANCL, as a core complex member, is required for FANCD2 monoubiquitination in vivo, FANCL has not been shown to directly ubiquitinate FANCD2 in vitro or in vivo. In the ubiquitin pathway, the E3 ligase is responsible for transferring ubiquitin from an E2 ubiquitin conjugating enzyme to a substrate. UBE2T has been proposed as the E2 for FANCD2 on the basis that it physically interacts with FANCL, is required for FANCD2 ubiquitination in vivo, and 
depletion results in chromosomal instability (94). No patients have, however, been identified with mutations in UBE2T.

FANCM is another FA protein to be identified by biochemical purification of the core complex and subsequent identification of unknown binding partners (109). FANCM is exceptional in that it has two conserved functional motifs, a helicase motif at the $\mathrm{N}$ terminus and an endonuclease motif at the $\mathrm{C}$ terminus that is homologous to the excision repair protein ERCC4/XPF. The endonuclease motif, however, is degenerate at highly conserved residues, and therefore may not be functional. Though neither helicase nor endonuclease activity has been observed, FANCM does possess ATP dependent DNA translocase activity, and the helicase domain binds forked DNA structures in vitro (109, 116). FANCM is hyperphosphorylated in response to DNA damage and is a member of the core complex (109).

FANCN was identified in a way similar to FANCJ, by a targeted search for mutations within FA patients for which the causative mutation was unknown, and was shown to be identical to PALB2. PALB2 had been identified as a protein that interacted with BRCA2, was required for proper BRCA2 localization and activity, and, when depleted, resulted in MMC hypersensitivity, a hallmark of FA (196). Pathogenic mutations in PALB2 were identified, and cellular MMC sensitivity and BRCA2 localization were corrected upon ectopic expression of PALB2 $(146,195)$. Importantly, PALB2 is thought to function in concert with FANCD1/BRCA2 downstream of FANCD2. Consistent with this, FANCD2 is ubiquitinated after DNA damage (146).

Though not a classical FA gene because patients have not been identified with mutations in the gene, the deubiquitinase USP1 deserves mention in a review of proteins 
impinging on the FA pathway. Through an RNAi based screen of deubiquitinases, USP1 was identified as a gene, which, when inhibited, resulted in accumulation of the long, monoubiquitinated form of FANCD2 (124). Furthermore, inhibition of USP1 protects cells from DNA breaks and rearrangements caused by MMC. Though evidence of direct deubiquitination is lacking, USP1 may function in downregulating the FA response after DNA damage.

The biochemical purification of the FA core complex and subsequent identification of component proteins by mass spectrometry has been productive in identifying FA proteins. As previously discussed, FANCB, L, and M were all identified in this way. One other component of this complex is FAAP100 (Fanconi anemia associated protein, 100kD). Similar to other FA proteins, it is necessary for FANCD2 monoubiquitination, and loss of the protein leads to chromosomal instability. No patients have, however, been identified with mutations in this gene (90).

Finally, the recent identification of FANCM led to the search for and identification of FAAP24 (Fanconi anemia associated protein, 24kD). FANCM, as previously mentioned, is a member of the ERCC4/XPF family of endonucleases. Family members usually function as heterodimers, in which the partner also has an ERCC4 endonuclease domain, and the domain is functional in one and degenerate in the other. Examples include ERCC1/XPF and MUS81/EME1. Based on this paradigm, a search for proteins in the human genome with homology to the nuclease domain of FANCM revealed FAAP24. FAAP24 binds specifically to FANCM, is a member of the FA core complex, and is required for FANCD2 ubiquitination. Like FAAP100, no patients have been identified with mutations in FAAP24 (23). 


\section{Protein interactions}

Xeroderma pigmentosum (XP) is the prototypical genetic disease with multiple implicated genes, cancer susceptibility, and defects in DNA repair (24). Many XP gene protein products participate in a protein complex, so this paradigm was employed in initial studies on FA proteins (7). Intuitively, then, it was not surprising that the FA core complex emerged containing at least 8 of the FA proteins. The core complex is represented in Figure 1-1, a diagram of the current understanding of the pathway. Interestingly, the stability of the complex is impaired in many of the FA cell lines in which one of the FA core complex members is mutant. Many of the mutants found in nature for the FA genes result in unstable and thus non-expressed proteins. Consequently, lack of one of the FA proteins often impairs the expression or stability of other members of the complex. Even when one core complex member is mutant and others are present, as is sometimes the case, then the complex appears unable to attain its usual localization $(78,119,200)$. The FA core complex has been shown to localize to the nucleus and subcompartmentalize to chromatin as represented in Figure 1-1 (141). The core complex varies in size as subcellular localization changes. The cytoplasmic core complex is the smallest, with a size of approximately $500-600 \mathrm{kDa}$. The nuclear form reaches a size of $2 \mathrm{MD}$, and a distinct, chromatin-bound form is approximately $1 \mathrm{MD}$ (178). Because known FA proteins are constant within the various forms of the core complex, the size differential is attributed to unknown binding partners of the FA core complex. Most interestingly, the downstream FANCD2 complex exhibits a functional, if not physical, interaction with the FA core complex. The FANCD2 protein demonstrates a monoubiquitinated form in response to DNA damage and S phase. Except for the rare 
FA-D1, FA-J, and FA-N complementation groups, FANCD2 fails to become monoubiquitinated in all FA cells. Thus, immunoblotting for ubiquitinated FANCD2 represents a general way to assess normal FA protein and pathway function (161). The requirement for core complex formation in order to achieve FANCD2 monoubiquitination, coupled with the presence of FANCL, a ubiquitin ligase, in the core complex, has led to the notion that the sole function of the core complex is to act as a ubiquitin ligase for FANCD2. In an important experiment, however, Matsushita et. al. showed that targeting a FANCD2-ubiquitin fusion to chromatin via a histone $2 \mathrm{~B}$ fusion was sufficient to correct cisplatin sensitivity in FA-D2 cells, but not in FA-C, FA-G, or FA-L cells (102). This implies that the core complex may have other functions in the crosslink response other than monoubiquitinating FANCD2 and targeting it to chromatin. Modes of interaction among the FA proteins have been and continue to be an area of intense research. The FANCA and FANCG proteins appear to directly interact and indeed stabilize each other. Recent yeast two hybrid experiments have revealed that FANCF appears to be a molecular "tether" of sorts between the FANCA-FANCG heterodimer and FANCC $(53,104)$. Similarly, yeast two hybrid studies have shown a direct interaction between FANCB and FANCL, and FANCA association with this heterodimer is dependent on other core complex members (105). Furthermore, FANCE is the only FA protein that is a member of both the FA core complex and the FANCD2 complex, implying physical communication between the two (132). It seems logical to hypothesize, based on the evidence for subcomplexes within the FA pathway, that smaller complexes form and may participate in a variety of functions within the cell including but not limited to monobuiquitination of FANCD2. 


\section{Function DNA Repair}

With no yeast or lower eukaryotic homologues corresponding to almost all of the FA genes, unraveling the function of the proteins involved in FA has been uniquely challenging. FA mutant cells have been traditionally classified as having a defect in the normal cellular DNA repair response. Notably, FA is phenotypically similar to disorders of DNA repair that result in cellular hypersensitivity to DNA damage, such as xeroderma pigmentosum (XP), ataxia telangiectasia (AT), and Nijmegen breakage syndrome (NBS). These disorders share a predisposition to cancer, chromosomal instability, and a hypersensitivity to a particular type of DNA damage. The defect in FA is exemplified by the diagnostic test for FA: incubation of FA cells with DNA crosslinkers results in quantifiable chromosomal breakage and aberrations. In recent years, the characterization of FANCD2 has steered the FA field more into the mainstream of cancer biology. D'Andrea's group demonstrated the interaction of FANCD2 with BRCA1 in DNA damage-inducible nuclear foci (48). Subsequent identification of BRCA2 as the FANCD1 gene has solidified a role for the FA pathway in the cellular response to DNA damage.

Interstrand crosslinks are thought to be removed by a process involving excision of the lesion by ERCC1/XPF, processing through a double strand break intermediate in $\mathrm{S}$ phase, and repair by homologous recombination or other DSB repair pathway (36). The FA pathway has been logically examined at each of these steps. Evidence suggests that crosslinked DNA is excised properly in FA mutant cells and processed to a DSB. FA-A, FA-D2, and FA-C cells treated with MMC or 4'-hydroxymethyl-4,5',8-trimethylpsoralen 
(HMT), a photoactivatable crosslink-inducing agent, restored DNA migration in the comet assay with wild type kinetics, indicating effective crosslink incision $(137,149)$. When DSB formation was monitored by pulsed field gel electrophoresis or $\gamma \mathrm{H} 2 \mathrm{AX}$ foci formation, DSBs were formed normally in FA-C and FA-D2 lines $(137,149) . \gamma \mathrm{H} 2 \mathrm{AX}$ foci formation is one of the earliest known events following DSB formation, and, as such, indicates that the defect in FA is most likely downstream of the DSB.

Once the DSB is created in the process of removing a crosslink, DSB repair is thought to occur by one of three mechanisms: non-homologous end joining (NHEJ) or single-strand annealing (SSA), which may introduce errors, or homology directed repair (HDR), generally considered to be error-free (190). Several lines of evidence support a role for FA proteins in HDR. First, FA proteins interact physically or functionally with a set of proteins strongly linked to HDR, including BRCA1, BRCA2, and RAD51.

BRCA1 and BRCA2 have been strongly tied to DNA repair in several ways, including isolation of a BRCA1 supercomplex containing other proteins involved in DNA repair such as BLM, NBS, RAD50, and MRE11 (188). FANCD2 colocalizes with BRCA1 and RAD51 in foci after DNA damage and during S phase (173). RAD51 is a protein required for homologous recombination that forms filaments at sites of DSBs at the onset of the repair process. More recently, FANCD2 has also been shown to interact physically and functionally with BRCA2/FANCD1. A physical interaction was shown by yeast two hybrid and coimmunoprecipitation, and BRCA2 damage-inducible foci fail to form in the absence of FANCD2 $(61,186)$. Recent data has also placed FANCG in a complex with BRCA2 (62). Further implicating FA proteins in HDR, in FANCD1/BRCA2 mutant cells, RAD51 foci fail to form in response to DNA damage (51). Finally, cells deleted or 
mutated for either BRCA1 or 2 are phenotypically similar to FA cells, displaying gross chromosomal rearrangements when challenged with DNA damaging agents (185).

Given this set of proteins interacting with FA proteins, many have looked for defects in homologous recombination in FA cells. Using the chicken B-cell line, DT40, FANCG, FANCC, and FANCD2 mutant cells were all shown to be defective in HDR of an I-SceI induced DSB $(123,198,199)$. In a similar assay monitoring homology directed repair of an I-SceI DSB, patient-derived cells from groups FA-A, G, and D2 as well as mice homozygous for $F A N C A$ deletion were shown to be defective in $\operatorname{HDR}(120,203)$. Taken together, these results argue that the defect in FA may be, indeed, in HDR. In apparent contrast to these results, however, elevated levels of interplasmid, extrachromosomal homologous recombination have been seen in FA-A, C, and G cells, suggesting that it is the regulation of HDR that is perturbed in FA and not the actual enzymatic machinery (34). Also arguing against a role for FA proteins in HDR is epistasis analysis of BRCA2/FANCD1 or RAD51 and FANCD2. When BRCA2 or RAD51 is depleted by RNAi in FA-D2 cells, an additive effect on MMC sensitivity is seen, indicating they may function in separate, distinct pathways (129). In apparent contrast, depletion of BRCA1 in FA-A cells had an additive effect on quadriradial formation, but depletion of BRCA2/FANCD1 had no additional effect, suggesting BRCA2 functions in the FA pathway, but BRCA1 functions in a non-epistatic manner (15). This apparent contradiction could be caused by the different phenotypes considered, crosslinker sensitivity vs. chromosomal aberrations, or it could be caused by an inherent difference between FA-A and FA-D2 cells. DNA repair pathways contain proteins that have multiple, partially overlapping functions, and epistasis analysis of the 
BRCA proteins and the FA pathway is therefore difficult to interpret. Given cellular phenotypes, patient phenotypes, and what is known about the biochemistry of FA, certainly a defect in HDR is an attractive hypothesis for the defect in FA patients, but, at this point, the data remain inconclusive.

\section{Cell Cycle}

The phenotype of DNA repair cannot be discussed without addressing the cell cycle phenotype of FA. Indeed, as the lesion caused by crosslinkers is thought to be encountered in S phase, DNA repair and the cell cycle are inextricably linked (3). Several lines of evidence link FA to S phase of the cell cycle. FA cells have been known to have increased time within S phase and display increased unscheduled DNA synthesis following DNA damage, generally considered to result from a failure to activate the $\mathrm{S}$ phase checkpoint (174). Two PI3-like kinases, ATM and ATR, are thought to oversee the cell cycle response to DNA damage, and both have been shown to functionally interact with the FA pathway. ATM, the protein mutated in ataxia telangiectasia, is activated primarily in response to types of DNA damage caused by ionizing radiation, namely double strand breaks. ATM has multiple downstream targets that activate DNA repair pathways and stall the cell cycle to give sufficient time for repair to occur. One downstream target of ATM is FANCD2 on serine 222, and phosphorylation is necessary for activation of the S phase checkpoint but is not required for FANCD2 monoubiquitination or foci formation (174). Mutation of serine 222 on FANCD2 does not abolish the ability of FANCD2 to correct FA-D2 cells.

ATR is activated following damage that stalls replication forks, such as UV light or hydroxyurea. Like ATM, it has a set of downstream targets for activating DNA repair 
processes and stalling the cell cycle. ATR is hypomorphic in a disorder known as Seckel syndrome, which is phenotypically similar to FA. Patients with Seckel syndrome variably display thumb abnormalities, aplastic anemia, and a propensity to cancer. Similarly, cells from Seckel patients exhibit gross rearrangements when challenged with MMC, further mirroring the FA phenotypes (6). Importantly, FANCD2 is not monoubiquitinated when ATR is decreased in Seckel cells or by RNAi, definitively linking ATR to activation of the FA pathway (6). ATR is essential for the S phase checkpoint, as cells lacking ATR do not show an appropriate decrease in DNA synthesis following DNA damage (139). Nbs1, one of three proteins affected in Nijmegen Breakage Syndrome (NBS), has, by epistasis analysis, been shown to act in the same path as FA proteins in maintaining the S phase checkpoint downstream of ATR (139). Evidence also exists that FANCD2 may, in addition to being a substrate of ATM, be a phosphorylation substrate for ATR as well $(57,139)$. Also arguing for a role for the FA proteins in S phase, core complex FA proteins associate with chromatin specifically in $\mathrm{S}$ phase, and FANCD2 is monoubiquitinated in S phase irrespective of DNA damage, implying that the FA pathway plays a role in normal cell physiology during S phase (48, 112).

Despite accumulating evidence linking FA protein function to $\mathrm{S}$ phase, FA proteins are present and clearly play a role at other phases of the cell cycle. Many investigators have described the increased percentage of G2/M after crosslink treatment, an observation used as a diagnostic tool for FA patients $(39,75,114,152)$. FANCC binds cdc2, the mitotic kinase, arguing for a role in moving from G2 to mitosis (79). In support of this role, both FA-C and FA-D2 cells are unable to maintain the G2 checkpoint 
following ionizing radiation (44). Finally, FA proteins are regulated at other stages of the cell cycle, including the phosphorylation of FANCG at S383 and S387 during mitosis, coinciding with the exit of the proteins from condensed chromatin (113). Taken together, the FA proteins clearly impinge on the cell cycle checkpoints, while at the same time evidence suggests the proteins are more directly involved in DNA repair. Whether these two roles for the FA proteins represent a unified function or distinct functions remains an unanswered question.

\section{Oxidative damage and defective cell signaling}

With at least 13 proteins involved in the FA pathway, it is possible that some or all of the proteins are multifunctional, possessing roles in addition to their roles in DNA repair or the cell cycle. In support of this notion, FA proteins have been implicated in the cellular response to oxidative stress. Historically, FA cells have been noted to be sensitive to increased oxygen conditions. Initial observation revealed that FA mutant cells have increased levels of reactive oxygen intermediates and 8-hydroxy-deoxyguanine (8OHdG), a DNA lesion that arises from oxidative damage $(32,45,71,170)$. These data led to the notion that the FA pathway may be involved in the normal response to oxygen stress. Indeed, in further studies, FA proteins were shown to interact with several proteins essential to counteract free oxygen radicals in the response to oxygen. A small population of FANCC interacts with NADPH:cytochrome c (P-450) reductase (RED), an enzyme crucial to oxidative metabolism of various drugs and other compounds (74). In this study, overexpression of FANCC inhibited the enzymatic activity of RED, implying a model whereby, in the absence of FANCC, RED activity is not appropriately attenuated, leading to the accumulation of reactive oxygen metabolites. A similar model 
was proposed following observation of an interaction between FANCG and cytochrome p450 2E1 (CYP2E1) (45). In this case, higher levels of CYP2E1 were observed in FA-G mutant cells than in wild type or FANCG-complemented cells, suggesting that FANCG is involved in proper regulation of CYP2E1. In the absence of this interaction, unregulated oxygen metabolism may be damaging to the cell. Not only have FA proteins been shown to negatively regulate proteins that create oxygen radicals as part of their enzymatic activity, but FANCC has also been shown to positively regulate glutathione S transferase P1 (GSTP1), an enzyme involved in removing oxygen metabolites (27). In this case, FANCC prevents the inactivation of GSTP1 following apoptotic stimuli and prevents cell death. An important prediction of the model of FA proteins in the response to oxidative stress is that FA cells would be hypersensitive to agents that induce oxidative damage, such as hydrogen peroxide. Studies have reported contradictory data that FA cells do show an impaired response to such agents. FA-C cells are not sensitive to a wide range of free radical-producing agents, including $\mathrm{H}_{2} \mathrm{O}_{2}$ (77). In apparent contradiction, however, MEFs from fancc -/- mice show increased sensitivity to $\mathrm{H}_{2} \mathrm{O}_{2}$ as measured by cell killing, and FA cells display an increased accumulation of 8OHdG following $\mathrm{H}_{2} \mathrm{O}_{2}$ treatment $(150,170,209)$. Importantly, however, all FA cell lines were able to repair the breaks caused by such lesions soon after treatment, leading to the question whether this phenotype is functionally significant (209).

As the most common phenotype of FA patients is aplastic anemia, a logical hypothesis is that bone marrow of patients becomes aplastic due to increased apoptosis among the hematopoeitic stem cell populations. Indeed, this population has been shown to be hypersensitive to interferon $\gamma$ (IFN- $\gamma$ )-mediated apoptosis in both fancc-/- mice and 
in FA-C patients $(144,191)$. IFN- $\gamma$ normally acts through the IFN receptor, leading to phosphorylation of STAT-1, a mitogenic transcription factor through which many of the downstream effects of IFN- $\gamma$ are transduced. Paradoxically, despite hypersensitivity to IFN- $\gamma$, STAT-1 phosphorylation is impaired in FA-C cells, and complementation of FAC cells with FANCC restores wild-type STAT-1 activity (133). Furthermore, FANCC was shown to bind STAT-1, suggesting that FANCC is essential for properly regulating STAT-1 activation (133). Since IFN- $\gamma$ exerts its pro-apoptotic responses primarily through STAT-1, but STAT-1 activation is impaired in FA-C cells, the hypersensitivity to IFN- $\gamma$ should be STAT independent. To explain the IFN- $\gamma$ hypersensitivity, therefore, PKR, the protein kinase that responds to dsRNA has been implicated. PKR is IFN- $\gamma$ responsive, does not require STAT signaling, and demonstrates increased activation in FA-C mutant cells, a phenotype that is restored to wild type upon expression of a functional FANCC (134).

\section{Conclusion}

It has been 15 years since the Buchwald group reported the cloning of the first FA gene, FANCC. Since that beginning, the knowledge of FA has increased exponentially. Numerous genes have been cloned, and protein-protein interactions have been established. Biochemical functions are just beginning to be discovered and understood. The work and associations that have been made that have transformed the study of FA from that of an obscure genetic disease to that of a system of proteins that have direct and profound connections to cancer biology. Most dramatically, links to the familial breast cancer genes BRCA1 and BRCA2 have led to FA attaining a place in the forefront of 
cancer biology. The current understanding of the molecular pathogenesis of the FA pathway is summarized in Figure 1-1.

In spite of the knowledge gained, many questions remain as to the significance of the presence and localization of the protein complexes in both the cytoplasm and in the nucleus. Divergent research has established FA in the realm not only of DNA repair and the cell cycle, but also of cytokine deregulation, signaling defects, redox metabolism, and apoptosis. Further work will undoubtedly help ascertain whether FA proteins will have a unified function or if multiple and separable functions will be described. It is the search for this function that is the focus of this research. 
Table 1-1: Complementation groups, genes, and features of proteins responsible for Fanconi Anemia

\begin{tabular}{|c|c|c|c|c|c|}
\hline SUBTYPE & GENE & LOCATION & $\begin{array}{l}\text { MOLECULAR } \\
\text { WEIGHT }\end{array}$ & Functional Motif(s) & $\begin{array}{l}\text { FANCD2-UB } \\
\text { IN MUTANT }\end{array}$ \\
\hline A & FANCA & $16 \mathrm{q} 24.3$ & $163 \mathrm{kD}$ & $\begin{array}{l}\text { Nuclear Localization Signal } \\
\text { (NLS), Partial Leucine Zipper }\end{array}$ & - \\
\hline B & FANCB & $\mathrm{Xp} 22.2$ & $95 \mathrm{kD}$ & Putative NLS & - \\
\hline $\mathrm{C}$ & FANCC & $9 q 22.3$ & $63 \mathrm{kD}$ & & - \\
\hline D1 & $\begin{array}{l}\text { FANCD1/ } \\
\text { BRCA2 }\end{array}$ & $13 \mathrm{q} 12.3$ & $380 \mathrm{kD}$ & $\begin{array}{l}\text { BRC repeats, Transcriptional } \\
\text { Activation Domain, NLS }\end{array}$ & + \\
\hline D2 & FANCD2 & $3 \mathrm{p} 26$ & $\begin{array}{l}155 \mathrm{kD} \\
162 \mathrm{kD}\end{array}$ & $\begin{array}{l}\text { Monoubiquitinated after DNA } \\
\text { damage/ S phase }\end{array}$ & $\mathrm{N} / \mathrm{A}$ \\
\hline $\mathrm{E}$ & FANCE & $16 \mathrm{p} 22-\mathrm{p} 21$ & $60 \mathrm{kD}$ & & - \\
\hline $\mathrm{F}$ & FANCF & $11 \mathrm{p} 15$ & $42 \mathrm{kD}$ & Homology to ROM & - \\
\hline G & FANCG & $9 \mathrm{p} 13$ & $68 \mathrm{kD}$ & Leucine Zipper, TPR repeats & - \\
\hline I & FANCI & $15 \mathrm{q} 25-26$ & $150 \mathrm{kD}$ & FANCD2 paralog & - \\
\hline $\mathrm{J}$ & $\begin{array}{l}\text { FANCJ/ } \\
\text { BACH1/ } \\
\text { BRIP1 }\end{array}$ & $17 q 22-24$ & $130 \mathrm{kD}$ & DEAH Helicase & + \\
\hline $\mathrm{L}$ & $\begin{array}{l}\text { FANCL/ } \\
\text { PHF9 }\end{array}$ & $2 \mathrm{p} 16.1$ & $43 \mathrm{kD}$ & Ubiquitin Ligase & - \\
\hline M & FANCM & $14 \mathrm{q} 21.3$ & $250 \mathrm{kD}$ & $\begin{array}{l}\text { Helicase, Endonuclease } \\
\text { (degenerate?) }\end{array}$ & - \\
\hline $\mathrm{N}$ & $\begin{array}{l}\text { FANCN/ } \\
\text { PALB2 }\end{array}$ & $16 \mathrm{p} 12.1$ & $130 \mathrm{kD}$ & & + \\
\hline
\end{tabular}




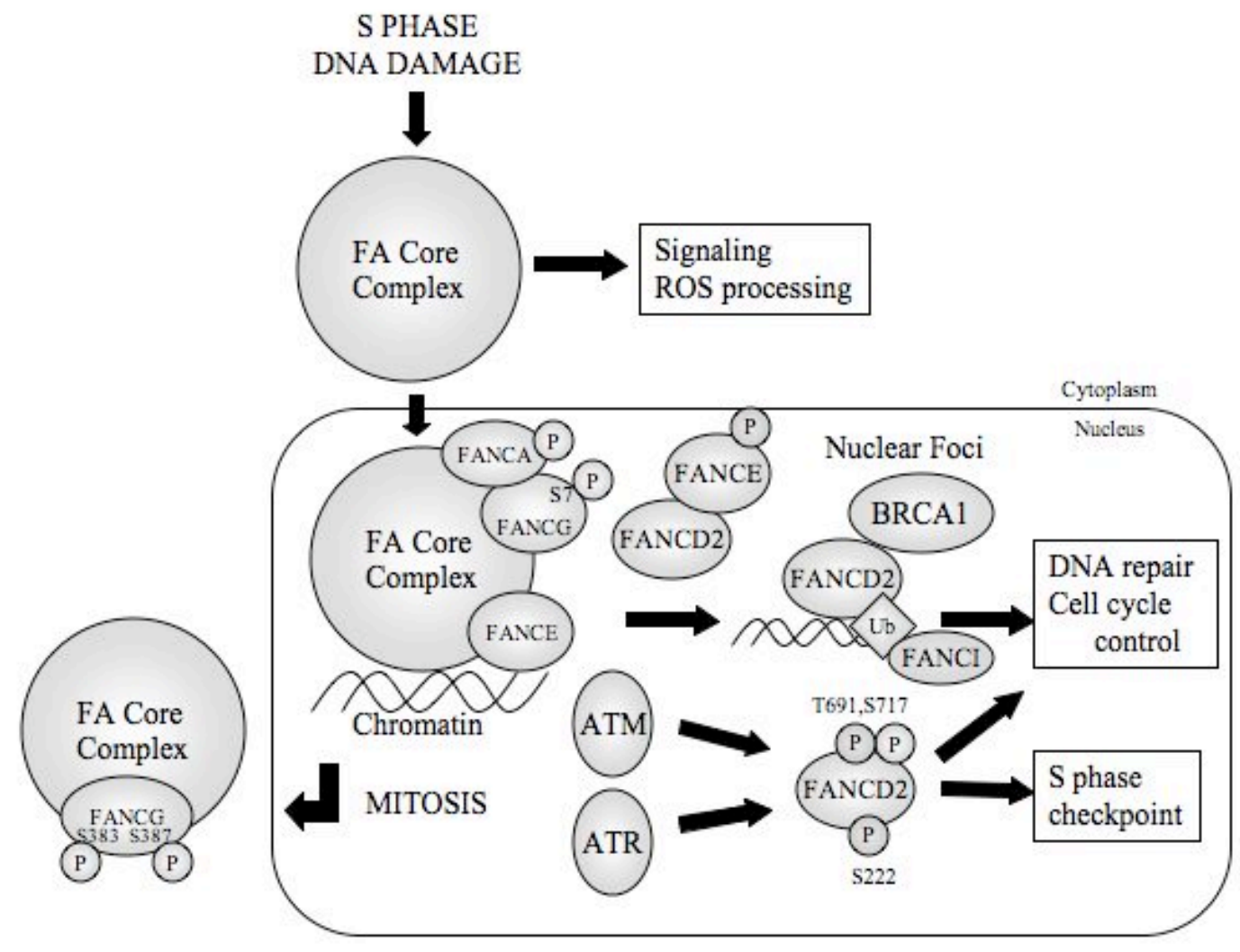

Figure 1-1: Current understanding of FA protein pathway.

FA Core complex localizes to chromatin during $\mathrm{S}$ phase and in response to DNA damage.

Within the core complex, FANCA, FANCG, and FANCM are phosphorylated. In the presence of intact core complex, FANCD2 is monoubiquitinated on K561 and colocalizes in nuclear foci with BRCA1 where it carries out its roles in DNA repair and/or cell cycle control. FANCI is also monoubiquitinated, associates with FANCD2, and localizes to chromatin. FANCD2 is a phosphorylation target of ATM and ATR. At mitosis, FANCG is phosphorylated and the core complex is excluded from the nucleus and condensed chromatin. 


\section{CHAPTER 2: \\ Thesis Rationale and Specific Aims}

FA, being a disease of cancer predisposition, defective hematopoeisis, and congenital defects, is a clinically significant problem and therefore warrants investigation. Even more compelling, however, is the potential for FA biology to offer insight broadly into human carcinogenesis. The study of rare genetic disorders has revealed key players in human genome surveillance, maintenance, and repair pathways. Many of those key regulators are summarized in Table 2-1. Found in the list are genes involved in all of the DNA repair processes currently known, including homologous recombination, non-homologous end joining, mismatch repair, and nucleotide excision repair. FA may represent a branch of one of these known pathways or may represent a new pathway for maintenance of genome stability.

Complicating the study of FA is the fact that few of the proteins involved are suggestive of any function of the pathway. Furthermore, lack of orthologous proteins in lower species gives no clues as to the evolution of the pathway and is suggestive that the FA pathway may have arisen to combat genomic insults faced uniquely by higher eukaryotes. The overall aim of this research was, then, to investigate the function of the proteins involved in the FA pathway and examine their roles in the context of the cellular response to DNA damage to cooperatively maintain genome stability. Our overall approach to this problem was to analyze the regulation of individual proteins and identify new binding partners with known or discernable function. Specific aim 1 addresses the regulation by phosphorylation of FANCA, a protein mutated in FA, while specific aim 2 addresses the broader question of the function of the FA pathway. 


\section{Specific Aim 1:}

Previous work in our lab and others suggested that FANCA was a phosphoprotein and that this phosphorylation was inducible by DNA damage $(76,178)$. We hypothesized this phosphorylation is critical to the function of the FA pathway. The purpose of this work is:

To determine the phosphorylation sites on FANCA. We proposed that stabilizing the phosphorylation using phosphatase inhibitors would allow use of mass spectroscopy to identify phosphorylated residues. We show that FANCA is phosphorylated on serine 1449, near the $\mathrm{C}$ terminus of the protein. Using a phospho-specific antibody for phosphoserine 1449 we show FANCA is phosphorylated after DNA damage, consistent with previous findings.

To evaluate the functional significance of FANCA phosphorylation. If serine 1449 phosphorylation is a functionally critical event, we expect cell lines mutant at serine 1449 to display FA-associated phenotypes. Patient-derived FA-A cell lines transduced with FANCA mutated at serine 1449 to alanine (S1449A) were used to test a variety of phenotypes. In all phenotypes tested, FANCA S1449A failed to completely correct the mutant phenotype to wild type, indicating that phosphorylation of serine 1449 is a functionally important event.

To discover the kinase responsible for phosphorylating FANCA. Serine 1449 is found within a consensus ATM/ATR kinase site, so we hypothesized that ATR or ATM, kinases associated with the DNA damage response, may be responsible for serine 1449 phosphorylation. Using kinase specific inhibitors, RNA interference, and kinase- 
deficient cell lines, we show that ATR phosphorylates FANCA serine 1449 in vitro and is required for phosphorylation in vivo. Phosphorylation by ATR kinase places core complex regulation within the broader cellular DNA damage response.

\section{Specific Aim 2:}

The FA pathway has been investigated for defects in the known pathways of DNA repair, and no specific link has been found. We hypothesize, therefore, that the FA pathway represents a novel mechanism for DNA repair, and preliminary data suggests this may be tied to RNA and transcription. The purpose of this work was:

\section{To determine if a functional and/or physical interaction exists between members of}

the FA pathway and RNA Polymerase II. If FA proteins interact with RNAPII, we expect to demonstrate a physical interaction through cofractionation, coprecipitation, and colocalization and/or a functional interaction through the use of inhibitors of RNAPII. We show FA proteins bind RNA in vitro. Pharmacological inhibition of transcription blocks the FA pathway and sensitizes cells to DNA crosslink damage. Furthermore, RNAPII cofractionates and coprecipitates with FANCD2, suggestive of both a functional and physical link between the FA proteins, RNA, and transcription.

\section{To discover a mechanism for the FA pathway linking it to RNA Polymerase II. If} RNAPII is essential to the FA pathway, then we hypothesize there is a defect in RNAPII activity or regulation in FA cells. By examining known RNAPII activities in response to DNA damage, we sought to determine if this was intact in FA cells. RNAPII is polyubiquitinated after DNA damage and targeted for the proteasome, a modification that 
does not occur in FA cells. This provides one mechanistic link between the FA pathway and RNAPII.

Further experiments are required to fully understand the function of the FA pathway, but the data presented here identifies a new mechanism of regulation and provides support for a previously unknown function for FA proteins. 
Table 2-1: Rare genetic disorders that have contributed to understanding of cancer biology.

Disease Genes with responsible mutation

\begin{tabular}{|l|l}
\hline \hline Li-Fraumeni Syndrome & p53
\end{tabular}

Ataxia Telangiectasia $\quad$ ATM

Hereditary Breast Cancer BRCA1, BRCA2

Xeroderma Pigmentosum

Familial Adenomatous Polyposis

Nucleotide Excision Repair genes

Mismatch Repair genes

Retinoblastoma APC

Nijmegen Breakage Syndrome $\mathrm{Rb}$

Nbs1/Mre11/Rad50 


\title{
CHAPTER 3:
}

\section{ATR-dependent phosphorylation of FANCA on serine 1449 after DNA damage is important for $\mathrm{FA}$ pathway function}

\begin{abstract}
Previous work has shown several proteins defective in Fanconi anemia (FA) are phosphorylated in a functionally critical manner. FANCA is phosphorylated after DNA damage and localized to chromatin, but the site and significance of this phosphorylation are unknown. Mass spectrometry of FANCA revealed one phosphopeptide, phosphorylated on serine 1449. Mutation of this residue to alanine (S1449A) abolished a slower mobility form of FANCA seen after DNA damage. Serine 1449 phosphorylation was induced after DNA damage but not during $\mathrm{S}$ phase, in contrast to other posttranslational modifications of FA proteins. Furthermore, the S1449A mutant failed to completely correct a variety of FA-associated phenotypes. The DNA damage response is coordinated by phosphorylation events initiated by kinases ATM and ATR, and ATR is essential for proper FA pathway function. Serine 1449 is in a consensus ATM/ATR site, phosphorylation in vivo is dependent on ATR, and ATR phosphorylates FANCA on serine 1449 in vitro. Together these data support the conclusion that phosphorylation of FANCA on serine 1449 is a DNA damage-specific event that is downstream of ATR and is functionally important in the FA pathway.
\end{abstract}




\section{Introduction}

Fanconi anemia is a genetic disorder characterized by a variety of congenital defects, aplastic anemia, and a susceptibility to cancer $(4,80)$. At the cellular level, cells from patients are hypersensitive to agents that cause DNA crosslinking, including mitomycin C (MMC). Cells display increased levels of chromosomal aberrations, making FA a disease of genome instability. Patients have been categorized into at least thirteen complementation groups FA-A, B, C, D1, D2, E, F, G, I, J, L, M,N), and the genes responsible for eleven of these have been cloned (FANCA, B, C, D1=BRCA2, D2, E, F, $\mathrm{G}, \mathrm{J}=\mathrm{BACH} 1, \mathrm{~L}, \mathrm{M}, \mathrm{N}=\mathrm{PALB} 2)$ (Reviewed in $(25,68,146,171,195)$. Despite the progress made in identifying FA genes, the function of most of these proteins remains unknown. Several of the protein products interact in a complex, termed the core complex. The composition of this complex changes with subcellular localization, but a nuclear form contains the FANCA, B, C, E, F, G, L, and M proteins $(106-108,178)$. The integrity of the core complex is essential for FANCD2 monoubiquitination after DNA damage and during $\mathrm{S}$ phase, at which point FANCD2 relocalizes to foci that colocalize with proteins involved in homologous recombination such as BRCA1 and Rad51 (47, 173). The exact biochemical mechanism by which FA proteins impact DNA damage repair is unknown.

The FA core complex is regulated by cell cycle position and by DNA damage, but the mechanism of this regulation is largely unknown. In response to DNA damage and during S phase the core complex translocates from the cytoplasm to the nucleus and increases in molecular weight (178). Presence in the nucleus is essential for the complex 
to exert its function (119). The core complex is required for FANCD2

monoubiquitination, but may have other, as yet undetermined roles $(47,102)$. FANCA, FANCG, FANCM, FANCE, FANCD2, and FANCI are phosphoproteins, underscoring the importance of phosphorylation to the FA core complex and FA pathway $(57,76,108$, $113,140,164,174,187)$.

FANCG is phosphorylated on at least three functionally important serine residues, two of which are important for egress of the core complex from chromatin at mitosis, and the third of which is phosphorylated upon DNA damage and during S phase $(113,140)$. FANCM, recently identified, is phosphorylated in response to DNA damage, but the sites and significance of those phosphorylations are unknown (108). FANCD2, while not a member of the core complex, is phosphorylated by ATM kinase on serine 222, a modification essential for S phase arrest following DNA damage but not for FA pathway function (174). Two other phosphorylation sites have been mapped on FANCD2, with ATR and ATM kinases contributing variably to these events (57). FANCE has also been recently identified as a phosphoprotein via the Chk1 kinase (187). FANCI was identified as a target of ATM or ATR but the functional significance of the phosphorylations is unknown (164).

Similarly, FANCA is a phosphoprotein, but the kinase responsible, as well as the site of phosphorylation, has not been identified to date $(76,197)$. FANCA phosphorylation is abrogated in FA-A mutant cells derived from patients, suggesting it is a functionally important event $(2,76)$. Previous work in our lab showed that FANCA is phosphorylated on chromatin only after DNA damage (178). FANCA contains a consensus site for Akt phosphorylation at serine 1149 and is a substrate for Akt in vitro, 
but Akt is not the kinase for FANCA in vivo (131). Alternatively, the phosphorylation is sensitive to wortmannin, a PI-3 kinase inhibitor that inhibits ATR and ATM, suggesting these kinases may be involved (197). ATR and ATM are kinases that initiate phosphorylation signaling cascades in the response to DNA damage, with ATM most strongly activated in response to double strand breaks (DSBs), and ATR activated in response to a variety of replication stressors (103). In addition to both being kinases for FANCD2, ATR is also essential for FANCD2 monoubiquitination in response to DNA damage $(6,57,174)$. Furthermore, patients with Seckel syndrome, one form of which results from ATR deficiency, are phenotypically similar to FA patients (127).

In this study we set out to identify FANCA phosphorylation sites and to demonstrate the functional importance of this phosphorylation to the FA pathway. Here, we report the phosphorylation of FANCA at serine 1449, demonstrate its functional significance for proper FA pathway function, and provide evidence for ATR as a FANCA kinase.

\section{Materials and Methods}

Cell Culture - Cells were maintained at $37^{\circ}$ in a $5 \% \mathrm{CO}_{2}$ incubator. HeLa cells were cultured in Dulbecco's modified Eagle's medium (DMEM) supplemented with 10\% fetal bovine serum (FBS). GM 6914 FA-A mutant cells were grown in DMEM plus 15\% FBS. MG7 lymphoblasts were grown in RPMI $+15 \%$ FBS. Ataxia telangiectasia fibroblasts, AT221 JE-T pEBS7, and corrected cells, AT221 JE-T pEBS7-YZ5, were obtained from Dr. James Larner, Department of Radiation Oncology, University of Virginia, and were maintained in DMEM with 15\% FBS. 
Preparation of Flag-FANCA S1449A - pMMP-Flag-FANCA S1449A was constructed from pMMP-Flag-FANCA (78) using Stratagene's QuickChange site directed mutagenesis kit. The resultant plasmid was sequenced to confirm serine to alanine mutation and check for PCR-introduced mutations. GM 6914 and GM 6914 DR-GFP plus pMMP-Vector, pMMP-FANCA, or pMMP FANCA S1449A were produced by retroviral transduction as previously described $(76,130)$.

Mass spectrometry - All MS work was performed by the Mass Spectrometry Core at the University of Virginia. Briefly, silver stained bands (SilverQuest, Invitrogen) were trypsin digested and subjected to liquid chromatography mass spectrometry (LC-MS) on an ion spray mass spectrometer. Spectra were analyzed and peptides were identified using the Sequest search algorithm. Identity was confirmed manually.

Cell lysate and chromatin extract preparation - Whole cell lysates were prepared by suspending cell pellets in cell lysis buffer containing 300mM NaCl, 50mM Tris pH7.5, $1 \%$ Triton X-100, and protease and phosphatase inhibitors $(2 \mu \mathrm{g} / \mathrm{ml}$ Aprotinin, $1 \mu \mathrm{g} / \mathrm{ml}$ Pepstatin, $2 \mu \mathrm{g} / \mathrm{ml}$ Leupeptin, 1mM PMSF, $1 \mathrm{mM}$ Sodium Pyrophosphate, $1 \mathrm{mM} \mathrm{NaF}$, $1 \mathrm{mM} \beta$-glycerophosphate, and $\left.1 \mathrm{mM} \mathrm{Na}_{3} \mathrm{VO}_{4}\right)$. Cell suspensions were sonicated briefly, then cleared by centrifugation at $14000 \mathrm{rpm}$ for 15 minutes. Concentration of proteins in the supernatant was determined by Bradford assay. Chromatin extracts were prepared as described (141). 
Immunoprecipitation - To the indicated amount of protein in a volume of $1 \mathrm{ml}$ was added 20ul anti-Flag M2 agarose (Sigma) previously washed in Tris-buffered saline (TBS). Immunoprecipitates were incubated for 1.5 hours, and beads were washed three times in the same cell lysis buffer and dried. SDS loading buffer was added to the dried beads.

SDS-PAGE and Immunoblotting - SDS-PAGE using the method of Laemmli was followed by transfer onto nitrocellulose in buffer containing $25 \mathrm{mM}$ Tris, $200 \mathrm{mM}$ glycine, and 20\% methanol. Membranes were blocked in TBS $+5 \%$ BSA for 1 hour. Primary antibodies were diluted in TBS $+0.1 \%$ Tween 20 (TBST) and incubated 3 hours to overnight. Membranes were washed four times in TBST, then horseradish-peroxidase linked secondary antibodies (GE Healthcare) were added in TBST for 1 hour. After a second wash, proteins were visualized by chemiluminescence (Pierce SuperSignal West Pico). Antibodies used were against FANCA-N terminal $(1: 1,000)(78)$, FANCD2-N terminal $(1: 1,000)(140)$, FANCG-N terminal $(1: 1,000)(141), \beta$-tubulin $(1: 10,000)$ (DM1B, Calbiochem), topoisomerase II (1:1,000) (SWT3D1, Calbiochem), Ku86 $(1: 1,000)$ (B-1, Santa Cruz), ATR (for immunoprecipitation, PA1-450, Affinity BioReagents), ATR (1:1,000) (for immunoblotting, N-19, Santa Cruz), and phospho(Ser/Thr) ATM/ATR Substrate (1:5,000) (Cell Signaling).

Chromatography - Gravity anion exchange chromatography and gel filtration chromatography was performed on chromatin extracts as previously described (178). 
Synchronization - HeLa cells were treated overnight with $2 \mathrm{mM}$ thymidine, washed, released into regular media, and treated again overnight with thymidine to synchronize at the G1/S border. Cells were then released for 3 hours to obtain an $\mathrm{S}$ phase population and 6 hours to obtain a late $\mathrm{S} / \mathrm{G} 2$ population (141).

Phosphatase treatment - Phosphatase treatments were performed on both whole cell lysate and immunoprecipitated protein. For immunoprecipitated FANCA, dried beads were resuspended in $50 \mu 1 \lambda$-phosphatase buffer $\pm 400 \mathrm{U} \lambda$-phosphatase (Sigma) or PP2A (generous gift of Dr. David Brautigan) \pm phosphatase inhibitors (1mM Sodium Pyrophosphate, $1 \mathrm{mM} \mathrm{NaF}, 1 \mathrm{mM} \beta$-glycerophosphate, and $1 \mathrm{mM} \mathrm{Na}_{3} \mathrm{VO}_{4}$ ) and incubated at $30^{\circ}$ for 30 minutes. $50 \mu 12 \mathrm{X}$ SDS-loading buffer was added to stop the reaction. Alternatively, $400 \mathrm{U}$ of $\lambda$-phosphatase was added to $275 \mu \mathrm{g}$ total protein in cell lysis buffer (total volume $=75 \mu \mathrm{l})$ and incubated for 30 minutes at $30^{\circ} .75 \mu 12 \mathrm{X}$ SDS loading buffer was added to stop the reaction.

Preparation of anti-pS1449 polyclonal antiserum - The peptide, CQAAPDADLpSQEPHLF, identical to the $\mathrm{C}$ terminal 15 amino acids of FANCA, was conjugated to keyhole limpet hemocyanin $(\mathrm{KLH})$ and used to generate a polyclonal rabbit derived antiserum. Peptide synthesis, immunization, and serum collection were performed by Proteintech Group, Inc., Chicago, IL. Serum was first affinity purified with the phosphorylated peptide immobilized on a column (Aminolink, Pierce) according to manufacturer's instructions, eluted in $0.2 \mathrm{M}$ glycine $\mathrm{pH} 2.5$, adjusted to $\mathrm{pH} 7.5$ with $1 \mathrm{M}$ Tris- $\mathrm{HCl} \mathrm{pH} 9.5$, and diluted 1:1 in TBS. The resulting antibody was then cross- 
adsorbed to a column with immobilized unmodified peptide to produce antibody specific to phospho-serine 1449.

Cytotoxicity Assays - Colony survival assays were performed by plating 500 cells on a 10 $\mathrm{cm}$ plate and allowing them to spread for 8 hours, at which point cells were treated with varying concentrations of MMC in DMEM $+15 \%$ FBS for 1 hour. Cells were washed 2X with PBS, fresh media was added, and cells were incubated 10-12 days to grow into visible colonies. Colonies were stained with $0.1 \%$ crystal violet in methanol and counted.

Chromosome breakage analysis - $1 \mu \mathrm{M}$ colcemid was added to cells treated for 24 hours with $1 \mu \mathrm{M}$ MMC. After 6 hours, cells were collected with trypsin, washed $1 \mathrm{X}$ in PBS, swollen in hypotonic buffer $\left(40 \mathrm{mM} \mathrm{KCl}, 25 \mathrm{mM}\right.$ sodium citrate) for 20 minutes at $37^{\circ}$, and fixed in acetic acid:methanol (1:3) for 10 minutes. Cells were dropped onto slides, stained with Giemsa, and at least 25 metaphase spreads were analyzed for the presence of gaps, single chromatid breaks, isochromatid breaks, fragments, and polyradials.

Analysis of homologous recombination frequency - 6914 DR-GFP cells and an I-SceI expression vector, pCBASce, were generous gifts from Dr. Maria Jasin, Memorial SloanKettering. These cells have one copy of an integrated homologous recombination reporter and have been described elsewhere (120). We transduced these cells with pMMP-Vector, pMMP-FANCA, and pMMP-FANCA S1449A, selected in puromycin, and assayed for frequency of homologous recombination as described (120). 
siRNA - Duplex siRNA directed against ATR was 5'-

GACGGUGUGCUCAUGCGGC (Dharmacon). Control siRNA was siCONTROL Lamin A/C (Dharmacon). HeLa cells were transfected on day 1 at an siRNA concentration of $100 \mathrm{nM}$ using X-tremeGENE transfection reagent (Roche) according to manufacturer's instructions. On day two cells were trypsinized, split into two wells, and allowed to attach for eight hours. Cells were then transfected again as on day one. Twenty-four hours after the second transfection cells were treated with $1 \mu \mathrm{M} M M C$, then harvested for immunoblotting approximately forty-two hours after the second transfection.

In vitro kinase - ATR was immunoprecipitated from HeLa whole cell lysate in cell lysis buffer $(300 \mathrm{mM} \mathrm{NaCl}, 50 \mathrm{mM}$ Tris $\mathrm{pH} 7.5,1 \%$ Triton $\mathrm{X}-100$, plus protease and phosphatase inhibitors as above). $10 \mathrm{mg}$ of protein $(2.5 \mathrm{mg} / \mathrm{ml})$ was mixed with $12.5 \mu \mathrm{g}$ anti-ATR antibody (PA1-450, Affinity BioReagents) or 12.5 $\mu$ g rabbit IgG overnight. Immunoprecipitated proteins were collected with 100 $\mu$ l Protein A Sepharose (Invitrogen) for 1 hour, washed $3 \mathrm{X}$ in cell lysis buffer, then $3 \mathrm{X}$ in in vitro kinase buffer (50mM Tris $\mathrm{pH} 7.5,10 \mathrm{mM} \mathrm{MgCl} 2,1 \mathrm{mM}$ DTT, plus protease and phosphatase inhibitors as above), and divided into 4 parts for 3 in vitro kinase assays and a western blot. Beads were dried, then incubated in $20 \mu \mathrm{L}$ in vitro kinase buffer containing $1 \mu \mathrm{M}$ cold ATP and $10 \mu \mathrm{Ci}[\gamma-$ $\left.{ }^{32} \mathrm{P}\right] \mathrm{ATP}$. To this was added approximately $1 \mu \mathrm{g}$ of GST-fusion substrate. GST-FANCA C terminus has been described (78). GST-FANCA S1449A was generated by PCR mediated, site-directed mutagenesis of pGEX-FANCA(C) using Stratagene's QuickChange kit. GST fusion proteins were purified from bacteria on glutathione 
sepharose according to manufacturer's instructions (GE Healthcare). In vitro kinase reactions were incubated for 1 hour at $30^{\circ}$, then $25 \mu 1$ of $2 \mathrm{X}$ SDS loading buffer was added to stop the reaction. Resulting products were separated by 10\% SDS-PAGE, stained with Coomassie, then dried and detected by autoradiography.

Statistical Analysis was by ANOVA test for significance.

\section{Results}

\section{FANCA is phosphorylated in vivo on Serine 1449.}

Previous work in our lab and others has shown that FANCA phosphorylation correlates with intact FA pathway function and that a phosphatase-sensitive form of FANCA was found on chromatin following DNA damage $(76,178,200)$. In the report by Thomashevski, et. al., the phosphatase-sensitive, slower mobility form of FANCA could only be visualized by immunoblot following purification by chromatography (178). In an effort increase phosphorylation of FANCA, we treated HeLa cells stably expressing Flag-FANCA with the PP2A inhibitor, okadaic acid, for 30 minutes at $1 \mu \mathrm{M}$ and immunoprecipitated Flag-FANCA (10). Okadaic acid has been shown to increase the level of FANCA phosphorylation (197). We hypothesized that phosphorylated FANCA would be enriched from cells doubly treated with MMC and okadaic acid (Figure 3-1A, lane 5). Immunoprecipitated Flag-FANCA from this band (Figure 3-1A, lane 5) was excised from the silver-stained gel, trypsin digested, and peptides were analyzed by mass spectrometry. Notably, the band analyzed by mass spectrometry displayed no mobility shift, as it was from whole cell lysate not undergoing chromatography. FANCA peptides 
were identified that resulted in $62 \%$ coverage of FANCA, and only one

phosphopeptide was identified, containing phosphoserine 1449 of FANCA (Figure 3-1B).

Of particular note is the presence of serine 1449 within an LSQE sequence, a consensus site for the related kinases ATM and ATR (128). Within FANCA there are seven other SQ or TQ sequences, most basic consensus sequences for ATR and ATM, but no other LSQE sequences. Of the seven, five were covered in the mass spectrometry screen and were not found to be phosphorylated.

Consistent with our previously published results, a slower mobility form of FANCA was seen after MMC treatment and multistep chromatography (178). Chromatin extracts were prepared from GM6914 (FA-A) cells stably expressing Flag-FANCA. Extracts were passed over a Q Sepharose (Sigma) anion exchange column. The flowthrough, which contained most of the FANCA, was further purified by gel filtration size exclusion chromatography. Fractions 14-18, containing FANCA, were pooled and immunoprecipitated using anti-Flag resin, separated by SDS-PAGE, and immunoblotted for FANCA. A slower mobility form of FANCA was observed (Figure 3-1C, lanes 5,6). This form was eliminated by reaction with two different phosphatases, PP2A and $\lambda$ phosphatase (Figure 3-1C, lanes 4,7). This form persisted when phosphatases were inhibited (Figure 3-1C, lanes 3,8). This slower mobility form is not detectable in the initial extract before undergoing chromatography, though FANCA is faintly detectable and on longer exposure FANCA is clearly present as a single band (Figure 3-1C, lane 1). In order to confirm that the phosphorylation seen after chromatography was on serine 1449, serine 1449 was mutated to alanine (S1449A) using PCR-mediated sitedirected in vitro mutagenesis. GM6914 cells (FA-A) were infected with pMMP-Flag- 
FANCA wt or pMMP-Flag-FANCA S1449A, and chromatin extracts were subjected to anion exchange chromatography and subsequent low percentage and prolonged SDSPAGE. A higher mobility form of FANCA could not be detected in extracts not undergoing chromatography (Figure 3-1D, lane 4), nor in extracts from cells expressing FANCA S1449A (Figure 3-1D, lane 2). A higher mobility FANCA form was detected in extracts after chromatography from cells expressing wild-type FANCA (Figure 3-1D, lane 1). Taken together, these data indicate that FANCA is phosphorylated on serine 1449 , and this phosphorylation site is required for the appearance of the slower mobility form of FANCA found on chromatin after DNA damage.

Anti-phosphoserine 1449 antiserum detects phosphorylated FANCA.

In order to directly detect the site of phosphorylation, we raised an antiserum against a 15 amino acid peptide centered around and containing a phosphorylated serine 1449 residue. The antiserum was affinity purified over a phosphorylated peptide column, cross-adsorbed to an unmodified peptide column, then used to detect phosphorylated FANCA. HeLa whole cell lysates from cells treated with MMC were analyzed by SDSPAGE and immunoblotted for phospho-FANCA S1449. An increase in signal was observed in cells treated with okadaic acid ( $1 \mu \mathrm{M}$ for 30 minutes), consistent with an increase in phosphorylation (Figure 3-2A, lane 3). Similarly, treatment of extracts with lambda phosphatase eliminated the signal detected with the anti-phosphoserine 1449 antiserum, indicating that the antiserum specifically detected FANCA phosphorylated at S1449 (Figure 3-2A, lane 5). 
FANCA is phosphorylated after DNA damage.

Since the previously identified, phosphatase-sensitive species of FANCA was only detected following DNA damage, we sought to investigate whether serine 1449 was phosphorylated after DNA damage. As shown in Figure 3-2A, lanes 1 and 2, the amount of endogenous phosphorylated FANCA increases after MMC treatment, as detected with the phospho-specific antiserum. To confirm that this phosphorylation was on serine 1449, HeLa cells expressing wild type Flag-FANCA or Flag-FANCA S1449A were lysed and extracts were analyzed by immunoblotting with anti-phosphoserine 1449 antibody. This antibody specifically detected an increase in the amount of phospho-FANCA following DNA damage only in cells overexpressing wild type FANCA (Figure 3-2B, lane 4) and not in cells expressing FANCA S1449A (Figure 3-2B, lane 6). In Figure 32B, lanes 1 and 2, endogenous FANCA was detected on a longer exposure, as shown in Figure 3-2A, lanes 1 and 2.

In further support of our work, Dr. Steve Elledge's group had identified FANCA as a substrate for ATR/ATM in a phosphoprotein screen by immunoprecipitation using an antibody specific for substrates of ATR/ATM (SJ Elledge, personal communication, 2006, (101)). The antibody used was raised against a phospho-leucine (serine/threonine) glutamine $\left(\mathrm{L}(\mathrm{S} / \mathrm{T})^{*} \mathrm{Q}\right)$ motif (Cell Signaling). Based on the sequence context of S1449, this antibody would be expected to recognize phosphoserine 1449. HeLa cells expressing Flag-FANCA or Flag-FANCA S1449A were lysed and immunoprecipitated with antiFlag resin. The $\alpha-\mathrm{L}(\mathrm{S} / \mathrm{T}) * \mathrm{Q}$ antibody specifically detected immunoprecipitated wild type FANCA only after DNA damage (Figure 3-2C, lane 2) and did not detect FANCA S1449A before or after DNA damage (Figure 3-2C, lanes 3,4), supportive of both the 
work from the Elledge lab and the DNA damage-inducibility of the phosphorylation event.

FANCA is not phosphorylated on serine 1449 during S phase.

Other FA proteins that are modified in response to DNA damage are also modified during S phase. Specifically, FANCD2 is both monoubiquitinated and phosphorylated after DNA damage and during S phase $(47,57)$. Similarly, FANCG is phosphorylated at serine 7 after DNA damage and during S phase (140). Consequently, we sought to determine if phosphoserine 1449 followed the same paradigm. HeLa cells were synchronized at $\mathrm{S}$ phase using a double thymidine block, and chromatin was extracted and subjected to gravity anion-exchange chromatography to allow detection of phosphatase-sensitive FANCA as previously published in our lab. Cells were analyzed by flow cytometry to verify synchrony at $\mathrm{S}$ phase (data not shown). Surprisingly, the slower mobility, phosphatase-sensitive form of FANCA could be detected after DNA damage (Figure 3-3A, lane 2), but not during S phase or in asynchronous extracts (Figure 3-3A, lanes 1,3), suggesting that phosphorylation of FANCA is a DNA damage-specific event.

FANCA is found in a larger protein complex termed the FA core complex. Previous work in our lab has shown the composition of the core complex differs, dependent on cell compartment and DNA damage (178). Specifically, a chromatin bound core complex after DNA damage has an apparent molecular weight of 1 MD. Since FANCA is phosphorylated after DNA damage but not during S phase, we sought to determine if it followed that the composition of the core complex on chromatin was 
different under these two conditions. Using chromatography to detect the phosphatase sensitive FANCA, the size of the core complex was observed from chromatin extracts using gel-filtration chromatography. Consistent with previous results, the slower mobility form of FANCA was only detected in MMC treated core complex (Figure 33B, fractions 16,18). Surprisingly, however, the core complex differed in apparent molecular weight after gel filtration. The S phase complex had a peak in fraction 12 , consistent with a molecular weight of about 1.5 MD (Figure 3-3B), and the MMC treated complex had a peak at a smaller molecular weight in fractions 16 and 18 (Figure 3-3B), consistent with the composition of the complex being different under these conditions.

We verified these results using anti-phosphoserine 1449 antibody on cell extracts from HeLa cells synchronized at various stages of the cell cycle or treated with MMC. Phospho-FANCA S1449 was detected only after MMC treatment (Figure 3-3C, lane 2) and not during various phases of the cell cycle (Figure 3-3C, lanes 3-5). FANCD2 was monoubiquitinated both during the cell cycle stages and after MMC (Figure 3-3C), confirming that phosphorylation of FANCA and FANCD2 monoubiquitination can occur distinct from one another.

Phosphoserine 1449 FANCA is increased on chromatin after DNA damage.

The original phosphorylated FANCA reported by our lab was found in a chromatin associated core complex prepared from a DNA-damaged extract (178). Thus we sought to determine whether phosphoserine 1449 FANCA was found on chromatin after DNA damage. Chromatin extracts were prepared from HeLa cells treated with MMC and phosphorylated FANCA was detected using phospho-specific antiserum. 
Indeed, phosphorylated and total FANCA was enriched on chromatin after DNA damage (Figure 3-4, lane 2), consistent with a previous report from our laboratory (141).

FANCA S1449A is able to bind FANCG

FANCA is found within the larger FA core complex, where it forms an association with, among other proteins, FANCG. We wished to investigate whether phosphorylation on S1449 was essential for this interaction. HeLa cells expressing FlagFANCA, Flag-FANCA S1449A, and the vector control were treated with MMC, and whole cell extracts were immunoprecipitated using anti-Flag (Figure 3-4B). Importantly, FANCG is still found in association with FANCA S1449A, indicating the core complex is at least partially intact in the absence of phosphorylation (Figure 3-4B, lanes 3,4).

FANCA S1449A fails to fully correct FA-A mutant cells.

Cells from FA patients display a marked hypersensitivity to DNA crosslinking agents, and correction of such cells with the complementing wild type cDNA results in resistance to these agents. If phosphorylation at serine 1449 were functionally important in the FA pathway, then mutants at S1449 would be expected to exhibit FA-associated phenotypes. In order to test the importance of serine 1449 phosphorylation, GM6914 FA-A mutant human fibroblasts were infected with the FANCA S1449A construct generated by site-directed mutagenesis. Cells expressing FANCA S1449A were assayed for sensitivity by MMC colony survival assay. FANCA S1449A failed to fully correct the MMC sensitivity seen in mutant FA-A cells (Figure 3-5A). Statistical testing using ANOVA demonstrated the S1449A phenotype is statistically different from wild type 
FANCA ( $\mathrm{p}=0.046)$ and from FA-A mutant cells $(\mathrm{p}=0.018)$. Thus, the phosphorylation site in FANCA is functionally important for a normal FA pathway.

A functionally intact FA core complex is required for FANCD2 monoubiquitination after DNA damage and during S phase $(47,173)$. FANCD2 monoubiquitination is therefore routinely used as a marker for intact FA pathway function. FANCD2 monoubiquitination was monitored in GM6914 (FA-A) cells expressing wild-type FANCA, FANCA S1449A, and the vector control in order to assess the effect of the phosphorylation site mutant. Nuclear extracts were analyzed by SDSPAGE and immunoblotting. Following MMC treatment, cells expressing wild-type FANCA showed the expected increase in the amount of monoubiquitinated FANCD2, while cells expressing FANCA S1449A had less monoubiquitinated FANCD2, as confirmed by densitometry analysis and calculation of the long/short (L/S) ratio (Figure 3-5B, lanes 2 and 3). The vector control, as expected, exhibited no monoubiquitinated FANCD2 (Figure 3-5B, lane 1). The amount of ubiquitinated FANCD2 is intermediate between mutant and wild type cells, but the difference was reproducible over multiple immunoblots and was confirmed by calculation of the L/S ratio. Mutation of the phosphorylation site, therefore, disrupts the functional integrity of the FA pathway. Because mutation of serine 1449 to alanine does not result in complete loss of FANCD2 monoubiquitination, we went on to clarify this defect using a time course of MMC treatment (Figure 3-5C). In whole cell extracts from GM6914 cells expressing wild type FANCA an increase in monoubiquitinated FANCD2 is detectable at 4 hours of MMC treatment, and the level continues to increase with further treatment (Figure 3-5C, lanes 
5-7). In contrast, in cells expressing FANCA S1449A, some ubiquitination is

detectable at 4 hours, but at later time points fails to increase (Figure 3-5B, lanes 10-12).

Cells from patients with FA have a characteristic increase in genome instability, displaying an increase in chromosomal aberrations both spontaneously and in response to DNA damage. For this reason, chromosomal breakage analysis is used as a clinical diagnostic test for FANCA. GM6914 fibroblasts expressing wild-type FANCA or FANCA S1449A and the vector control were exposed to MMC, treated with colcemid to arrest at metaphase, and metaphase spreads were prepared. Chromosomes were analyzed for the presence of gaps, single chromatid breaks, isochromatid breaks, fragments, and polyradials. Results are expressed as the number of aberrations per metaphase. At least 25 metaphases were counted per cell type. While cells corrected with wild type FANCA cDNA displayed low levels of aberrations, those supplied the phosphomutant FANCA exhibited an intermediate amount of abnormal chromosomes compared with the vector control (Figure 3-5D). These data are consistent with our other findings that FANCA S1449A fails to fully correct the FA phenotype.

\section{FANCA S1449A does not fully correct FA-A homologous recombination defect.}

Based on similarity of FA to other disorders of DNA repair and the interaction of FA proteins with proteins such as BRCA1 and BRCA2 known to be involved in homology directed repair (HDR), FA has been implicated in the repair of double strand breaks by HDR $(47,58)$. Indeed, human cells from complementation groups FA-A, FAG, and FA-D2 have been shown to be defective in repair of a double strand break introduced on a recombination reporter (120). In order to assess the ability of cells 
expressing FANCA S1449 to perform HDR, GM6914 (FA-A) cells were obtained (courtesy of M. Jasin, MSKCC) with an integrated copy of the DR-GFP reporter (120). This reporter has two nonfunctional copies of GFP and a restriction site for the endonuclease I-SceI. A double strand break is introduced by expression of I-SceI. If HDR occurs, a functional GFP is produced, and HDR frequency can be calculated by the percentage of GFP positive cells. GM6914 DR-GFP-expressing cells were infected with wild-type FANCA, FANCA S1449A cDNA, or the vector control and selected for stable expression. I-SceI was introduced on an expression vector, and cells were cultured for three days to allow time for expression of the enzyme, induction of the DSB, and repair. After this time, cells were harvested and analyzed for GFP expression using flow cytometry. GM6914 DR-GFP FANCA corrected cells showed significantly more GFPpositive cells than the non-corrected vector control (Figure 3-5E) $(\mathrm{p}=0.027)$. The phosphomutant cells, GM6914 DR-GFP FANCA S1449A, had a percentage of GFPpositive cells intermediate between the two and statistically distinct from wild type FANCA $(\mathrm{p}=0.043)$, consistent with the intermediate phenotype measured by MMC sensitivity, FANCD2 ubiquitination, and chromosome breakage. Cells transfected with an empty vector in the place of I-SceI had very low levels of GFP positive cells (data not shown), indicating low levels of background homologous recombination on the reporter in the absence of a DSB.

Phosphorylation of FANCA is dependent on ATR kinase.

Based on the presence of serine 1449 within a consensus ATM/ATR site, as confirmed by the detection of the peptide by a screen performed by the Elledge group, 
and given previous work implicating ATR in FA, we hypothesized that ATR could be the kinase that phosphorylated FANCA at serine $1449(6,139)$. GM6914 FA-A mutant cells expressing wild type FANCA, FANCA S1449A, or vector control were exposed to MMC and treated with wortmannin, an inhibitor of members of the PI3-Kinase family, which includes both ATM and ATR (151). Phosphorylation of overexpressed, wild type FANCA decreased after wortmannin treatment (Figure 3-6A, lanes 3 versus 4). Similarly, endogenous phosphorylated FANCA on S1449 was diminished after wortmannin treatment in MMC-treated HeLa cells (Figure 3-6B, lanes 2 versus 3). We then wished to investigate the phosphorylation status of FANCA in cells lacking ATM and ATR. Ataxia telangiectasia (ATM mutant) fibroblasts and ATM corrected fibroblasts were treated with MMC and analyzed for serine 1449 phosphorylation. Serine 1449 phosphorylation was induced in both ATM mutant and corrected cells after MMC, indicating ATM is not required for this event (Figure 3-6C). In contrast, cells depleted for ATR by siRNA were unable to phosphorylate FANCA after DNA damage (Figure 36D, lane 4), and cells transfected with a control siRNA showed phosphorylation after DNA damage (Figure 3-6D, lane 2), indicating ATR is necessary for FANCA phosphorylation on S1449.

ATR kinase phosphorylates S1449 in vitro.

Given the role of ATR in vivo, we wished to investigate if serine 1449 in FANCA was a substrate for ATR in vitro. Endogenous ATR kinase was immunoprecipitated from HeLa cells (Figure 3-7B) and incubated with GST alone, a GST-FANCA C terminal fusion protein (amino acids 1250-1455) encompassing serine 1449, or GST-FANCA 
S1449A C terminal fusion in the presence of $\left[\gamma-{ }^{32} \mathrm{P}\right] \mathrm{ATP}$ and in vitro kinase conditions. All substrates were expressed and purified (Figure 3-7A, Coomassie), but ATR was only able to phosphorylate the GST-FANCA wild-type C terminal fusion, as detected by autoradiography (Figure 3-7A, autorad, lane 2, asterisk). The phosphorylation was eliminated in the S1449A mutant (Figure 3-7A, autorad, lane 3). This, together with the consensus site at serine 1449 for ATR or ATM, is suggestive that ATR is a kinase for FANCA on serine 1449 in vitro, but does not eliminate the possibility that the activity may be from an associated kinase in the immunoprecipitate. Taken together with the in vitro studies, these data indicate that ATR is responsible either directly or indirectly for phosphorylation of FANCA.

\section{Discussion}

With the exceptions of FANCL, a ubiquitin ligase, and the recently cloned $\mathrm{FANCJ}=\mathrm{BACH} 1$ and $\mathrm{FANCM}=\mathrm{Hef}$, the functions of the other FA proteins remain elusive, due partially to their lack of functional motifs $(86,92,106,108)$. Understanding the regulation and binding partners of the Fanconi proteins, including FANCA, can provide insight into the function of the proteins and the FA pathway. We report phosphorylation of FANCA on serine 1449 that is DNA damage-inducible and important to the function of the FA pathway. Importantly, we show this phosphorylation is dependent on ATR kinase. This, together with data showing monoubiquitination and phosphorylation of FANCD2 are dependent on ATR, places the FA pathway within the broader context of the DNA damage repair pathway $(57,139)$. Cells mutant at serine 1449 of FANCA have an intermediate FA phenotype as measured by MMC sensitivity, 
FANCD2 monoubiquitination, chromosome breakage, and homologous recombination. Most patient derived mutations result in proteins that are not expressed at all, leading to complete loss of function. We believe we see partial retention of function from FANCA S1449A by virtue of it being expressed, a conclusion consistent with clinical variants of the FA proteins $(2,202)$. Furthermore, FANCA S1449A forms appropriate interactions with FANCG (Figure 3-4B) and localizes to chromatin (data not shown), and it is therefore not surprising that partial function is preserved. Based on the importance of serine 1449 to the FA pathway, one would expect evolutionary conservation among mammalian species. Interestingly, serine 1449 is conserved in rat, but in mouse the corresponding amino acid is a tyrosine, another phosphorylatable residue, but one not phosphorylated by ATR. With ATR and ATM being apical in the DNA damage response pathway, it is interesting to speculate that differences in regulation at this amino acid between human and mouse could account for differences in the human and mouse mutant FA phenotypes, notably lack of spontaneous progression to aplastic anemia and cancer $(20,125,193,208)$.

The original work from our lab reporting phosphorylated FANCA, as well as Figures 3-1 and 3-3 from this work, show a significant mobility shift associated with phosphorylated FANCA (178). The sample from which phospho-serine 1449 was detected by mass spectrometry, however, showed subtle or no mobility shift on the silver stained gel (Figure 3-1A, lane 5). In addition, when using anti-pS1449 specific antiserum or anti-L(S/T)*Q antibody (Figure 3-2) on whole cell lysates, no mobility shift was seen for phospho-FANCA serine 1449 in comparison to wild-type FANCA. The mobility difference appeared after the use of subcellular chromatin fractionation and anion- 
exchange chromatography to partially purify FANCA (178). Yet, the slower mobility form of FANCA is dependent on the presence of the S1449 phosphorylation site (Figure 3-1D), is sensitive to phosphatases $\lambda$ and PP2A(Figure 3-1C), and is only present after DNA damage (Figure 3-3A,B). If the higher mobility form of FANCA represents FANCA phosphorylated on S1449, the phospho-specific antibody or the anti-L(S/T)*Q antibody would be expected to detect this form specifically. Attempts to show this have, to date, been unsuccessful, primarily due to the technical challenge of detection by antiFANCA antibody of the higher mobility form after multi-step chromatography. It remains, therefore, a formal and likely possibility that this form does not necessarily represent phospho-FANCA S1449, but rather is reflective of another modification in addition to and dependent on phosphorylation of S1449. In fact, given FANCA is a protein of $163 \mathrm{kD}$, phosphorylation alone is unlikely to cause such a large relative mobility shift. It is for this reason we have labeled the slower mobility form of FANCA phosphatase sensitive (PS) - FANCA, rather than phospho-FANCA. Other possible modifications include, among others, ubiquitination, sumoylation, acetylation, glycosylation, or additional phosphorylations that were not detected in our mass spec screen. Based on the data presented, however, this modification is unmasked by anion exchange chromatography (Figure 3-1C), as it is not detectable in chromatin extracts from the same cell not undergoing chromatography (Figure 3-1C, lane 1; Figure 3-1D, lane 4). I hypothesize chromatography modifies the mobility of FANCA, either through interaction with other proteins on the column, loss of protein-protein interactions, or interaction with the anion exchange residue itself, in a way dependent on the presence of phospho-serine 1449. Mobility on SDS-PAGE, while a function of molecular weight, is 
influenced by the protein's ability to bind SDS. Regions of concentrated charge have been shown to alter electrophoretic mobility $(37,63,142)$. While difficult to explain, phosphorylated FANCA may, after interaction with the anion exchange column, possess a charge difference resulting in altered mobility. A possible source of charge difference could be spontaneous deamidation of asparagine or glutamine to aspartate or glutamate, respectively, resulting in an overall increase in negative charge on the protein during purification. This remains an area of investigation for our lab, as this slower mobility, phosphatase-sensitive species may yield relevant information about other functionally important modifications of FANCA.

Our previous work identified phospho-FANCA only in a DNA damaged chromatin extract (178). In this work we went on to show that FANCA phosphorylated on serine 1449 localizes to chromatin in a DNA damage-dependent manner. In apparent contradiction to our work, Yagasaki et. al. reported wortmannin-sensitive, in vivo and in vitro phosphorylation of FANCA predominantly in the cytoplasm of lymphoblasts. They went on to show that phosphorylation was maintained in a deletion mutant of FANCA deleted for a putative nuclear localization signal (NLS) (197). A similar deletion was, however, later shown to be at least partially localized in the nucleus (89). Thus, it seems likely that, even in this prior study, the phosphorylation may have been a nuclear event. This apparent discrepancy could be caused by imperfect cellular fractionation of the reported cytoplasmic extract, by rapid shuttling in and out of the lymphoblast nucleus, or, potentially, by an undetected cytoplasmic phosphorylation. It is, however, worth noting that the original mass spectrometry screen in this study was from a whole cell extract, and with $62 \%$ coverage no other phosphorylations were detected. 
We report here phosphorylated FANCA is found on chromatin after DNA damage. Similarly, monoubiquitinated FANCD2 is found on chromatin after DNA damage, but monoubiquitination is defective in cells mutant at serine 1449 of FANCA. ATR kinase phosphorylates its binding partner, ATRIP, and relocates to chromatin after DNA damage (66). FANCA S1449A, however, localizes normally to chromatin (data not shown). An open but interesting question is whether FANCA is phosphorylated prior to or once arriving on chromatin. One hypothesis could be that FANCA is already present on chromatin, becomes phosphorylated after DNA damage and attains new function or localization. We have shown that FANCA phosphorylation is dependent on ATR, but ATR may not be the direct kinase for FANCA in vivo or in vitro. ATR phosphorylates a variety of downstream effectors and adaptors that could be responsible directly for the phosphorylation (208). We have investigated one of these downstream kinases, Chk1. In the presence of an inhibitor of Chk1, SB218078, FANCA is phosphorylated normally on S1449 after MMC treatment (Figure 3-8), indicating Chk1 is not required for FANCA phosphorylation (67). The presence of serine 1449 within an ATR/ATM consensus site, together with the data presented here and that provided by Elledge's group, is suggestive of a direct role for ATR.

Importantly, we report the first differentiation of the FA pathway after DNA damage and during $\mathrm{S}$ phase. Until now it has been understood that the function of the FA pathway in the DNA damage response was similar to its normal physiological function at $\mathrm{S}$ phase. In support of this was evidence that FANCD2 is monoubiquitinated and FANCG is phosphorylated both at S phase and following DNA damage $(140,173)$. The core complex was also known to localize to chromatin under both conditions (112). This 
is the first report of an event in the pathway to occur specifically after DNA damage. That the phosphorylation does not occur during S phase yet FANCD2 is still monoubiquitinated is an apparent contradiction. How the phosphorylation modulates FANCD2 ubiquitination is, however, unknown. Speculative mechanisms could include modulating the stability of FANCD2 itself or FANCD2 monoubiquitination after MMC treatment, perhaps by negatively regulating the deubiquitinase, USP1, after DNA damage in a way that is not required at S phase (124). Consistent with this, we observe a slight but consistent decrease in FANCD2 expression after MMC treatment in cells expressing FANCA S1449A (Figure 3-5B, lane 3; Figure 3-5C lanes 11,12). In any case, the separation of function seen after DNA damage versus S phase represents an important observation in FA biology.

\section{Acknowledgments}

We gratefully thank Maria Jasin and James Larner for sharing cell lines and David Brautigan for providing PP2A. We gratefully thank Steven Elledge for sharing unpublished data. Thanks to Wendy Golden for assistance with cytogenetic studies, to Mark Smolkin for assistance with statistical analysis, and to Elaine Cagnina for assistance with flow cytometry. 


\section{Figures}

\section{Figure 3-1: FANCA is phosphorylated in vivo on serine 1449.}

A. Whole cell lysates from GM6914 (FA-A) fibroblasts expressing Flag-tagged FANCA (lanes 2-5) or vector control (lane 1) treated with $1 \mu \mathrm{M}$ MMC for 18 hours (lanes 4 and 5) and/or $1 \mu \mathrm{M}$ okadaic acid for 30 minutes (lanes 3 and 5) were immunoprecipitated using anti-FLAG antibody. Precipitated proteins were separated by SDS-PAGE and silver stained. The band from lane 5 was excised and analyzed by mass spectrometry. The only detectable phosphopeptide is shown in B. C. Chromatin extracts from GM 6914 (FA-A) cells treated with $1 \mu \mathrm{M}$ MMC and expressing Flag-FANCA were purified over Q Sepharose anion exchange and size exclusion gel filtration chromatography, and fractions 14-18 were further immunoprecipitated using anti-Flag (lanes 3-8). Resulting immunoprecipitates were treated with $\lambda$-phosphatase (lane 7 ), $\lambda$-phosphatase + inhibitors (lane 8), PP2A (lane 4), or PP2A + inhibitors (lane 3), separated by SDS-PAGE, and immunoblotted for FANCA. Lanes 1 and 2 are extracts from the same cells or the vector control not undergoing chromatography or immunoprecipitation. D. Chromatin extracts from GM 6914 (FA-A) cells treated with $1 \mu \mathrm{M}$ MMC and expressing Flag-FANCA, FlagFANCA S1449A, or vector control were purified over gravity anion exchange chromatography (lanes 1-3), separated by SDS-PAGE, and immunoblotted for FANCA. Lane 4 is a chromatin extract from wild type Flag-FANCA expressing cells not purified by chromatography. IP: immunoprecipitation, PS-FANCA: phosphatase sensitive FANCA, PPAse: phosphatase, PP2A: phosphatase 2A. 
Figure 3-1: FANCA is phosphorylated in vivo on serine 1449
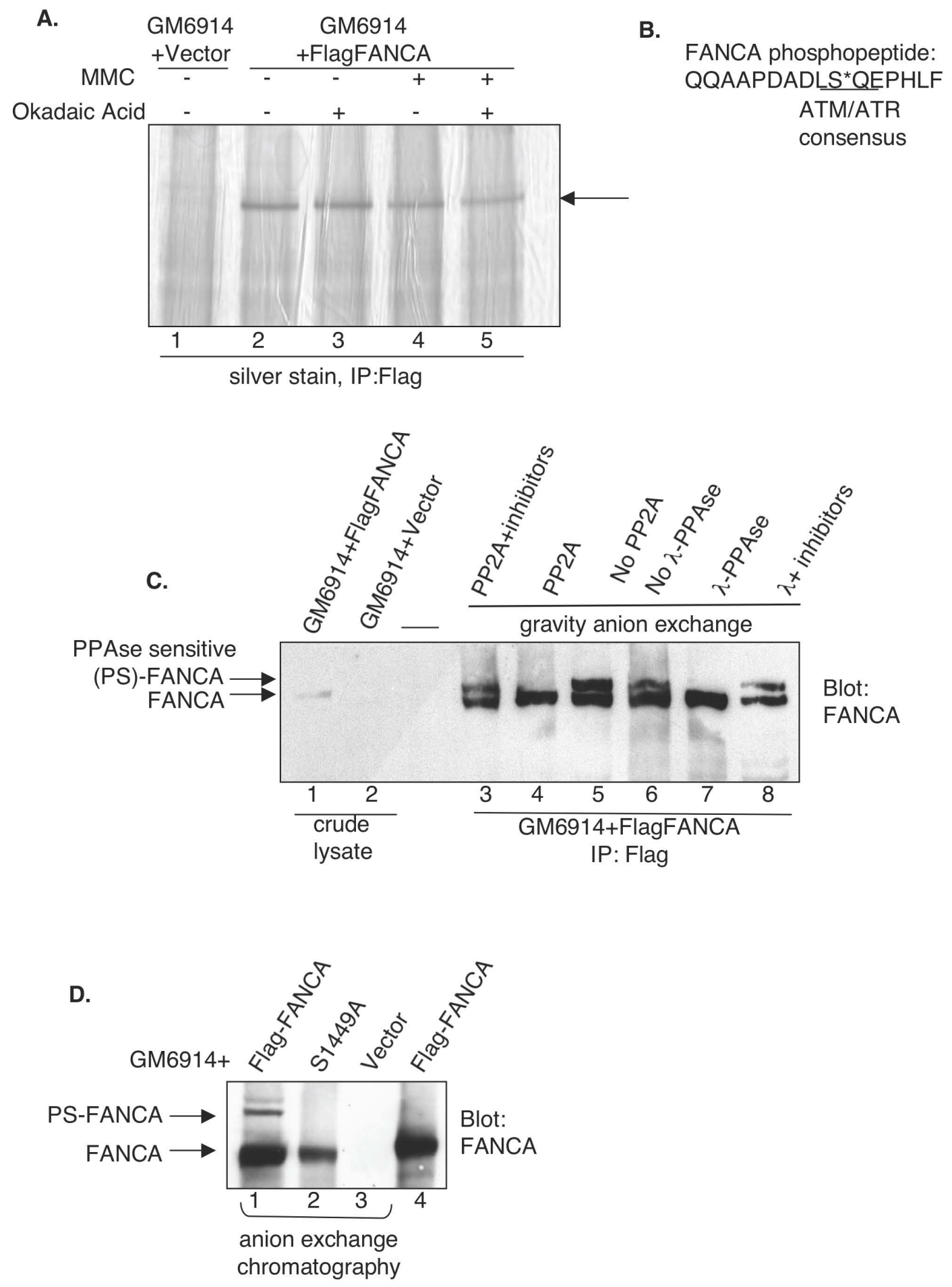
Figure 3-2: Phospho-FANCA serine 1449 is induced after DNA damage.

A. HeLa cells treated with $1 \mu \mathrm{M}$ MMC for 18 hours (lanes 2-5) and $1 \mu \mathrm{M}$ okadaic acid for 30 minutes (lane 3) were lysed, and $175 \mu \mathrm{g}$ protein was subjected to SDS-PAGE and immunoblotting for endogenous FANCA. In lanes 4 and 5, 275 $\mu$ g protein from HeLa cells treated with MMC was treated directly with $\lambda$ - phosphatase and run on SDS-PAGE. Proteins were immunoblotted using anti-phosphoserine 1449 antibody. The FANCA immunoblot shows similar levels of FANCA protein. $\beta$-tubulin was blotted as a loading control. B. HeLa cells expressing Flag-tagged FANCA, Flag-FANCA S1449A, or vector control were treated with MMC $1 \mu \mathrm{M}$ for 18 hours. Lysates were analyzed by SDS-PAGE and immunoblotting using the same antibodies as in (A). C. Cell lysates from cells in (B) were immunoprecipitated with anti-Flag antibody and subjected to SDSPAGE and immunoblotting using anti-phospho-(Ser/Thr) ATM/ATR substrate antibody. IP: immunoprecipitation, Ppase: phosphatase, P-S1449: phosphoserine 1449, P-L(S/T)Q: phospho-leucine (serine/threonine) glutamine (ATM/ATR substrate), MW: Molecular weight marker. 
Figure 3-2: Phospho-FANCA serine 1449 is induced after DNA damage

A.

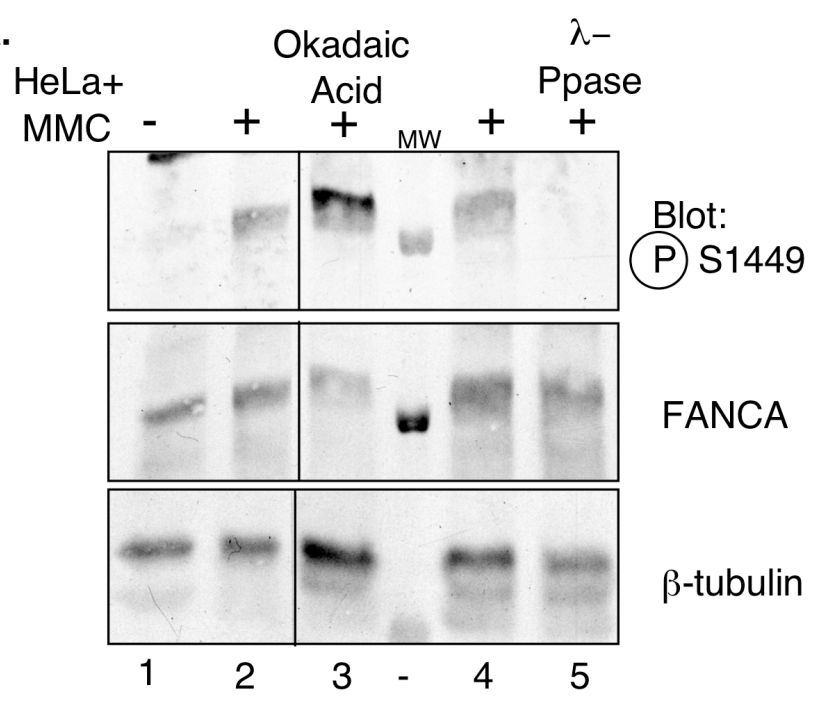

B.

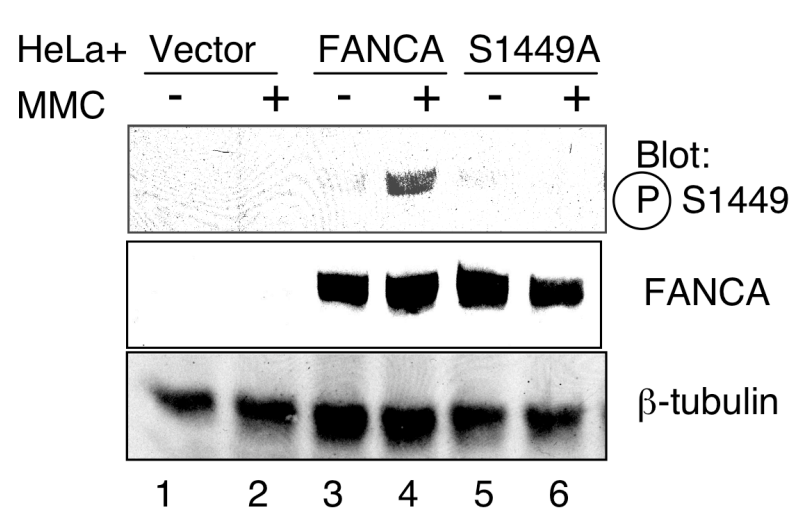

c.

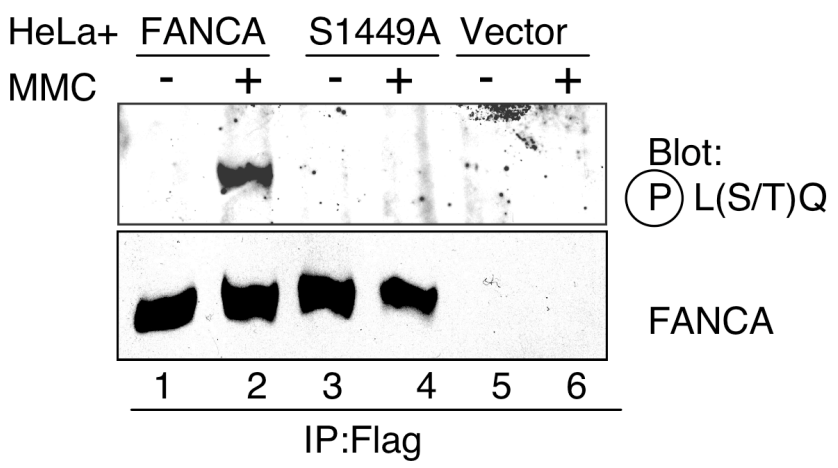


Figure 3-3: FANCA is not phosphorylated during $S$ phase.

A. HeLa cells were alternatively synchronized using the double thymidine block method and collected in S phase after a 3 hour release (lane 1) or treated with MMC (lane 2). Chromatin extract was partially purified by anion exchange chromatography, subjected to SDS-PAGE, and immunoblotted for FANCA. B. Extracts as in (A) were further purified by gradient anion exchange chromatography and gel filtration. Fractions were separated by SDS-PAGE and immunoblotted for FANCA. C. HeLa cells were synchronized by double thymidine block at the G1/S border (lane 4) and released for 3 hours into S phase (lane 5) or 6 hours into late S/G2 phase (lane 6). Alternatively, cells in lane 2 were treated with $1 \mu \mathrm{M}$ MMC for 18 hours. Whole cell extracts were separated by SDS-PAGE and immunoblotted for phosphoserine 1449, FANCA, FANCD2, and Ku86 as a loading control. PS-FANCA: Phosphatase sensitive - FANCA. 
Figure 3-3: FANCA is not phosphorylated during $\mathrm{S}$ phase

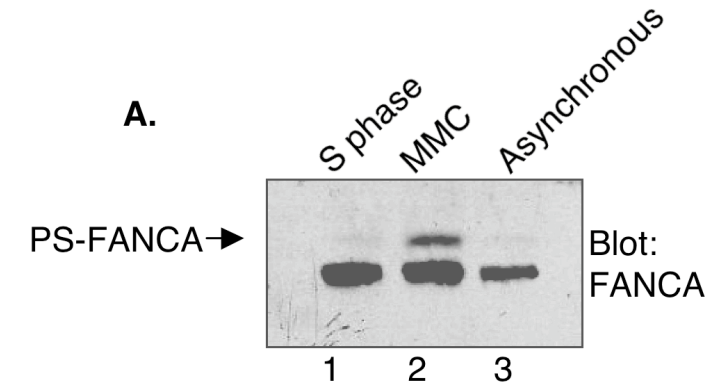

B.

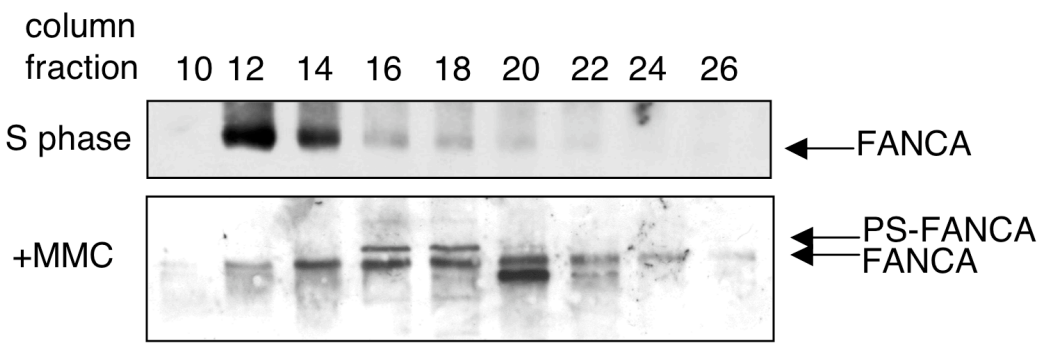

Blot: FANCA

c.
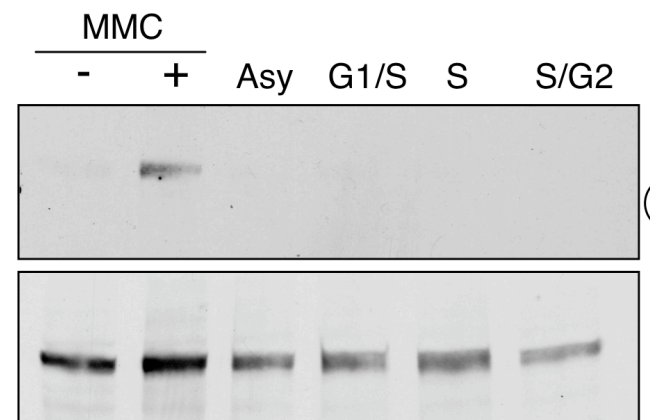

Blot:

(P) $S 1449$

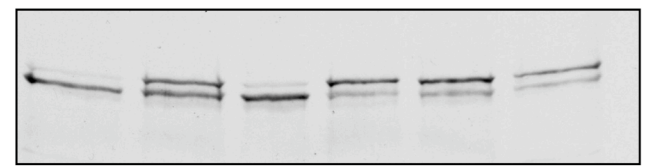

FANCA

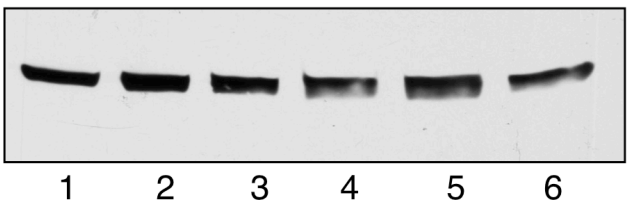

FANCD2

Ku86 
Figure 3-4: Phospho-FANCA S1449 is increased on chromatin after DNA damage and FANCA S1449A binds FANCG.

A. Chromatin extracts were prepared from HeLa cells treated with $1 \mu \mathrm{M}$ MMC for 18 hours. Extracts were separated by SDS-PAGE and immunoblotted for phospho-FANCA S1449, total FANCA, and topoisomerase II as a loading control. B: Whole cell extracts from HeLa cells expressing Flag-FANCA, Flag-FANCA S1449A, or the vector control and treated with $1 \mu \mathrm{M} \mathrm{MMC}$ for 6 hours were immunoprecipitated with anti-Flag. Immunoprecipitated proteins were separated by SDS-PAGE and immunoblotted for FANCA and FANCG. topoII: topoisomerase II, P-S1449: phosphoserine 1449, IP: immunoprecipitation. 
Figure 3-4: Phospho-FANCA S1449 is increased on chromatin after DNA damage and FANCA S1449A binds FANCG

A.

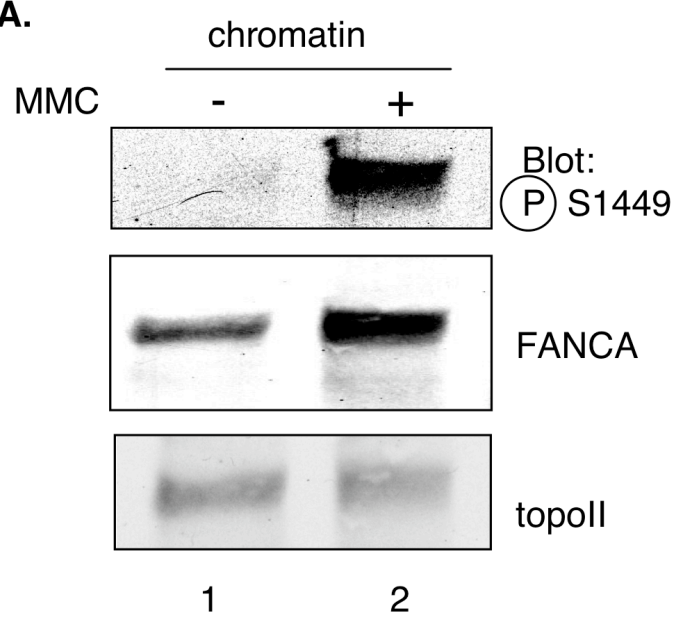

B.

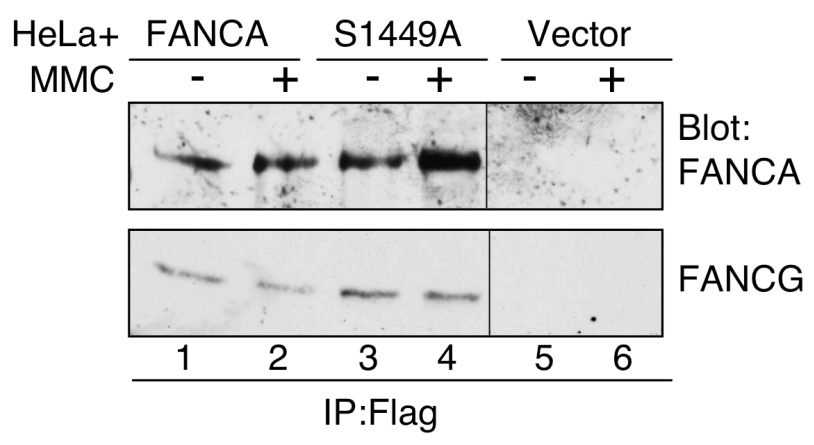


Figure 3-5: FANCA S1449A fails to completely correct FA-associated phenotypes.

A. Results of at least two colony survival assays are shown from GM6914 (FA-A) cells expressing wild type Flag-FANCA, Flag-FANCA S1449A, or the vector control. Error bars represent standard error of the mean (SEM). FANCA S1449A is statistically different from both the vector control $(p=0.018)$ and from wild-type FANCA $(p=0.046)$ B. Nuclear extracts were prepared from the same cells as in (A) treated with $0.1 \mu \mathrm{M}$ MMC for 18 hours. Extracts were separated by SDS-PAGE and immunoblotted for FANCD2. Ku86 serves as a loading control. L/S ratios were calculated using densitometric measurements of short and long band intensities. C. The same cells as in (A) were treated with $0.1 \mu \mathrm{M} \mathrm{MMC}$ for the indicated time then lysed directly in SDS loading buffer. Proteins were separated by SDS-PAGE and immunoblotted for FANCD2 and $\mathrm{Ku} 86$ as a loading control. L/S ratios were calculated by densitometry and plotted against time of treatment. D. Histogram plots are shown of chromosomal aberrations seen on metaphase spreads from GM6914 cells as in (A) and (B). E. The frequency of homologous recombination in GM6914 DR-GFP cells expressing wild type FlagFANCA, Flag-FANCA S1449A, or the vector control was measured using flow cytometry after HDR-mediated repair of a GFP reporter substrate. Frequency is expressed as a percentage of the level of recombination seen in wild-type FANCAexpressing cells. Both the vector control $(\mathrm{p}=0.027)$ and FANCA S1449A $(\mathrm{p}=0.043)$ are significantly different from wild-type FANCA. FANCD2-L: long form (monoubiquitinated form) of FANCD2, FANCD2-S: short form (nonubiquitinated) of FANCD2, L/S Ratio: long/short ratio. 
Figure 3-5: FANCA S1449A fails to completely correct FA-associated phenotypes

A.
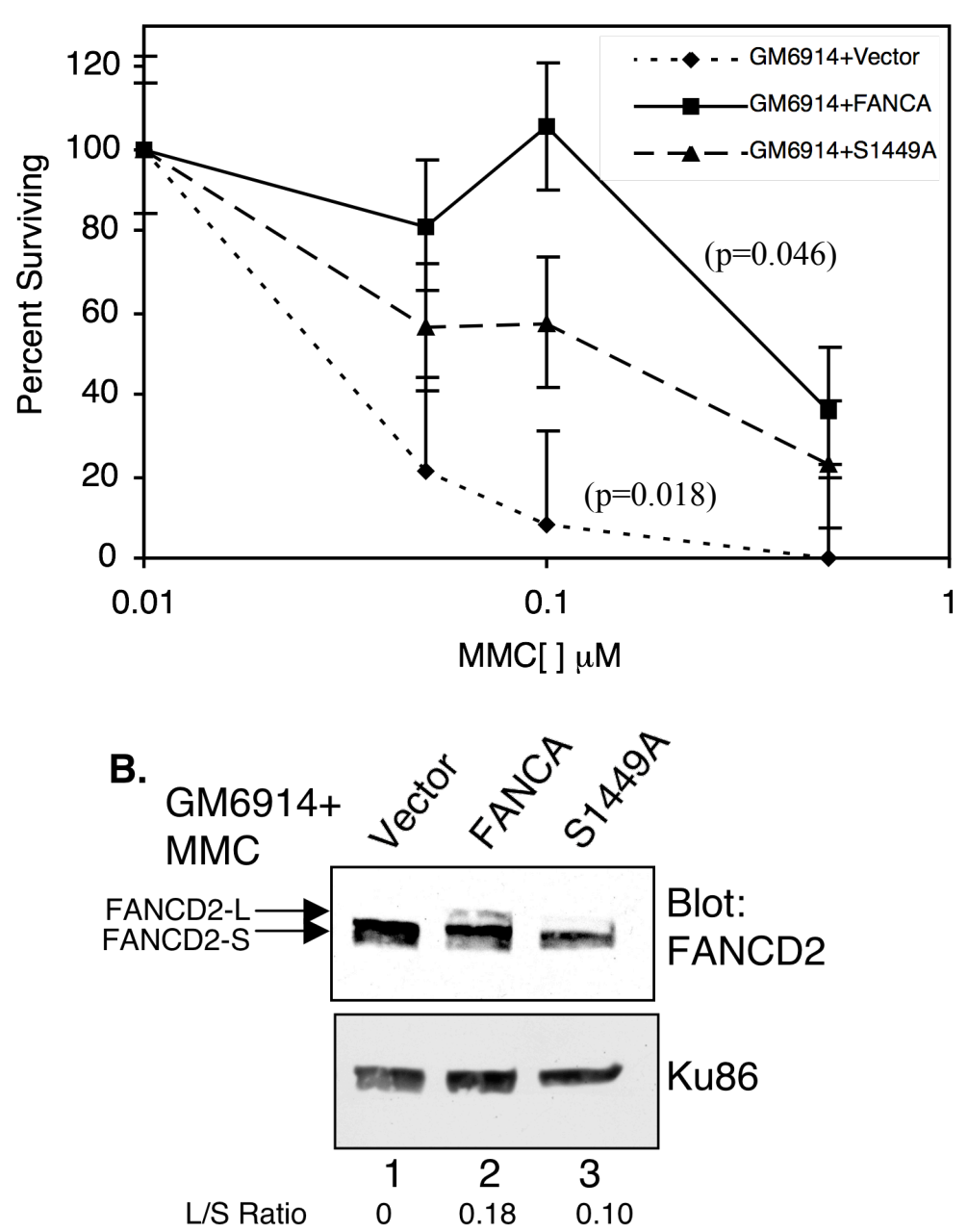

c.

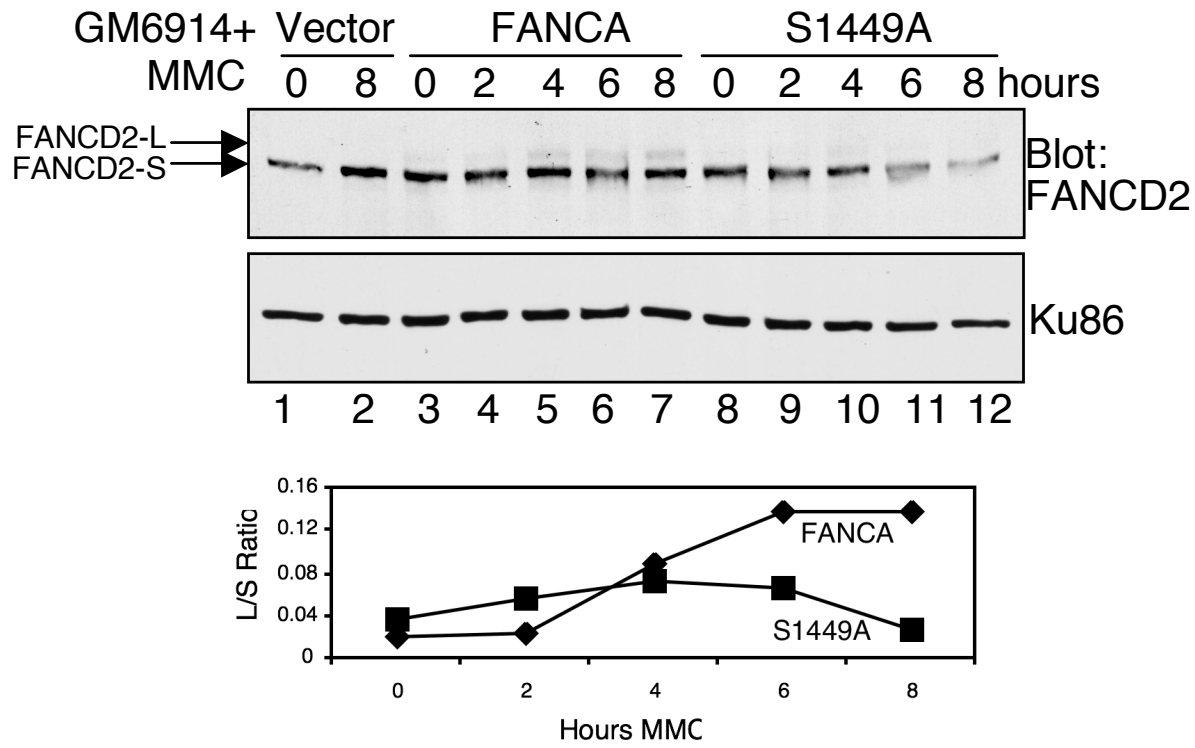


D.

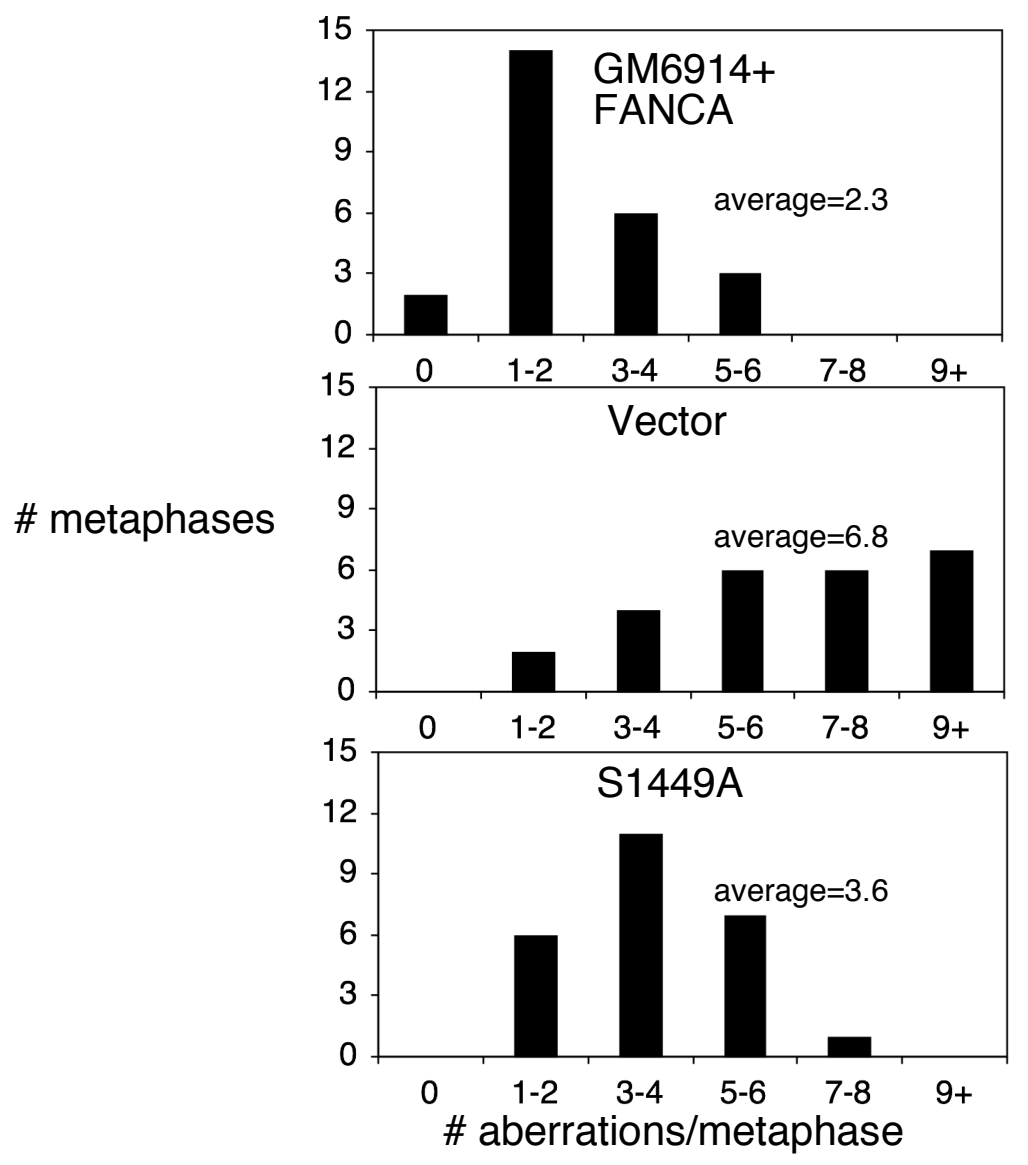

E.

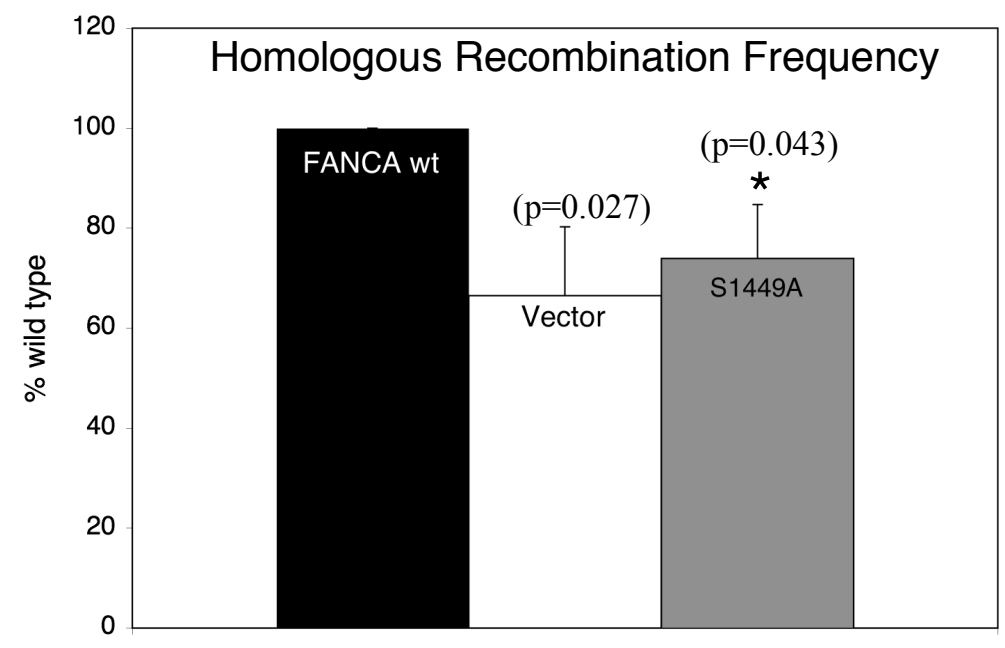


Figure 3-6: FANCA serine 1449 phosphorylation is dependent on ATR in vivo.

A. GM6914 cells expressing wild type Flag-FANCA, Flag-FANCA S1449A, or the vector control were treated with $0.1 \mu \mathrm{M} \mathrm{MMC}$ for 20 hours. At 16 hours $1 \mu \mathrm{M}$

wortmannin was added (lanes 2,4, and 6) for 4 hours. Whole cell lysates were separated by SDS-PAGE and immunoblotted for phospho-FANCA S1449 and total FANCA. B. HeLa cells were treated with $1 \mu \mathrm{M}$ MMC for 20 hours (lanes 2, 3). At 16 hours, 10 $\mu \mathrm{M}$ wortmannin was added (lane 3). Whole cell lysates were separated by SDS-PAGE and immunoblotted for phospho-FANCA S1449, total FANCA, and Ku86 as a loading control. C. ATM mutant and corrected fibroblasts (C) or HeLa cells treated with siRNA against ATR or control siRNA (D) were treated with $1 \mu \mathrm{M}$ MMC for 18 hours (lanes 2,4). Whole cell extracts were separated by SDS-PAGE and immunoblotted for phosphoFANCA S1449, total FANCA, ATR, and $\beta$-tubulin as a loading control. P-S1449: phosphoserine 1449, corr: corrected. 
Figure 3-6: FANCA serine 1449 phosphorylation is dependent on ATR in vivo

B.

A.

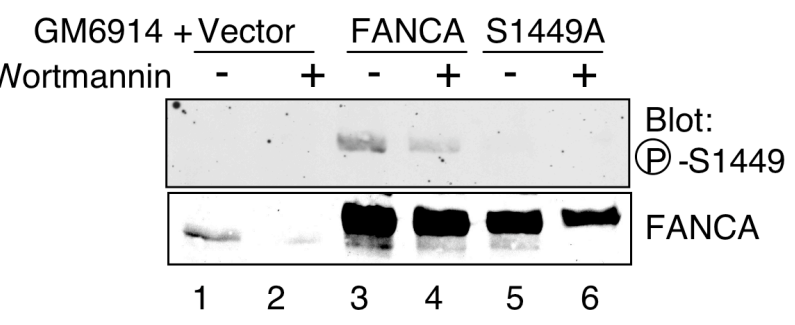

Wo

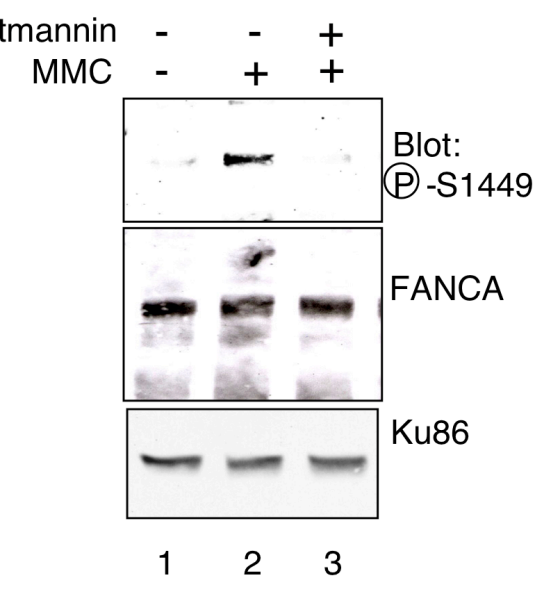

D.

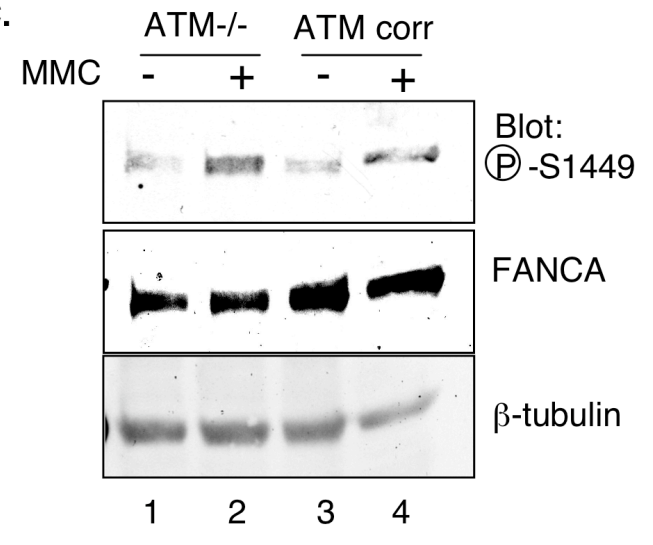

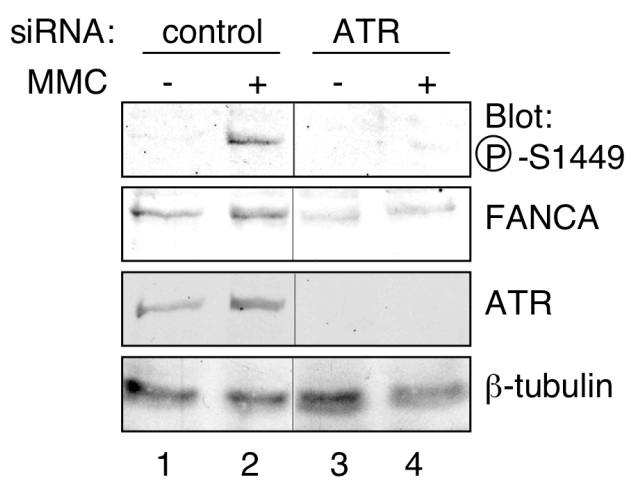


Figure 3-7: ATR phosphorylates serine 1449 of FANCA in vitro.

ATR kinase was purified from HeLa cells by immunoprecipitation using anti-ATR antibody. Following immunoprecipitation, beads were divided for western blot (B) and in vitro kinase assay (A). A. Immunoprecipitated ATR (lanes 1-3) or a control IgG immunoprecipitation (lanes 4-6) was incubated with GST (lanes 1, 4), GST-FANCA C terminus (lanes 2, 5), or GST- FANCA S1449A C terminus (lanes 3,6) in the presence of $\left[\gamma_{-}{ }^{32} \mathrm{P}\right]$ ATP. Products were separated by SDS-PAGE, stained with Coomassie, dried, and resulting labeled substrates were detected by autoradiography. B. Immunoblot for ATR shows immunoprecipitation of ATR with anti-ATR antibody (lane 3 ) but not with a control IgG immunoprecipitation (lane 2). C term: $\mathrm{C}$ terminus. 
Figure 3-7: ATR phosphorylates serine 1449 of FANCA in vitro

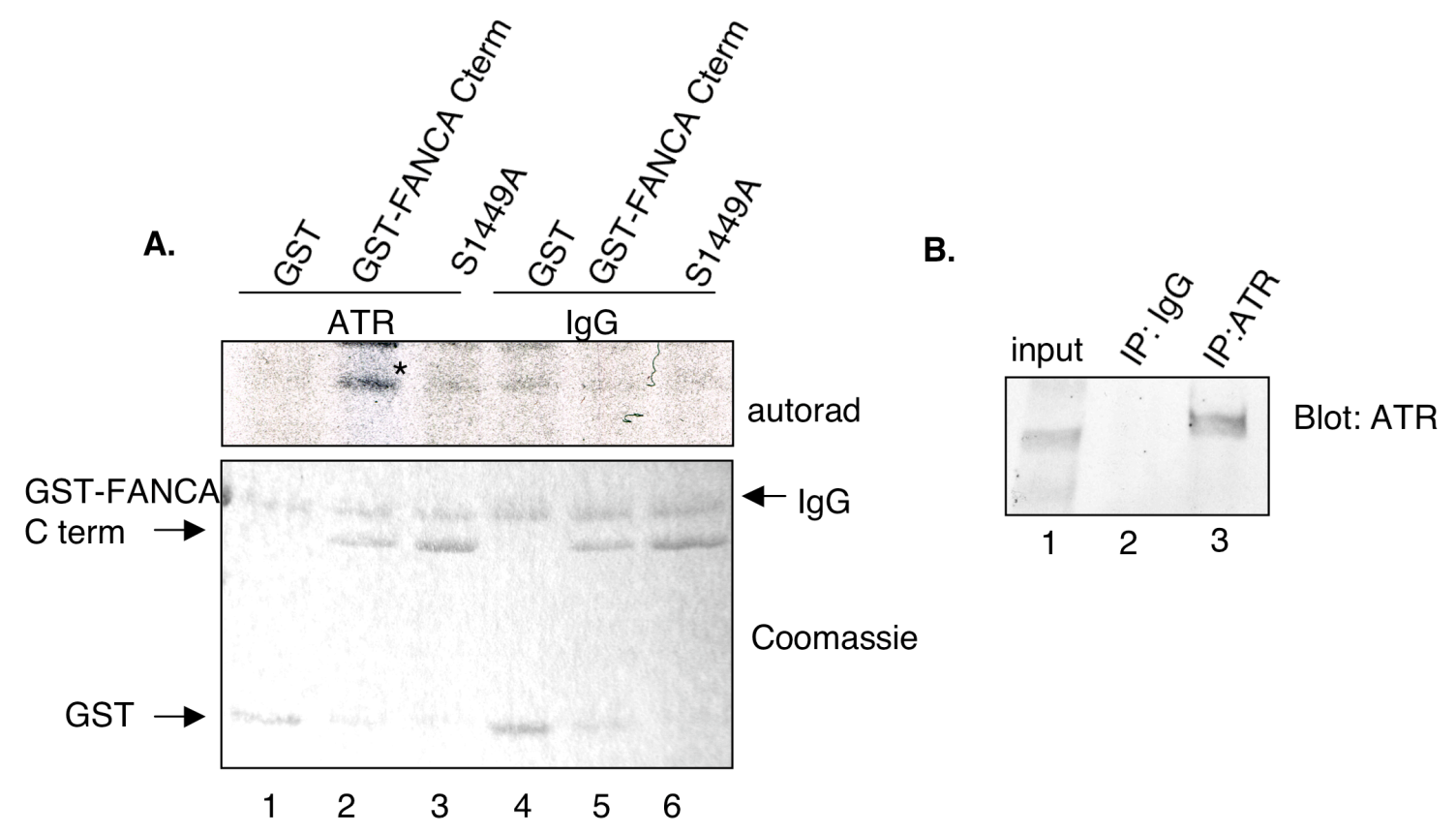


Figure 3-8: Chk1 inhibition does not block phospho-FANCA S1449.

HeLa cells were treated for 20 hours with $1 \mu \mathrm{M}$ MMC (lanes 2,3). At 16 hours $1 \mu \mathrm{M}$ SB218078 (Calbiochem) was added (lane 3). Whole cell lysates were separated by SDSPAGE and immunoblotted for phospho-FANCA S1449, total FANCA, and Ku86 as a loading control. 
Figure 3-8: Chk1 inhibition does not block phospho-FANCA S1449

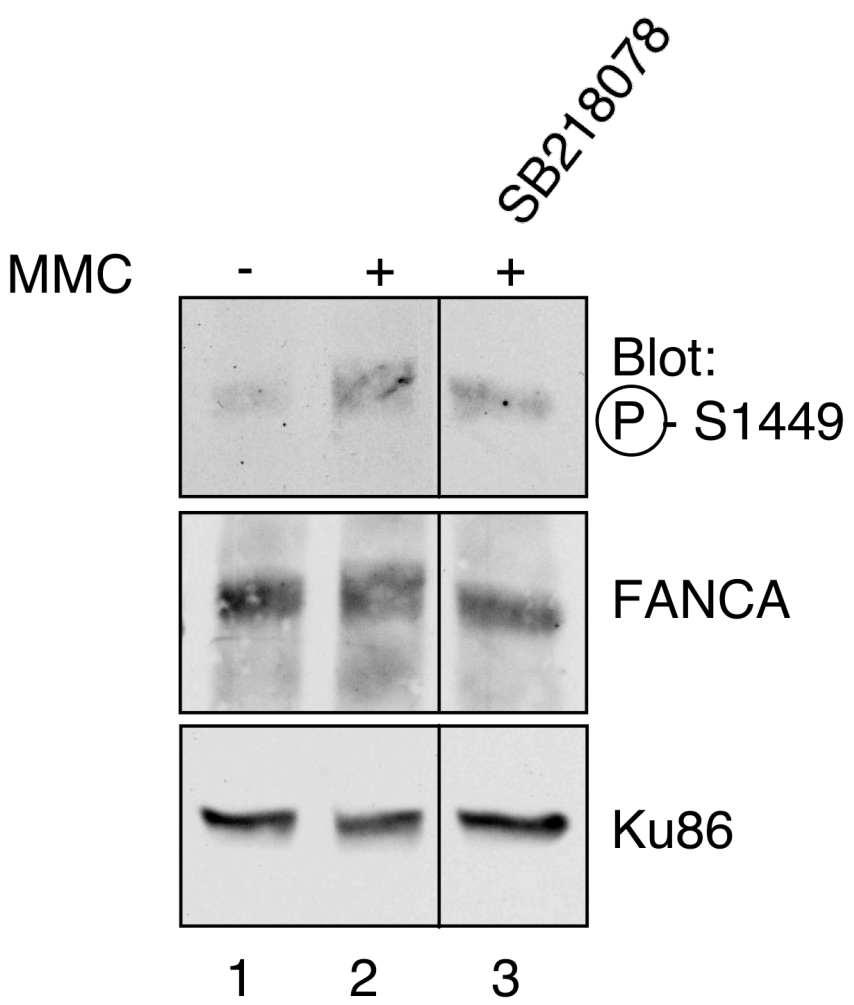




\title{
CHAPTER 4: Interaction of the FA pathway with RNA
}

\begin{abstract}
While insight has been gained into the proteins involved in FA, the lack of homologues in lower eukaryotes and the absence of conserved motifs in these proteins have cooperated to keep the function of the pathway unknown. Several lines of evidence, however, link the function of the FA pathway to RNA. First, phenotypes of FA patients are similar to other inherited disorders of RNA metabolism. Second, the FA pathway interacts with BRCA1, a protein that, in addition to its role in homologous recombination, is also known to modulate transcription. Third, aberrant RNA processing is known to cause genome instability, a hallmark of FA. Finally, FA has been shown to interact with PKR, a kinase activated in response to RNA.

Given these links to RNA, we hypothesize that the FA pathway and transcriptional machinery, including RNA Polymerase II, may cooperate to maintain genome stability. The aims of this study were to test whether a possible functional or physical interaction existed between the proteins of the FA pathway and the transcriptional machinery and, if so, to gain insight into a mechanism by which these two pathways could interact.

We show that FA proteins bind RNA in vitro and that RNAPII physically interacts with FANCD2. Inhibition of transcription blocks activation of the FA pathway and sensitizes cells to DNA damage. Finally, FA cells fail to target RNAPII for degradation via polyubiquitination after DNA damage. Together these preliminary data
\end{abstract}


are consistent with the notion that RNAPII and the FA pathway may functionally cooperate to maintain genome stability, a previously unknown function for FA. Further research is needed to establish and confirm the nature and significance of the relationship.

\section{Introduction}

While the exact function of the FA pathway remains unsolved, most hypotheses focus on a defect in DNA repair. Consequently, most research has been directed to elucidating a link between FA and DNA. RNA metabolism is a broad term to encompass all cellular activities that act on or are under the control of RNA. Traditionally, understanding of RNA metabolism was more or less limited to the central dogma of mRNA as a protein-encoding instrument; however, the complexity of RNA is being revealed as more is learned about noncoding RNAs with roles in the control of chromatin structure, gene expression, mRNA stability and translation, etc. (56). Clearly these pathways are complicated in their regulation and are of such significant importance that the cell would take measures to safeguard their integrity. That the FA pathway could, in some way, act on the complicated world of RNA, is an underrepresented idea for which there already exists some circumstantial evidence. First, FA bears striking similarity to other diseases that result from mutations in proteins involved in RNA metabolism. Second, BRCA1, linked clearly to FA, also interacts with RNA Polymerase II (RNAPII) and plays a role in transcription control. Third, aberrant RNA processing can, like FA, result in genome instability. Finally, though its importance has not been appreciated, some data exists in the literature linking FA to RNA.

RNA and human disease 
Proteins involved in RNA metabolism are not strangers to the world of inherited human disorders. In fact, a surprising number of these proteins are mutated in an array of genetic conditions with a broad variety of phenotypes. Table 4-1 summarizes some of these diseases, the genes containing the causative mutations, and the normal or abnormal functions of the proteins. Table 4-1 lists only diseases for which a mutation or mechanism of disease is identified. Recent studies correlating microRNA profiles with disease states, especially cancer, suggest RNA in a broad sense may play a much larger role than previously thought in a multitude of diseases and conditions $(18,70)$.

At first glance the disorders in Table 4-1 seem to represent a diverse, unrelated collection of diseases, but phenotypic similarities emerge between many of them. Even more striking are the phenotypic similarities to FA, a disease not traditionally associated with RNA metabolism. Many of these diseases may display impaired hematopoiesis as a primary phenotype. Most FA and Dyskeratosis Congenita (DC) patients will develop aplastic anemia; Diamond-Blackfan Anemia (DBA) patients develop erythroblastopenia; and Schwachman-Diamond Syndrome (SDS) patients primarily become neutropenic but may progress to aplastic anemia $(81,91,97,160)$. FA, DBA, DC, and SDS all share a predisposition to hematologic malignancy $(81,91,97,160)$. Furthermore, about $50 \%$ of DBA patients have congenital skeletal malformations, including those of the upper limb and hand, abnormalities similar to those found in FA $(81,91)$. A second group of disorders, Cockayne's Syndrome (CS) and Tricothiodystrophy (TTD) are disorders of proteins involved in nucleotide excision repair, specifically the branch associated with transcription coupled repair. These patients, among other phenotypes, have a constellation of congenital abnormalities similar to FA, but, notably, are without the 
strong cancer predisposition of FA and Xeroderma Pigmentosum, the classical disorder of nucleotide excision repair (83). Given the striking similarity of FA to these varied diseases involved with RNA, we hypothesize that proteins mutated in FA may also contribute, perhaps as one of multiple functions, to RNA metabolism.

$B R C A, F A$, and RNA

As previously introduced, FANCD2 relocalizes to foci containing BRCA1 after DNA damage and during S phase $(48,173)$. Further linking FA to the clinically significant problem of hereditary breast cancer was the discovery that BRCA2 was the protein mutated in the FA-D1 complementation group (58). Recently, the BRCA1 interacting helicase, BRIP1 (BACH1) was shown to be FANCJ, and the BRCA2 binding partner, PALB2, was identified as FANCN. $(86,87,92,146,195)$. From these studies it became clear that the FA pathway and the pathway for prevention of hereditary breast cancer overlap significantly, and this overlap was thought to be due to the role of both in homologous recombination. BRCA1 and BRCA2 deficient cells are hypersensitive to DNA damage and display chromosomal instability similar to that found in other disorders of DNA repair such as FA $(58,117,159)$. Furthermore, BRCA1 interacts physically and functionally with Rad51, further implicating it in recombination and genome stability (155).

Apart from its role in recombination, however, BRCA1 has diverse other functions in RNA metabolism. First, the $\mathrm{C}$ terminus of BRCA1 can serve as a transcriptional coactivator, and mutations in this region that abolish transactivator function are associated with breast cancer $(55,115)$. In its role as a transactivator, 
BRCA1 interacts with known transcription factors such as p53 (206). Second, BRCA1 can be purified with active RNAPII (154). This interaction may be necessary for BRCA1's role in transcription. Alternatively, RNAPII is polyubiquitinated and targeted for degradation following DNA damage. BRCA1, in combination with a binding partner, BARD1, has E3 ubiquitin ligase activity that may be responsible for the polyubiquitination of RNAPII $(167,194)$. Finally, BRCA1 is necessary for human female $\mathrm{X}$ inactivation, a process mediated in humans by Xist RNA (46). That BRCA1 is required for this RNA-mediated chromatin structure further suggests its ability to interact with and regulate processes involving RNA. Interaction of the FA pathway with BRCA1 suggests the FA pathway may also be involved in RNA-mediated processes.

\section{RNA and genome stability}

A DNA lesion will block DNA polymerase during replication. Less commonly considered, a DNA lesion will also block a transcribing RNA polymerase, leading to polymerase stalling $(14,158)$. Lesions in sites of active transcription are preferentially removed from the transcribed strand through a process known as transcription-coupled repair $(12,110)$. Patients with Cockayne's Syndrome, previously mentioned as a disease with phenotypic similarity to FA, are defective in transcription-coupled repair (83). In most cases the lesion is removed, and transcription can resume. However, in cases where the lesion is not removed, nascent RNA transcripts and/or stalled RNA polymerases contribute to genome instability. As evidence of this, transcriptionally active genes are more prone to recombination than nontranscribed regions of the genome $(122,177)$. The 
mechanism by which this occurs is largely not understood, but evidence exists implicating cotranscriptionally formed RNA:DNA hybrids called R loops $(60,88)$.

R loops form when an RNA strand pairs with the complementary DNA strand of the DNA duplex, leaving the other strand single stranded (205). R loops form in situations where transcription or mRNA processing are impaired and result in genome instability. In bacteria, mutants of topoisomerase I in which supercoiling persists at the transcription bubble form R loops and have a significant growth defect (35). Similarly, yeast mutants in the THO/TREX complex, a complex that functions in mRNA processing and export, form R loops and display a hyperrecombination phenotype (60). In humans, evolution has taken advantage of this tendency toward recombination to introduce diversity in the process of class switch recombination (CSR) at the immunoglobulin locus (204). R loop formation is thought to create a region of single stranded DNA in the strand opposite the one involved in the $\mathrm{R}$ loop that can serve as a substrate for activation induced deaminase (AID), the enzyme responsible for generating genetic diversity in CSR (204). Finally, similar to the situation in yeast, R loops form in animals when mRNA processing is impaired. In chicken DT40 cells, disruption of the ASF/SF2 splicing factor led to R loop formation and subsequent genome instability as measured by the appearance of double strand breaks and high molecular weight DNA fragments (88). Overexpression of RNAseH1, the enzyme responsible for degrading DNA:RNA hybrids, in these cells suppressed genomic instability. Triplex structures are also found at the telomere, where single stranded DNA folds into a t-loop, and telomeres are frequent sites of rearrangement (28). Given that FA has a major phenotype of genome instability, coupled with the linking of FA to RNA metabolism, we propose a model in which FA 
proteins may be involved in prevention of formation or resolution of $\mathrm{R}$ loops at sites of DNA damage.

\section{FA and $P K R$}

A small and underappreciated body of literature exists linking the FA pathway to RNA through an interaction with the RNA-dependent protein kinase (PKR). Hematopoietic cells from FA patients are hypersensitive to interferon- $\gamma($ IFN- $\gamma)$, resulting in increased apoptosis (144). In an attempt to describe the mechanism of this hypersensitivity, PKR, an IFN- $\gamma$ inducible kinase was discovered to be constitutively activated in cells lacking FANCC (134). A dominant negative PKR reversed the hypersensitivity to IFN- $\gamma$ and the increased apoptosis, suggesting that inappropriate PKR activation may be the cause of bone marrow failure in patients (134). Further work showed that FANCC and PKR interacted in a complex, and that this complex failed to form in FA mutant cells from a variety of complementation groups (207). PKR, in addition to being activated by IFN- $\gamma$, is activated by double stranded RNA (dsRNA) and blocks translation as part of the cellular response to invading viral genomes (192). It follows then, that in addition to being hypersensitive to IFN- $\gamma$, FA mutant cells are also hypersensitive to dsRNA (134). It has been a challenge in the field to relate this line of research to the accumulating body of evidence implicating FA in DNA repair. It remains a formal and untested possibility that the "primed" state of PKR in FA cells may actually result from abnormal RNA structures accumulating in the cell as a result of a failed repair attempt, and this is consistent with our model. 
Given the links between RNA metabolism and the FA pathway, we sought to establish a functional and/or physical connection between the FA pathway and RNAPII and identify a possible mechanism by which RNA, RNAPII, and the FA pathway cooperate to protect the genome. 
Table 4-1: RNA-related human diseases.

\begin{tabular}{|l|l|l|}
\hline Disease & Causative mutation & Function \\
\hline \hline Fragile X Syndrome & FMR1 & RNA binding protein \\
\hline Tricothiodystrophy & TFIIH & Transcription factor \\
\hline Diamond-Blackfan Anemia & RPS19, RPS24 & Ribosomal subunits \\
\hline Cockayne's Syndrome & $\begin{array}{l}\text { CSA(ERCC8), } \\
\text { CSB(ERCC6) }\end{array}$ & Transcription coupled repair \\
\hline Dyskeratosis Congenita & TERT, TERC RNA & Telomerase, telomere RNA template \\
\hline Myotonic Dystrophy & DM1 & Triplet expansion, Toxic RNA \\
\hline Schwachman-Diamond Syndrome & SBDS & Unknown, RNA metabolism \\
\hline Xeroderma Pigmentosum & $\begin{array}{l}\text { XPA-G,V. XPB,D are } \\
\text { members of TFIIH }\end{array}$ & Nucleotide Excision Repair \\
\hline
\end{tabular}

$(41,49,83,91,95,97,160,176)$ 


\section{Materials and Methods}

Cell Culture-Cells were maintained at $37^{\circ}$ in a $5 \% \mathrm{CO}_{2}$ incubator. HeLa cells were cultured in Dulbecco's modified Eagle's medium (DMEM) supplemented with 10\% fetal bovine serum (FBS). GM 6914 FA-A mutant cells and PD20 FA-D2 mutant cells were grown in DMEM plus 15\% FBS. PD20, PD20 + Flag-FANCD2, and PD20 + HAFANCD2 K561R were provided by Dr. Alan D'Andrea.

In vitro RNA binding - Cells were lysed in lysis buffer containing $150 \mathrm{mM} \mathrm{NaCl}, 50 \mathrm{mM}$ Tris, $\mathrm{pH} 7.5,1 \%$ Triton $\mathrm{X}-100,1 \mathrm{mM} \mathrm{MgCl} 2$, and protease and phosphatase inhibitors ( $2 \mu \mathrm{g} / \mathrm{ml}$ Aprotinin, $1 \mu \mathrm{g} / \mathrm{ml}$ Pepstatin, $2 \mu \mathrm{g} / \mathrm{ml}$ Leupeptin, $1 \mathrm{mM}$ PMSF, $1 \mathrm{mM}$ Sodium Pyrophosphate, and $\left.1 \mathrm{mM} \mathrm{Na}_{3} \mathrm{VO}_{4}\right)$. Lysates were sonicated briefly and cleared by centrifugation, and concentration was determined by Bradford assay. To an equal amount of protein was added homoribopolymers bound to an immobilized support, polyA, C, G, or $\mathrm{U}$ (Sigma). Proteins were incubated with beads at $4^{\circ} \mathrm{C}$ for 2 hours, washed three times in lysis buffer, and dried. SDS loading buffer was added to the dried beads.

SDS-PAGE and Immunoblotting - SDS-PAGE was followed by transfer onto nitrocellulose in transfer buffer containing $25 \mathrm{mM}$ Tris, $200 \mathrm{mM}$ glycine, and $20 \%$ methanol. Membranes were blocked in TBS $+5 \%$ BSA for 1 hour. Primary antibodies were diluted in TBS $+0.1 \%$ Tween 20 (TBST) and incubated with the membrane 3 hours to overnight. Membranes were washed four times in TBST, then horseradish-peroxidase linked secondary antibodies (GE Healthcare) were added in TBST for 1 hour. After a 
second wash, proteins were visualized by chemiluminescence. Antibodies used were specific for FANCD2-N terminal (1:1000) (140) and RNAPII (1:1000) (N-20, Santa Cruz).

Cytotoxicity Assay - Cytotoxicity assays utilized crystal violet staining and were either short or long term. Briefly, cells were plated in 24 or 6 well dishes. For long term assays, MMC was added at increasing concentrations with an inhibitor of RNAPII for 3-6 days. For short term assays, cells were pretreated with inhibitor for 2 hours, MMC was added at increasing concentrations for 6 hours, washed 2 times in PBS, and incubated a subsequent 24 hours. At the conclusion of the experiment, cells were washed with PBS, fixed in $10 \% \mathrm{MeOH}$ and $10 \%$ acetic acid for 5 minutes, and stained with $1 \%$ crystal violet in $\mathrm{MeOH}$ for 3 minutes. Excess crystal violet was then washed off with water. Crystal violet was extracted from stained cells with $\mathrm{MeOH}+0.1 \%$ SDS for 20 minutes to 1 hour. Crystal violet concentration in the extractions was then measured at OD595, and cell survival was calculated as a fraction of the MMC-untreated control.

Cell Lysis and Chromatography - Whole cell lysates were prepared in lysis buffer containing $150 \mathrm{mM} \mathrm{NaCl}, 50 \mathrm{mM}$ Tris, $\mathrm{pH} 7.5,1 \%$ Triton $\mathrm{X}-100$, and protease and phosphatase inhibitors $(2 \mu \mathrm{g} / \mathrm{ml}$ Aprotinin, $1 \mu \mathrm{g} / \mathrm{ml}$ Pepstatin, $2 \mu \mathrm{g} / \mathrm{ml}$ Leupeptin, $1 \mathrm{mM}$ PMSF, $1 \mathrm{mM}$ Sodium Pyrophosphate, and $\left.1 \mathrm{mM} \mathrm{Na}_{3} \mathrm{VO}_{4}\right)$. Whole cell extracts were cleared by centrifugation at $14000 \mathrm{rpm}$ for 15 minutes, and protein concentration was determined by the Bradford assay. Where indicated, whole cell lysates were passed over a Nickel-NTA agarose column (Qiagen) equilibrated to lysis buffer, and the flow-through 
was collected. The column was washed in lysis buffer, and proteins were eluted from the column in lysis buffer containing $300 \mathrm{mM}$ imidazole.

Immunoprecipitation - To the indicated protein sample was added $20 \mu \mathrm{l}$ of a $50 \%$ slurry of anti-Flag M2 agarose (Sigma) washed in lysis buffer. Proteins were incubated with immunoaffinity agarose for 2 hours to overnight, then washed 3 times in lysis buffer. Beads were dried and to them was added SDS loading buffer.

Transfection and purification of ubiquitinated proteins - pCS2 vector and pCS2-Flag-His Ubiquitin (gifts of Dr. David Wotton) were transfected into GM6914 cells expressing His-FANCA or the vector control using Fugene 6 (Roche) according to manufacturer's instructions. 24 hours after transfection, cells were treated \pm MMC for 16 hours. MG132 was subsequently added at $5 \mu \mathrm{M}$ for 4 hours. Cells were lysed and anti-Flag immunoprecipitation performed as described above.

\section{Results}

\section{FA proteins bind RNA in vitro}

We wished to investigate whether FA proteins could bind RNA. Lacking any clues as to possible sequence or structure specificity, we took the approach of investigating binding to generic RNA substrates as chains of specific ribonucleotides bound to immobilized beads. Whole cell lysates were incubated with the indicated ribohomopolymer bound to beads, and bound proteins were separated by SDS-PAGE and immunoblotted for FANCD2. The top panel of Figure 4-1A shows binding of proteins 
from undamaged cells, and the bottom panel of Figure 4-1A shows binding after DNA damage with MMC. FANCD2 bound preferentially to poly-guanine (polyG) but also to poly-cytosine (polyC) (Figure 4-1A, lanes 5,6). Though Figure 4-1A shows apparently weak binding, longer exposure confirmed specificity. Binding was present both before and after MMC treatment, but the predominant form of FANCD2 seen was the short, or nonubiquitinated form (Figure 4-1A). We then wished to investigate whether a mutant of FANCD2 that is defective for monoubiquitination (FANCD2 K561R) was still able to bind RNA. FANCD2 K561R showed a similar pattern to wild-type FANCD2, binding predominantly polyG but also polyC before and after DNA damage (Figure 4-1A, lanes 9,10). Because Figure 4-1A shows results from two independent gels, in order to directly compare RNA binding before and after MMC, the same experiment was performed, but only with polyG, and bound proteins were separated on the same gel. Results are shown in Figure 4-1B. Binding of both FANCD2 and FANCD2 K561R to polyG was diminished after MMC treatment (Figure 4-1B, lane 4), and the short form was predominant (Figure 4-1B, lane 4, top panel). The long form could be detected bound to polyG after MMC treatment, but the relative abundance bound to polyG was less than the relative abundance in the input after MMC (Figure 4-1B, lane 2, top panel). Taken together, we conclude FANCD2 binds polyG and polyC RNA in vitro. The RNA binding decreases after DNA damage and is primarily a property of the short (nonubiquitinated) form of FANCD2.

RNAPII inhibition prevents FANCD2 monoubiquitination. 
If RNA is involved in the FA pathway, we hypothesized that removing the RNA transcript would result in failure to activate the pathway, as monitored by the monoubiquitination of FANCD2 after DNA damage (48). We took the approach of removing the RNA by inhibiting the action of RNAPII. $\alpha$-amanitin is a specific inhibitor of RNAPII that blocks the polymerase at the translocation step of RNA synthesis (52). DRB (5,6-dichloro-1-beta-D-ribofuranosylbenzimidazole) is an inhibitor of RNAPII acting by a different mechanism, the inhibition of kinase activity essential for transition from the initiating to the elongating polymerase $(98,157)$. HeLa cells treated with MMC in the presence of either RNAPII inhibitor showed a complete or partial inability to monoubiquitinate FANCD2 after MMC treatment (Figure 4-2A, lane 4 and Figure 4-2C, lane 4). One possible explanation for the loss of FANCD2 monoubiquitination is the absence of new synthesis of proteins that may be required for monoubiquitination following transcription inhibition. To address this possibility, cells were treated with cycloheximide or puromycin, both translation inhibitors. Translation-inhibited cells showed constitutive FANCD2 monoubiquitination (Figure 4-2B, lanes 3,4,7-10) irrespective of MMC treatment. Thus, new protein synthesis is not required for FANCD2 monoubiquitination and does not account for the loss of FANCD2 monoubiquitination after transcription inhibition. Constitutive FANCD2 monoubiquitination after cycloheximide treatment could be explained by loss of synthesis of the deubiquitinase, USP1 (124).

Mammalian cells contain two forms of RNAPII, designated IIO and IIA, both of which are apparent on immunoblot for the large subunit of RNAPII (Figure 4-2D). IIA is the hypophosphorylated form associated with transcription initiation, and IIO is the 
hyperphosphorylated, elongating polymerase (136). Both $\alpha$-amanitin and DRB treatment result in loss of the IIO active form (Figure 4-2D, lanes 3-6), confirming the inhibition of transcription. After cycloheximide treatment both forms are retained, though in lesser amounts (Figure 4-2D, lanes 7-8).

RNAPII inhibition sensitizes wild type cells to MMC.

Since inhibition of transcription prevents FANCD2 monoubiquitination, and FANCD2 monoubiquitination is required for the normal response to $\mathrm{MMC}$, we wished to see if RNAPII inhibition sensitized cells to DNA damage induced by MMC (48). HeLa cells were pretreated with RNAPII inhibitors DRB or $\alpha$-amanitin, cycloheximide, or DMSO as a control, and then treated with increasing concentrations of MMC. Transcription-inhibited cells, but not translation-inhibited cells, were hypersensitive to MMC treatment in cell survival assays (Figure 4-3A,B), indicating active transcription is required for a normal response to $\mathrm{MMC}$.

RNAPII inhibition does not increase the sensitivity of FA cells to MMC

An important prediction of the hypothesis is that if RNAPII inhibitors are acting to sensitize cells to MMC by interfering with the normal DNA crosslink response, then RNAPII and the FA pathway should be epistatic, and FA cells, which are already defective in this pathway, should be no more sensitive to MMC after RNAPII inhibition. GM6914 (FA-A) cells corrected with wild-type FANCA or the vector control were both treated with DRB and analyzed for sensitivity to MMC. Sensitivity of corrected cells to MMC was slightly increased after DRB treatment, whereas sensitivity of FA mutant cells 
to MMC was identical both before and after DRB treatment (Figure 4-3C), suggesting that RNAPII and the FA pathway are epistatic in the phenotype of MMC sensitivity.

RNAPII cofractionates and coprecipitates with FANCD2.

Having suggested a functional relationship between RNAPII and the FA pathway through the use of pharmacological inhibitors of RNAPII, we sought to determine if a physical interaction existed between members of the FA pathway and RNAPII. Knowing that pharmacological inhibitors have multiple and potentially toxic effects, a physical interaction would be important evidence in support of the observations in the presence of inhibitors. Unpublished work in our lab using chromatography to purify complexes containing FANCD2 has shown that FANCD2 exists in at least three distinct complexes. The smallest complex contains mostly FANCD2, thought to be in a tetrameric form. The other two complexes, based on size, contain unidentified binding partners. The function or significance of these complexes is unknown. One of these, A 1.5 MD FANCD2containing complex is isolated in the flow through of a nickel chromatography column. FANCD2-containing complexes were purified from whole cell extracts of PD20 cells (FA-D2) and PD20 corrected with Flag-FANCD2 using nickel chromatography. The nickel flow through (Figure 4-4, lanes 5-8) as well as an elution in 300mM imidazole (Figure 4-4, lanes 9-12) were collected and further purified by anti-Flag immunoprecipitation. The majority of FANCD2 in both the long (ubiquitinated) and short (non-ubiquitinated) forms was found in the immunoprecipitates prepared from the nickel column eluate (Figure 4-4, lanes 11-12). Only non-ubiquitinated FANCD2 was found in the immunoprecipitates from the nickel flow through (Figure 4-4, lanes 7-8). 
While the IIA (hypophosphorylated, inactive) form of RNAPII bound anti-Flag agarose nonspecifically, the II0 (phosphorylated, active) form of RNAPII specifically bound the short form of FANCD2 in the nickel flow through (Figure 4-4, lanes 7-8). This suggests a physical association exists between non-ubiquitinated FANCD2 and the hyperphosphorylated, II0 form of RNAPII. MMC treatment did not alter this association (Figure 4-4, lane 8).

RNAPII is not polyubiquitinated in FA cells.

RNAPII is polyubiquitinated on its largest subunit, Rpb1, after DNA damage and targeted for degradation via the proteasome (145). The E3 ubiquitin ligase responsible for this polyubiquitination is unknown, but both the von Hippel Lindau tumor suppressor protein (pVHL) - associated complex and the BRCA1/BARD1 heterodimer have been implicated $(69,82,167)$. Importantly, cells from patients with Cockayne syndrome are deficient in the ability to polyubiquitinate RNAPII after UV damage (13). After DNA damage with hydrogen peroxide, however, RNAPII is polyubiquitinated in a way that is not dependent on the Cockayne syndrome proteins (65). Taken together, these data imply that polyubiquitination of RNAPII is a common response to DNA damage and can be mediated by multiple pathways. Given phenotypic overlap of FA with Cockayne's syndrome and the relationship of FA to BRCA1, a potential E3 ubiquitin ligase for RNAPII, we sought to determine if RNAPII was polyubiquitinated following MMC treatment in FA cells.

GM6914 (FA-A) cells, chosen for established transfectability, and the same cells corrected with a 6X His-tagged FANCA cDNA, GM6914 + pMMP His FANCA, were 
transfected with an empty vector, pCS2, or the same vector expressing a Flag and 6XHis-tagged ubiquitin, pCS2 FlagHisUb. Transfected cells were treated with MMC to induce RNAPII ubiquitination and with the proteosome inhibitor, MG132, to prevent ubiquitinated forms from being degraded. Cells were lysed and anti-Flag immunoprecipitation was used to collect all ubiquitinated proteins. Following SDSPAGE, an immunoblot for RNAPII large subunit showed that RNAPII was only detected in corrected cells (Figure 4-5) and not in FA-A mutant cells. Detection of ubiquitinated RNAPII was weak, as indicated in Figure 4-5, but reproducibly present. This indicates that RNAPII was either itself directly ubiquitinated only in corrected cells or coprecipitated with a protein that was specifically ubiquitinated in corrected cells.

\section{Discussion}

The significance of the described experiments lies in the suggestion of a new pathway for DNA repair, in which the FA proteins participate and RNA is a key mediator. While still at the hypothesis stage, presented here are data in support of this model. First, FA proteins bind RNA in vitro, a biochemical function previously not described, though it remains unknown if this is a direct or indirect property of FANCD2. Furthermore, inhibition of RNAPII through the use of pharmacological inhibitors of RNAPII blocks activation of the FA pathway, as monitored by monoubiquitination of FANCD2, and sensitizes cells to crosslinking damage by MMC. How this occurs is unknown. The FA pathway may rely on the RNA synthesis activity of RNAPII, as would be the case if a certain RNA product of RNAPII was responsible for FA pathway activation in response to DNA damage. Alternatively, activation of the FA pathway may 
rely on a property of the enzyme itself, such as polyubiquitination after DNA damage, as was suggested here by Figure 4-5, showing that FA mutant cells fail to polyubiquitinate RNAPII.

This is the lingering question, whether RNA is itself important, or whether the interaction with RNAPII is the important interaction. Figure 4-1 shows FANCD2 can bind RNA homopolymers in vitro. Similarly, FANCA behaves similarly, binding polyG specifically (data not shown). This experiment has several limitations. First, we can not conclude if this is a direct association or indirect association via other binding partners, for example RNAPII. To answer the question as to whether or not RNA is important, two main approaches can be taken. In a positive approach, one could look for RNA bound to members of the FA pathway. In the opposite approach, treatment with RNAse would remove any RNA, and the FA pathway could be monitored for loss of activity or loss of relevant interactions. Many of these experiments have been attempted with inconclusive results.

A major complication of showing RNA bound to the FA complex is lack of the knowledge of what would be the RNA target. If the hypothesis is that RNA assists in the repair of DNA damage, then one would not necessarily expect any sequence or structure specificity of the RNA. In one experiment I performed (data not shown), radioactively labeled total RNA isolated from HeLa cells was incubated with anti-Flag immunoprecipitations from cells expressing Flag-FANCA. Increased RNA binding was seen on the core complex in comparison to a negative immunoprecipitation. This was inconclusive, however, as RNA may have been nonspecifically binding to protein, just by virtue of the fact that protein was immunoprecipitated. To further control this 
experiment, I would need a similarly tagged irrelevant complex that did not bind RNA, and this control was not performed. Electrophoretic mobility shift assays (EMSAs) were performed with a variety of RNA substrates; mRNA, tRNA, 5s RNA, and U1 RNA, as well as DNA. Results were negative, but, again, we felt this was inconclusive because we lack knowledge of what the appropriate substrate would be.

Since DNA crosslinkers form crosslinks with some sequence specificity, it remains possible that the FA complex may bind RNA with sequence specificity. Newer methods are available for cloning RNA found in protein complexes, among them crosslinking immunoprecipitation (CLIP) (183). RNA is crosslinked to proteins using UV light, then bound RNAs are immunoprecipitated bound to protein. Proteins are separated by SDS-PAGE, then RNAs are released and cloned using linker ligation. Multiple attempts were made to crosslink RNA to FA core complex, and results were inconclusive due to technical reasons. PCR amplification of RNA products was very sensitive, such that background binding (in a negative immunoprecipitation) could not be distinguished from specific binding. This fact, coupled with our assumption that the core complex may not bind with any sequence specificity, led us to discontinue these experiments.

Multiple attempts were also made to use RNAse to determine if RNA was a key element in the FA pathway. Members of the core complex, at least FANCA and FANCG, remain bound to one another after RNAse treatment of immunoprecipitated complex. FANCD2 remains ubiquitinated in MMC-treated extracts to which RNAse was added. The lack of any observable effect, may, however, be due to protection of the RNA from RNAse degradation by the bound protein. Interestingly, RNAse treatment of 
permeabilized cells prior to fixation for FANCD2 immunofluorescence did lead to reproducible changes in FANCD2 localization. These changes were, however, difficult to characterize and interpret, and a control RNA binding protein was needed to show the RNAse treatment was effective. Further experimentation in this area would be worthwhile to characterize the nature of the localization pattern changes after RNAse.

The inhibition of FANCD2 ubiquitination with $\alpha$-amanitin and DRB treatment is supportive of the involvement of the FA pathway in transcription. Because $\alpha$-amanitin and DRB behave similarly in this system, and because $\alpha$-amanitin primarily targets RNAPII, we have interpreted these data to indicate that RNAPII is the relevant RNA polymerase. RNA Polymerase III is, however, also inhibited by $\alpha$-amanitin, though it is much less sensitive. While we have attempted to keep $\alpha$-amanitin dosing within a range that is specific for RNAPII, and we show RNAPII is inhibited in Figure 4-2D, we cannot exclude effects of RNA Polymerase III from the loss of FANCD2 monoubiquitination. Furthermore, as FANCD2 is monoubiquitinated during S phase or after DNA damage, presumably when that damage is encountered in S phase, we wondered if lack of FANCD2 ubiquitination was due to cell cycle arrest and prevention of cells from entering S phase. We analyzed the cell cycle profile of cells treated with $\alpha$-amanitin and found no significant alteration in cell cycle, indicating cell cycle arrest was not responsible for loss of FANCD2 monoubiquitination (data not shown). Taken together, loss of FANCD2 ubiquitination (Figure 4-2) and sensitization to DNA damaging agents (Figure 4-3) caused by both $\alpha$-amanitin and DRB is evidence linking the FA pathway to transcription by RNAPII. 
The observation that translation inhibition by cycloheximide or puromycin does not inhibit FANCD2 monoubiquitination, but rather FANCD2 is constitutively monoubiquitinated, is not only crucial to supporting our hypothesis but also may suggest additional mechanisms within the pathway. FANCD2 is deubiquitinated by USP1 (124). USP1 expression is cell cycle regulated both at the mRNA level and by degradation via the proteosome. Cycloheximide may, therefore, result in increased ubiquitinated FANCD2 by inhibiting new synthesis of the deubiquitinase. This possibility could be formally tested by analyzing USP1 levels before and after CHX treatment. Alternatively, cycloheximide treatment results in the accumulation of untranslated mRNAs, and these mRNAs themselves could cause FANCD2 monoubiquitination.

Monoubiquitinated FANCD2 is thought to be the active form of FANCD2, primarily due to the fact that this modification is defective in FA core complex mutants. Interestingly, however, we show in Figures 4-1 and 4-4 that the short form of FANCD2 both binds RNA and physically interacts with FANCD2. A mechanism to account for this observation would be that FANCD2 under normal, non-damaged conditions binds RNA or RNAPII in a genome-monitoring role. Upon encountering damage in the context of this relationship to RNAPII, FANCD2 could be released and monoubiquitinated in a manner dependent on the core complex. This mechanism is consistent with Figure 4-2, where inhibition of transcription blocks monoubiquitination of FANCD2. If FANCD2 is unable to form the initial complex with RNAPII, damage would not be detected, and FANCD2 would not become monoubiquitinated.

Also of interest is the apparent preference of FANCD2 to bind polyguanine RNA over other polynucleotides. As discussed previously, this may not be a direct interaction, 
but may be mediated through other proteins. Regardless, what is at the root of this specificity is unknown, but polyG $D N A$ tracts form specific secondary structures known as $\mathrm{G}$ quartets (96). G quartets are physiologically relevant, as they are found at the class switch recombination locus in B cells, at telomeres, and cotranscriptionally at G-rich DNA (96). G quartets have some intriguing links to FA. First, DNA crosslinkers such as MMC and cisplatin preferentially form crosslinks at GG sequences, so the FA pathway may be acting at these sequences. Second, transcription of G-rich DNA results in opening of the $\mathrm{G}$ rich strand from the $\mathrm{C}$ rich (coding) strand. At this site what is known as a G loop forms, consisting of an RNA-DNA hybrid on the coding, C-rich strand, and G quartets on the other, unpaired strand (38). The G loop is essentially a similar structure to the R loop previously discussed as a source of genomic instability $(88,204)$. Furthermore, C. elegans mutated in the $d o g-1$ gene display genomic instability, specifically a disposition toward deletion of $\mathrm{G}$ rich regions (21). The closest homologue to $d o g-1$ in humans is $B R I P 1$, or FANCJ, indicating the FA pathway may have a similar role in maintaining $\mathrm{G}$ rich regions of the genome.

Finally, we have shown that FA cells fail to ubiquitinate RNAPII in response to DNA damage. Whether the FA proteins participate directly in polyubiquitination or if this defect is simply downstream of a separate defect of the FA pathway is unknown. The purpose of polyubiquitination on RNAPII is to remove and degrade stalled polymerases via the proteasome and to downregulate transcription in the context of DNA damage. Polyubiquitination is restricted to the II0 (active) form of RNAPII, the form that binds FANCD2 (Figure 4-4) (166). The observation that FA cells fail to polyubiquitinate RNAPII after DNA damage leads to the prediction that FA cells may not properly 
downregulate transcription after DNA damage, possibly leading to the transcription of damaged genes. Studies are underway to investigate relative levels of transcription after DNA damage, with the hypothesis that transcription will remain on in FA mutant cells treated with MMC.

As stated previously, a working hypothesis is that $\mathrm{R}$ loops contribute to genome instability seen in FA cells and that the intact FA pathway is involved in preventing these structures from forming or promoting their resolution. Because one side of an R loop is an RNA:DNA hybrid, RNAseH1 may be involved in the resolution of R loops. Previous work has shown that RNAseH overexpression can correct the R looping phenotype caused by mutation of DNA topoisomerase 1 in $E$. coli and by loss of ASF/SF2 splicing factors in chicken DT40 cells $(59,88)$. It is also likely that endogenous RNAseH1 has a role in resolving R loops. In E. coli, R loops can be formed in the context of transcription-induced negative supercoiling (99). An RNAseH mutant can be partially complemented by overexpression of DNA gyrase, suggesting a role for RNAseH in removing $\mathrm{R}$ loops formed as a result of supercoiling (35). Based on these studies, we wish to see if overexpression of RNAseH1 can suppress an FA defect or if loss of RNAseH1 sensitizes wild type cells to DNA crosslinking agents. Preliminary data (not shown) confirms that loss of RNAseH1 sensitizes cells to MMC, but these studies have been complicated by the difficulty of detecting endogenous RNAseH1 and overexpressing active enzyme. More studies are needed to further investigate this mechanism.

Given the localization to chromatin of both the core complex and FANCD2, combined with the data shown here linking FA to the transcription machinery, the FA 
proteins may either act upon or are influenced by chromatin structure in the context of transcription. A role for histone modifications in the modulation of transcription is well established. Generally, histone acetylation favors gene expression, while methylation is associated with gene silencing. Studies are underway to determine if cells from FA patients are deficient in placement of various histone modifications at sites of transcription. Specifically, acetylation of lysine 56 on histone 3 (H3K56) is a recently discovered modification in yeast, and the lysine residue is conserved in humans. Acetyl-H3K56 placement correlates with actively transcribed genes, and it is localized to transcriptionally active puff sites on polytene chromosomes in Drosophila (153). In addition, mutation of this residue in yeast is associated with an increased sensitivity to agents that cause DNA double strand breaks, but, similar to FA, there is no increased sensitivity to damage from UV light or ionizing radiation (100). We hypothesize FA cells may be defective in this (or other) transcription-associated chromatin modifications.

A possible model to integrate these data must incorporate FA proteins and what was previously known about FA biochemistry. The proposed mechanism must also function in interstrand DNA crosslink repair, as FA patients are hypersensitive to DNA crosslinking agents and not to other DNA damaging agents. Taking into account these points and data presented here, models are proposed in Figure 4-6, and steps at which FA proteins may act are represented. Briefly, RNAPII becomes stalled in response to a DNA crosslink. An R loop may form at the site of the stalled polymerase. FA proteins may act in the prevention of R loop formation. After the polymerase stalls and/or the R loop forms, RNAPII becomes polyubiquitinated and targeted for degradation. The FA proteins may be involved directly in polyubiquitination or in an upstream event required 
for polyubiquitination. Failure to remove a stalled RNAPII may block the cells ability to repair the lesion and result in damage. Finally, the FA proteins may act in the resolution or repair of a stalled RNA polymerase and/or R loop. Failure of the FA pathway at any of these steps could result in the lesion being processed to a strand break and cause the genome instability seen in FA.

\section{Acknowledgements}

We kindly thank Dr. David Wotton for Flag-His ubiquitin constructs and Dr. Alan D’Andrea for providing PD20 cell lines. 
Figures

Figure 4-1: FA proteins bind RNA in vitro.

A. Whole cell lysates from PD20 cells expressing Flag-FANCD2, FANCD2 K561R or the vector control were left untreated or treated with 500nM MMC, incubated with the indicated polyN RNA attached to beads, and then washed. Bound proteins were separated by SDS-PAGE and immunoblotted for FANCD2. B. The same procedure as in (A) except MMC treated and untreated experiments were analyzed on the same gel. A: adenine, C: cytosine, G: guanine, U: uracil, FANCD2-L: long form (monoubiquitinated) of FANCD2, FANCD2-S: short form (nonubiquitinated). 
Figure 4-1: FA proteins bind RNA in vitro

A.

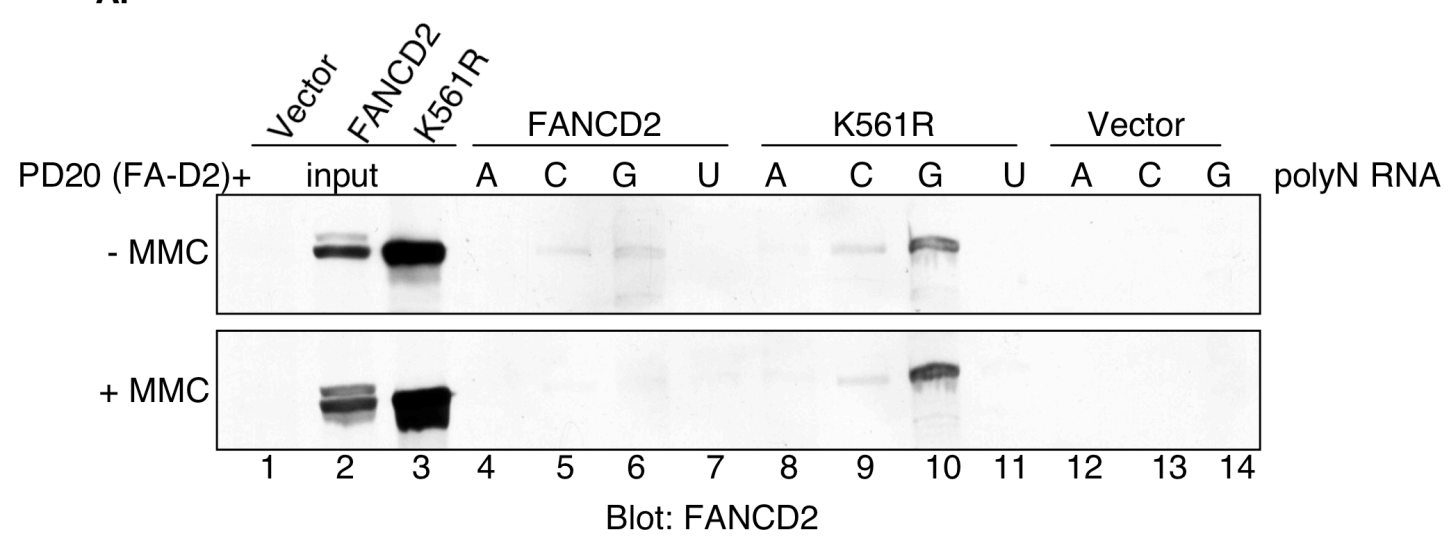

B.

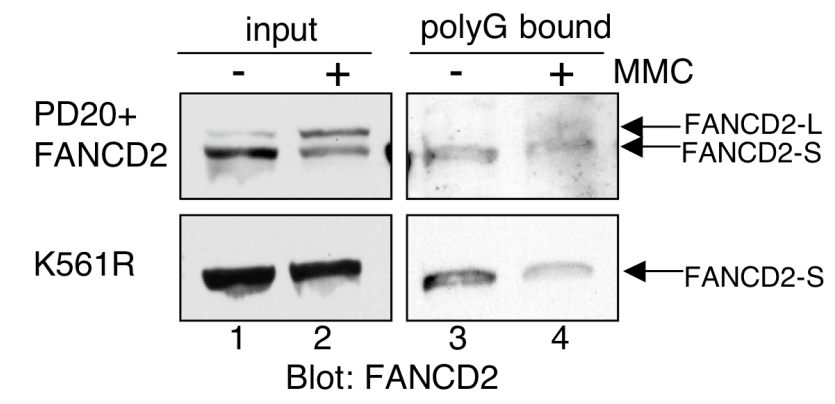


Figure 4-2: Inhibition of RNAPII inhibits FANCD2 monoubiquitination.

A, B, C, D. HeLa cells were pre-treated with the indicated inhibitor for one hour $(\alpha-$ amanitin $100 \mu \mathrm{g} / \mathrm{ml}$, DRB $100 \mu \mathrm{M}$, CHX $50 \mu \mathrm{g} / \mathrm{ml}$, puro 50 or $100 \mu \mathrm{g} / \mathrm{ml})$, then treated with MMC (1 $1 \mu \mathrm{M})$ for 6 hours. Cells were lysed directly, separated by SDS-PAGE, and immunoblotted for FANCD2 (A,B,C) or RNAPII (D). Filamin blot in (B) and $\beta$-tubulin blot in (D) are for loading verification. In (C) bands were quantified by densitometry and L/S ratios were calculated. Puro: puromycin, CHX: cycloheximide, DRB: 5,6-dichloro1-beta-D-ribofuranosylbenzimidazole, L/S Ratio: Long/short ratio, $\mathrm{II}_{\mathrm{o}}$ : hyperphosphorylated RNAPII, $\mathrm{II}_{\mathrm{a}}$ : hypophosphorylated RNAPII. 
Figure 4-2: Inhibition of RNAPII inhibits FANCD2 monoubiquitination

A.

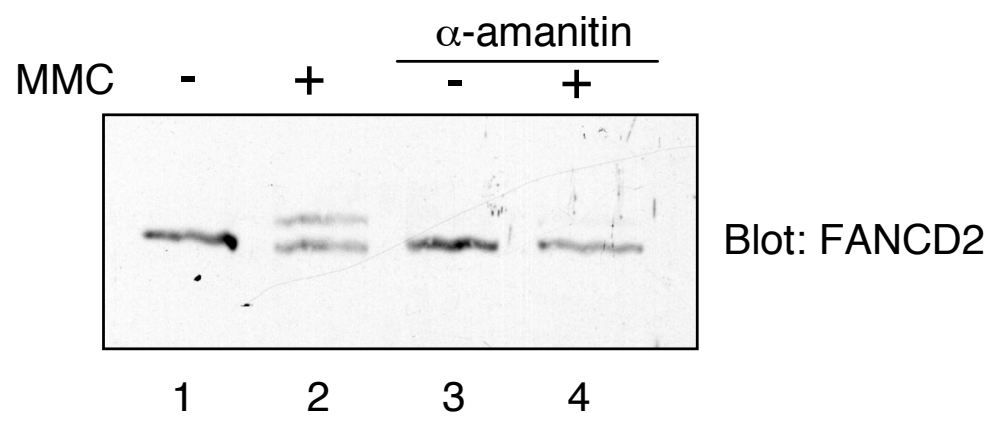

B.

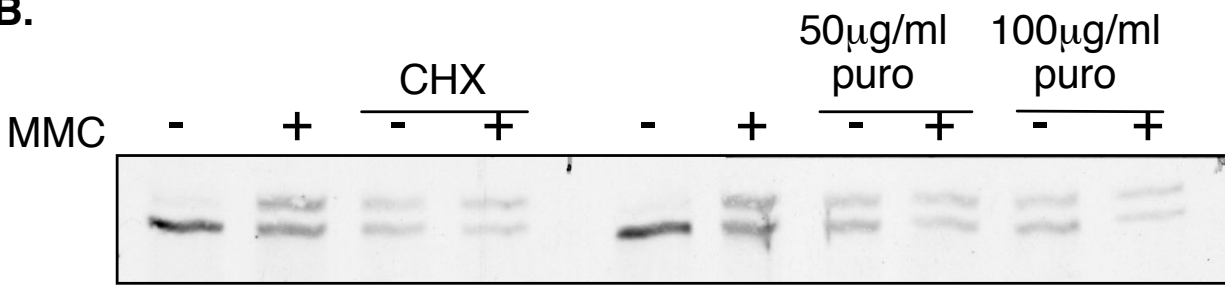

Blot: FANCD2

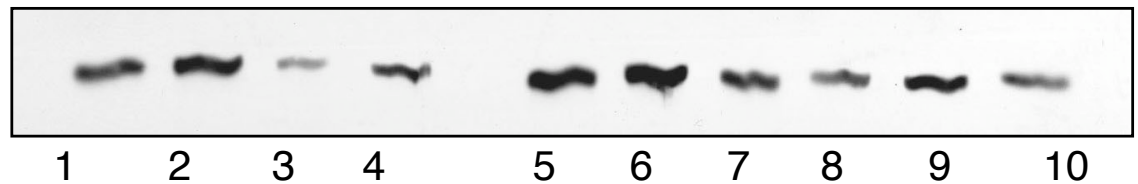

Filamin

C.
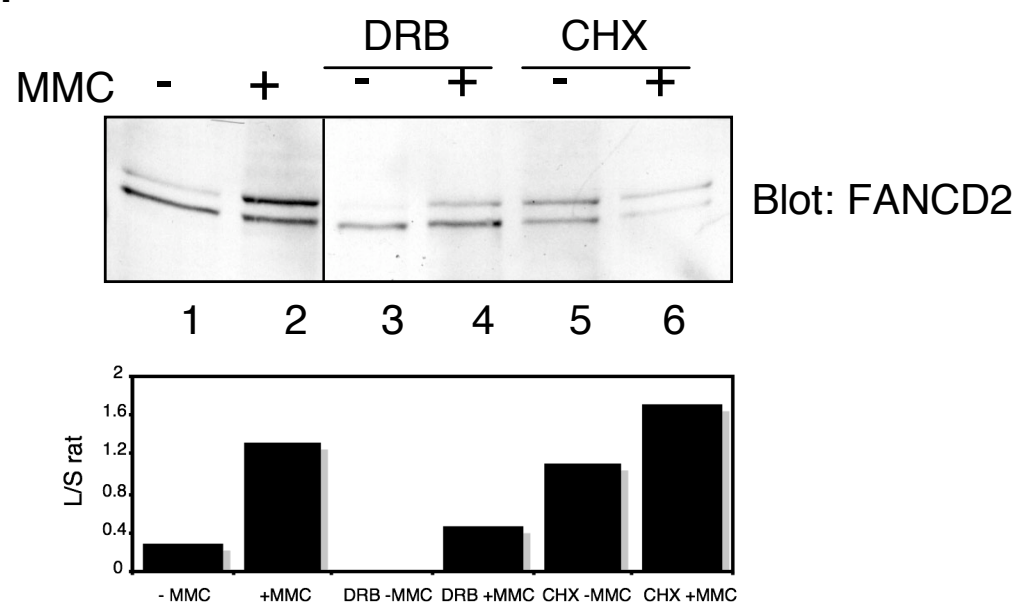

D.

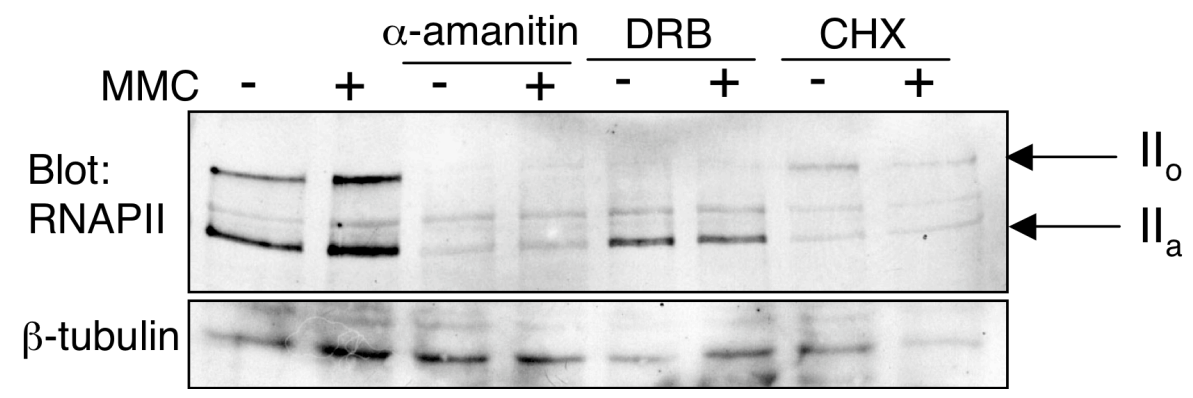


Figure 4-3: RNAPII inhibition sensitizes wild type cells to MMC.

A, B. HeLa cells were pretreated with $\alpha$-amanitin $(100 \mu \mathrm{g} / \mathrm{ml})$, DRB $(100 \mu \mathrm{M})$, or cycloheximide $(50 \mu \mathrm{g} / \mathrm{ml})$ as indicated. Cell survival after MMC treatment was determined using a short term crystal violet assay. C. Survival of GM6914 (FA-A) mutant or corrected cells after MMC treatment was determined in the presence of $1 \mu \mathrm{M}$ DRB using a long term crystal violet assay. Data presented is representative of at least 3 independent experiments. 
Figure 4-3: RNAPII inhibition sensitizes wild type cells to MMC

A.

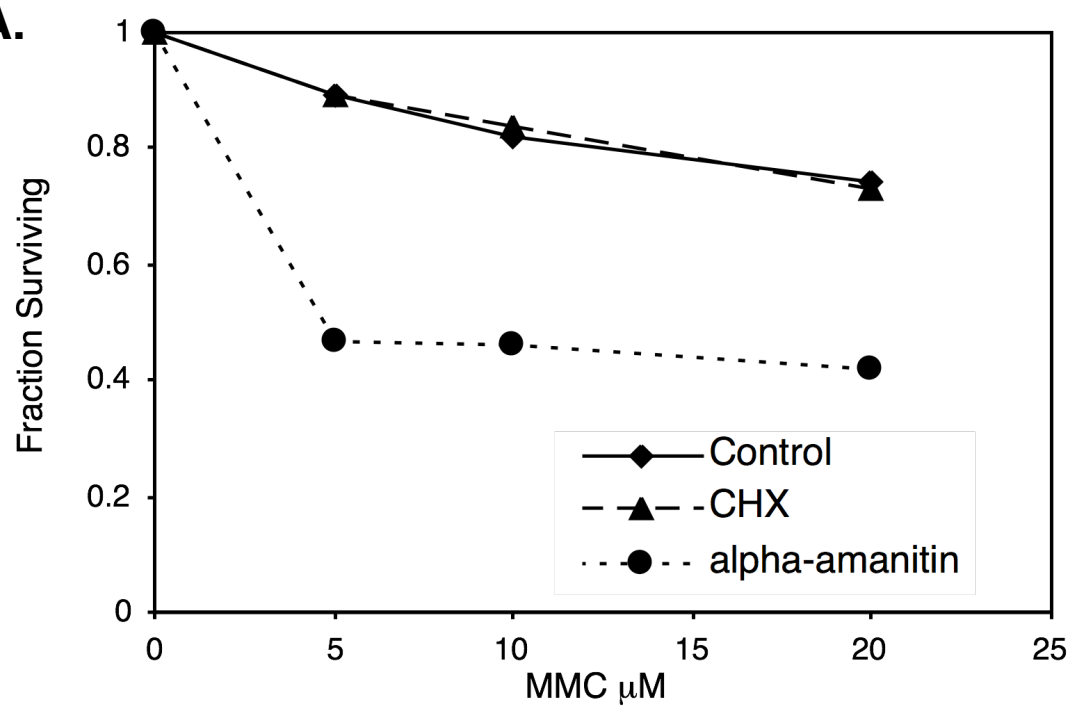

B.

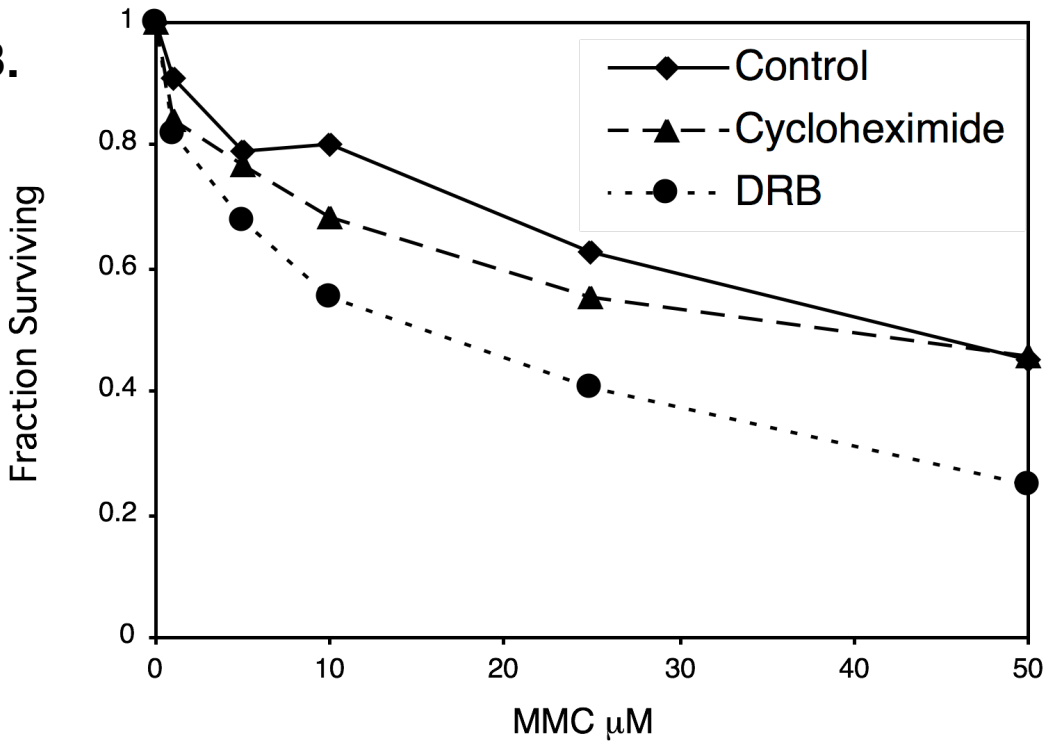

C.

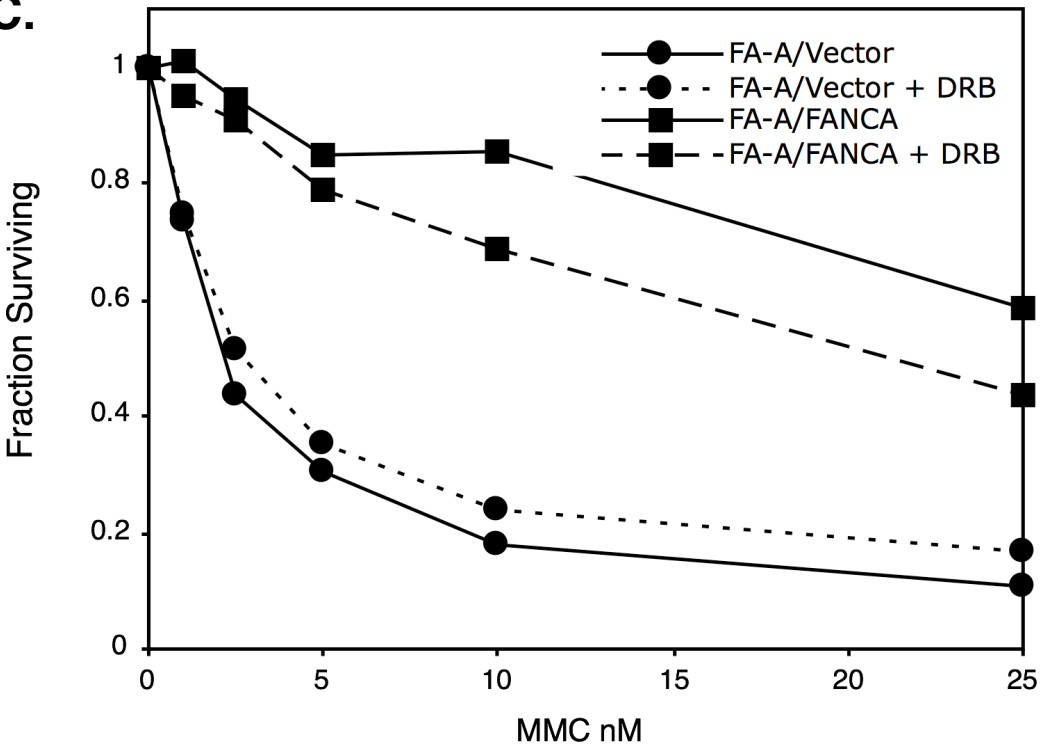




\section{Figure 4-4: RNAPII interacts with FANCD2}

FANCD2-containing complexes were purified from whole cell extract (lanes 1-4) of PD20 (FA-D2) cells expressing Flag-FANCD2 or the vector control \pm MMC $(0.5 \mu \mathrm{M})$ by nickel chromatography. Proteins from either the flow-through (lanes 5-8) of a nickelNTA agarose column or an elution in 300mM imidazole (lanes 9-12) were further purified by Flag immunoprecipitation, separated by SDS-PAGE, and immunoblotted for FANCD2 and RNAPII. IP: immunoprecipitation, $\mathrm{II}_{0}$ : hyperphosphorylated RNAPII, $\mathrm{II}_{\mathrm{a}}$ : hypophosphorylated RNAPII. 
Figure 4-4: RNAPII interacts with FANCD2

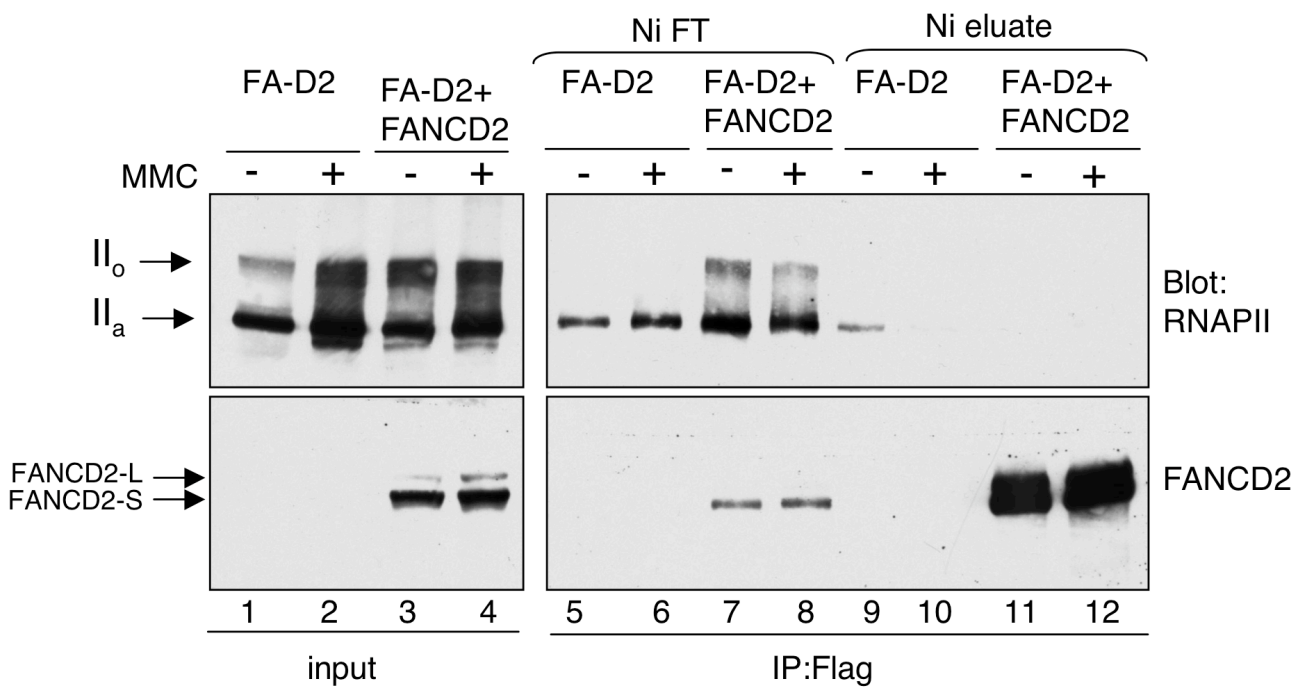


Figure 4-5: RNAPII is not polyubiquitinated in FA cells after DNA damage.

GM6914 (FA-A) cells or the same cells corrected with His-FANCA were transfected with a Flag-His-Ubiquitin construct or the vector control. Cells were treated with 100nM MMC for 18 hours and with 5 $4 \mathrm{M}$ MG132 for the last 4 hours. Whole cell lysates were immunoprecipitated by Flag, and immunoprecipitated proteins were separated by SDSPAGE and immunoblotted for RNAPII. FlgHisUb: Flag-His-Ubiquitin, $\mathrm{II}_{0}$ : hyperphosphorylated RNAPII, $\mathrm{II}_{\mathrm{a}}$ : hypophosphorylated RNAPII. 
Figure 4-5: RNAPII is not polyubiquitinated in FA cells after DNA damage

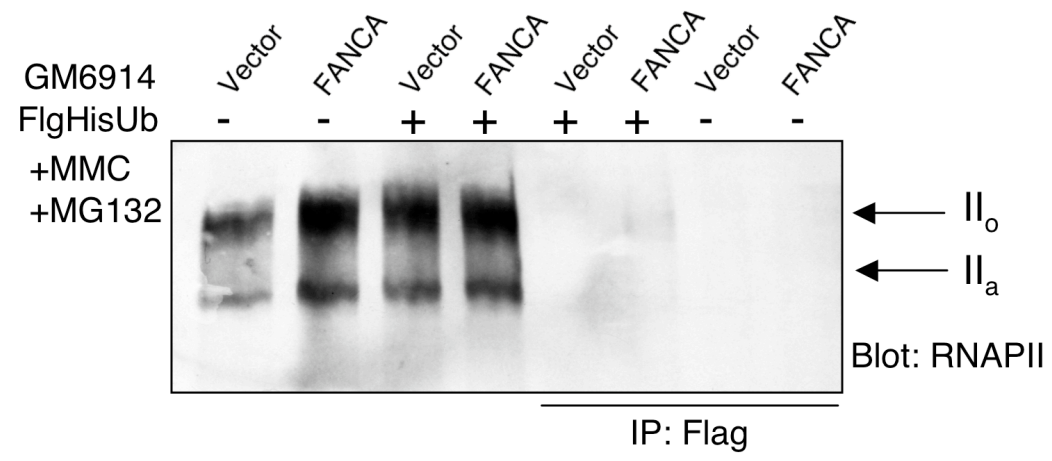


Figure 4-6: Model representing potential roles for FA pathway and RNAPII in promoting genome stability

FA proteins may interface with RNAPII on a variety of levels, and this model presents a variety of steps at which FA proteins may act. First, the FA pathway may guard actively transcribed genes against the formation of detrimental R loops. Second, the FA pathway may be involved in the proper downregulation of transcription and degradation of RNAPII in the context of DNA damage. Third, FA proteins may be involved in the biochemical resolution of stalled polymerases at sites of DNA crosslinks. The absence of the FA pathway at any or all of these steps would result in DNA damage and genome instability. 
Figure 4-6: Model representing potential roles for $F A$ pathway and RNAPII in promoting genome stability
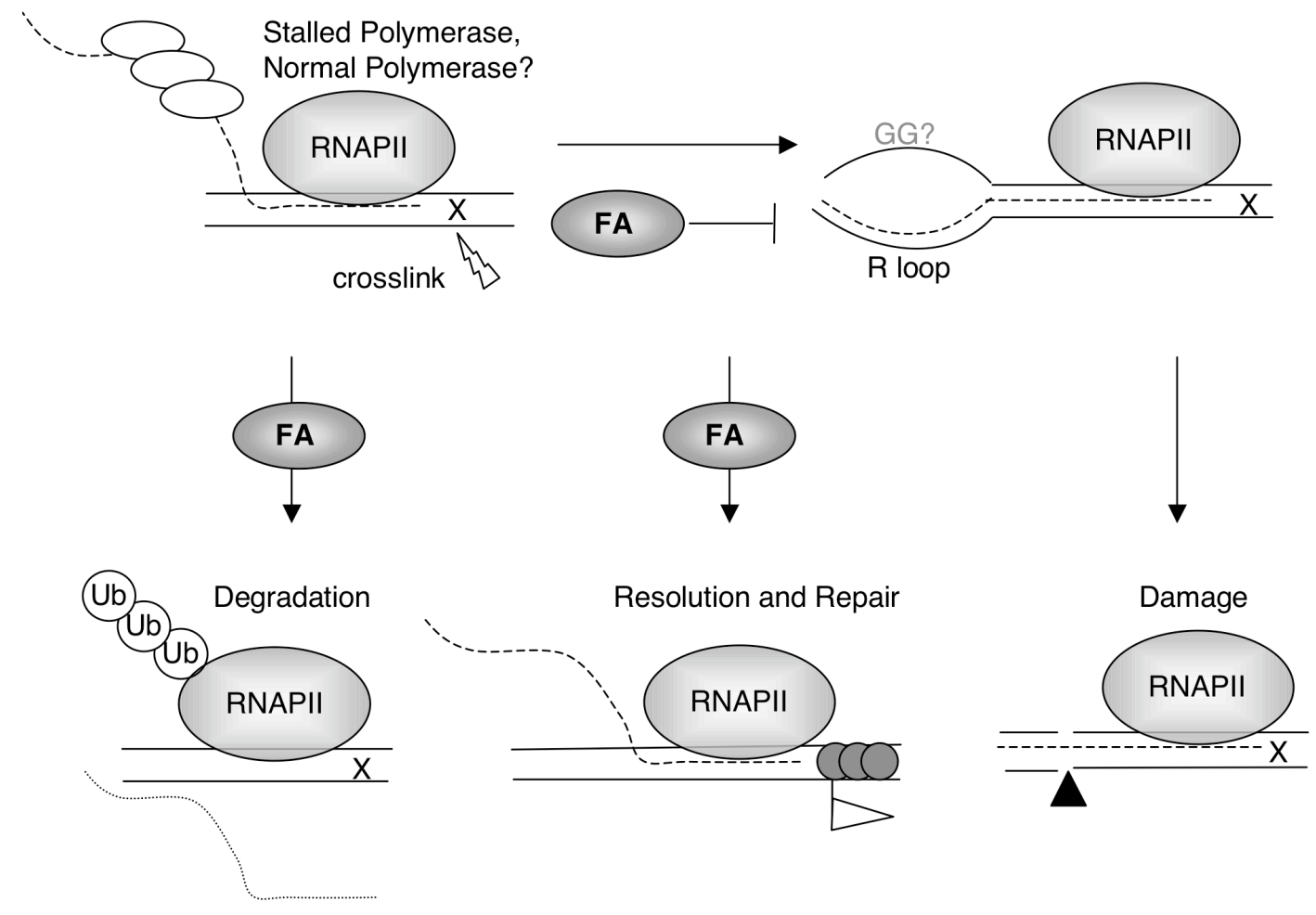


\section{CHAPTER 5 \\ Conclusions and Future Directions}

In the preceding chapters two major contributions to the field of FA biology have been discussed. In Chapter 3 a functionally significant phosphorylation event is described that is dependent on ATR, a major player in the DNA damage response. This is significant in that it describes a previously unknown regulation of the FA pathway and links it to the overall cellular DNA damage response. This phosphorylation is significant in that it is found after DNA damage and not during S phase, as is the case with the regulation of other FA proteins by post-translational modification. Chapter 4 begins to unravel a radically different hypothesis for how the proteins involved in FA may be functioning. Furthermore, it broadly proposes a novel mechanism for maintenance of genome integrity involving RNA. Both avenues of investigation suggest further experimentation for understanding FA biology.

With regard to the phosphorylation of FANCA, the outstanding question is by what mechanism is the phosphorylation regulating pathway function? Two possible explanations arise immediately based on paradigms of phosphorylation of other wellstudied proteins: 1) FANCA phosphorylation may regulate localization of key components of the DNA repair machinery and 2) FANCA phosphorylation may regulate composition of the FA core complex or other complexes, known or unknown, that impinge on DNA repair.

The consideration of the localization of FANCA is complicated by the fact that it is both a nuclear and cytoplasmic protein. Clearly, however, the nuclear function is required for normal sensitivity to DNA crosslinkers, as patient-derived mutations that do 
not achieve nuclear localization fail to complement MMC sensitivity (76). Nuclear localization is not sufficient, however, to complement the FA defect, as the FANCA S1449A mutant achieves nuclear localization (data not shown), but still demonstrates FAassociated phenotypes. Furthermore, FANCA is localized to the nucleus in response to DNA damage, but can also be actively transported out of the nucleus in a CRM1dependent manner $(40,112)$. Thus, it is entirely possible that both nuclear and cytoplasmic functions are essential for pathway function. In this work we show that FANCA phosphorylated on serine 1449 is increased on chromatin in response to DNA damage, and yet FANCA S1449A can also localize to chromatin. Thus, it appears that phosphorylation is not essential for localization to chromatin. However, it remains possible that phosphorylation may be required for proper localization within the chromatin context, such as specifically to sites of DNA damage. Phosphorylation may also regulate egress from chromatin and/or the nucleus to perform currently unknown functions.

Further experiments to study localization of phospho-FANCA will likely involve the adaptation of the phospho-serine 1449 specific antibody to immunofluorescence (IF) applications. Use of this antibody in IF will allow comparison of total FANCA localization to phospho-FANCA, colocalization experiments with proteins involved in DSB repair, such as $\gamma-\mathrm{H} 2 \mathrm{AX}$ and Rad51, and studies of the dynamic localization following various cellular treatments. Similarly, IF analysis of FANCA S1449A will allow comparison with wild-type FANCA localization. FANCA localization by IF has been challenging due to problems of antibody specificity and overexpression artifacts. 
GFP-FANCA and GFP-FANCA S1449A would be useful reagents, and our lab already has an expression construct for GFP-FANCA.

The term "FA core complex", while useful and widely accepted, simplifies the actual condition. Stable subcomplexes clearly form, and certain interactions are stronger than others, indicating that the composition of the core complex may actually be quite fluid $(90,105)$. Our lab has shown by chromatography that the core complex has at least distinct nuclear, cytoplasmic, mitotic, and chromatin-bound forms (178). The size of the core complex as measured by gel filtration chromatography necessitates that there are unidentified members of the complex. FANCE is known to shuttle in and out of the core complex, as it is the only core complex member to also be found in physical association with FANCD2 (132). Most studies describing the core complex are immunoprecipitation experiments, which provide evidence of interactions within a population, rather than describing the state within a given cell at a given point in time. Therefore, evaluating the composition of the core complex with phosphorylated or unphosphorylated FANCA is not as direct as just determining if known members are present. Our analysis shows that at least basic core complex interactions are maintained in the presence of FANCA S1449A. Complex composition could be further elucidated by chromatography of the core complex in the presence of wild-type FANCA and FANCA S1449A. The size of the complexes with wild-type or mutant protein could be compared, and fractions could be immunoprecipitated and/or silver stained to look for bands present in one complex and not the other. In this way it could be determined if core complex composition is affected by FANCA phosphorylation. Similarly, as new complex members are identified and 
verified, as has been a goal within our lab, they should be tested for association with phosphorylated or unphosphorylated FANCA.

A logical outgrowth of the question of core complex composition in association with phospho-FANCA is the question of post-translational modifications of other FA proteins. Specifically, our lab has shown that FANCG is phosphorylated on three functionally critical serine residues $(113,140)$. Two of these phosphorylations occur at mitosis, where at least one is placed by mitotic kinase cdc2, and are responsible for egress of the complex off chromatin at mitosis (113). The other phosphorylation, on serine 7 of FANCG, is increased after MMC treatment and the mutant, serine 7 to alanine (S7A), fails to complement MMC sensitivity of FA-G mutant cells (140). In this way it behaves similarly to phosphorylation of FANCA on serine 1449; however unlike S1449 phosphorylation, phosphorylation of FANCG also seems to occur constitutively at S phase. The kinase for FANCG at serine 7 is unknown. Several questions could be asked in regards to the relationship of these phosphorylation events. First, is ATR responsible for FANCG phosphorylation on serine 7? This could be addressed using methods analogous to those presented in Chapter 3. Secondly, are these phosphorylations dependent on one another? In straightforward experiments, phospho-specific antibodies against phospho-serine 1449 of FANCA could be used in cells expressing FANCG S7A. Conversely, anti-phospho serine 7 of FANCG antibodies could be used in cells expressing FANCA S1449A. Finally, it would be interesting to know the phosphorylation of FANCA and FANCG in the core complex. Are the phosphorylations coordinated spatially and temporally, or can the phosphorylation status vary within the complex? Similarly, what is the status of phosphorylation within various subcellular 
compartments? Since our lab has shown the composition of the complex varies with subcellular compartment, an interesting question is how phosphorylation either affects or is affected by these changes. Asking these questions is complicated again by the fact that most methods for studying complex composition rely on steady state analysis of the complex in a population, where we are truly interested in the phosphorylation status of proteins within a single complex. A simple first way to approach this problem is to fractionate cells to analyze only complex from certain compartments for phosphorylation. Phospho-specific immunofluorescence would also be very useful for analyzing events within single cells. Dependence of one phosphorylation on the other would suggest a sequential phosphorylation and the requirement of some critical intermediate signaling pathway. Independence of the phosphorylation events is suggestive that the two may direct different downstream events and suggests a divergence of function for the FA pathway. Indeed, two different phosphorylations may be a way to fine-tune the effects of the complex for distinctive actions within the cell.

Finally, in studying human diseases such as FA, one should return often to the therapeutic implications of the work. The FA pathway should be able to be exploited clinically by virtue of the fact that it, when absent, results in hypersensitivity to DNA damaging agents - the same agents used therapeutically in cancer chemotherapy. Logically, if the FA pathway could be suppressed within tumor cells, the resulting tumor would be specifically hypersensitive to the chemotherapy. As proof of principle, one study compared activation of the FA pathway in head and neck cancers that were either cisplatin-sensitive or cisplatin-resistant. Three out of four tumor lines that were cisplatinsensitive showed lack of formation of FANCD2 foci, while all cisplatin-resistant tumor 
lines showed FANCD2 foci formation (16). In an attempt to take clinical advantage of the sensitivity, a search for small molecule inhibitors of the FA pathway was initiated (22). Interestingly, three out of four compounds identified were kinase inhibitors, further emphasizing that phosphorylation is critical to the FA pathway. Knowledge of a functionally important phosphorylation on FANCA suggests a clinical target for sensitization of tumors to chemotherapy. Small molecule inhibitors of this phosphorylation could be investigated, or, alternatively, peptide inhibitors could be designed to compete for phosphorylation. The therapeutic implications of this phosphorylation underscore the importance of understanding critical signaling events in pathways related to human disease.

The potential interaction of FA proteins with RNA is exciting in that it represents an entirely new process for genome maintenance. The exact mechanism is, however, unknown, and leaves open vast possibilities for further research. The idea that RNA may direct DNA repair is a logical one that has been hypothesized but not yet proven, though supportive evidence is accumulating (182). The Elledge group, in the same proteomic screen for targets of ATM and ATR kinases that identified serine 1449 of FANCA as outlined in chapter 3, also found proteins involved in gene expression and RNA posttranscriptional processing to be surprisingly overrepresented as targets of ATM and ATR (101). In addition, transcription by RNA Polymerase I is diminished after DNA damage, surprisingly in a manner dependent on the ATM kinase, a kinase traditionally thought to control only DNA-related processes (73).

Mammalian cells have essentially three systems with which to deal with double strand DNA breaks; non-homologous end joining (NHEJ), homology-directed repair 
(HDR), and single strand annealing (SSA) (189). Of these, NHEJ and SSA are errorprone, and both HDR and SSA require an identical template. Cells in G1 phase of the cell cycle encountering DNA double strand breaks, therefore, have a problem. Lacking a sister chromatid for recombination, they must rely upon the error-prone mechanism of NHEJ - that is, unless an identical template were present, which for most active genes exists in the form of an RNA transcript. This has led to the hypothesis that RNA transcripts may serve as the template for HDR in G1 phase of the cell cycle (182). In support of this hypothesis, it was recently shown that an RNA molecule could serve as the template for repair of a DNA double strand break in yeast, a process previously documented only in retroviruses and telomere maintenance (168). Is it possible that this pathway exists and that the FA pathway participates in the process of transcript-templated HDR?

One prediction of this model would be the requirement of reverse transcriptase (RT) activity. Indeed, one reverse transcriptase in humans is well studied - TERT, the RT active in maintaining telomere length. As mentioned in earlier chapters, patients with mutations in this gene have a disorder called dyskeratosis congenita, a disorder with remarkable phenotypic similarity to FA. Retrotransposons within the human genome encode a reverse transcriptase function in order to complete retrotransposition (33). Another possibility for the RT function is an alternative activity for a known DNA polymerase. In fact, RT function has been attributed in vitro to human Y family translesion DNA polymerases $\eta, \iota$, and $\kappa$ (43). Linking to FA again, mutations in Pol $\eta$ are found in patients with Xeroderma Pigmentosum - variant (XP-V), a disease phenotypically similar to FA. Finally, mitochondrial DNA polymerase $\gamma$ has also been 
shown to possess RT function (118). All of these together solidify the conclusion that RT function exists in human cells at a level that could support the hypothesis of transcript-templated HDR.

Arguing against the involvement of FA in the model of transcript-templated HDR is the observation that the FA pathway seems to act primarily during $\mathrm{S}$ phase, whereas the transcript-templated HDR would be needed primarily in G1. Indeed, FANCD2 is monoubiquitinated at $\mathrm{S}$ phase, core complex proteins accumulate on chromatin during $\mathrm{S}$ phase, and FA mutant cells arrest at G2/M, likely as a result of having persistent DNA damage after S phase $(39,112,173)$. The work presented here, however, is the first to show a DNA-damage specific modification, phosphorylation of FANCA, which is not also found constitutively at $\mathrm{S}$ phase. Furthermore, as transcription of genes continues throughout S phase, there is no reason transcript-templated HDR would be restricted to G1. In fact, since sister chromatids are not reliably present for all genes until the end of $\mathrm{S}$ phase, it is possible transcripts could remain the preferred template through $\mathrm{S}$ phase.

How can we test this model? First, one would predict after DNA damage (and maybe constitutively) FA proteins would be associated with areas of active transcription. Colocalization of FA proteins and RNAPII by immunofluorescence studies have been initiated, but are complicated by poor ability to visualize endogenous FA proteins by immunofluorescence and the abundance of RNAPII. Alternatively, areas of active transcription can be labeled using bromouridine, and colocalization of FA proteins could be examined. Chromatin immunoprecipitation (ChIP) of FANCA and RNAPII to an actively transcribed gene would show colocalization, but this is complicated by not knowing if this process is damage-dependent and the inability to specifically introduce 
crosslink damage into a target gene for ChIP. Finally, as stated previously, the model predicts the dependence of crosslink repair on reverse transcriptase function. This function may be sensitive to known pharmacological inhibitors of RT. In wild-type cells, you would expect these inhibitors would sensitize cells to DNA damage by crosslinkers, whereas FA cells would be expected to show no increased sensitivity as the pathway is already absent in these cells. Additionally, functional studies should be performed on Rloop mimicking structures to see if FA proteins can either bind to or resolve these structures.

The conclusion of this work allows reflection on what I perceive to be the outstanding questions in FA biology - outstanding in that they are both unanswered and pivotal to further advance in the field.

First, I believe the phenotype for FA-D1 patients needs to be clarified. Is it truly FA or a related, more severe disease? Patients, though the absolute numbers in this group are small, seem to develop cancer earlier and develop different tumors, including frequently Wilms' tumor or medulloblastoma (5). Aplastic anemia, characteristic of FA, is less frequently seen than in other complementation groups, but this may be masked by the early onset of malignancy. FANCD1/BRCA2, FANCN/PALB2, and FANCJ/BACH1 are the only FA proteins known to harbor a carrier risk for malignancy, though the mutations that lead to this increased risk are still being worked out. On a biochemical level the proteins responsible for this group also behave differently. FANCD1/BRCA2 homozygous deletions are lethal in mice and presumably in humans, so the spectrum of mutations results in hypomorphic alleles. Other FA mutations are null mutations, resulting in complete absence of protein. Finally, BRCA2 is thought to act 
downstream of FANCD2, as it is not required for FANCD2 monoubiquitination (58). Similar arguments may apply to FA-N and FA-J complementation groups, which also act downstream of FANCD2, though recent identification and small number of patients leave these an open question $(92,143)$. These proteins that act downstream of FANCD2 may be the downstream effectors of several pathways, and attempts to understand their function may actually complicate the understanding of FA biology - and why this multiprotein pathway has evolved seemingly only in higher vertebrates to protect the genome. Study of the core complex and FANCD2, I believe, will be more valuable in yielding information about the FA pathway, while study of BRCA2, PALB2, and FANCJ may be more useful in studying general DNA repair.

The function of the FA pathway is clearly the open question, and despite a vast increase in knowledge about FA, little progress has been made. I see two areas that will help clarify function - the separation of the nuclear and cytoplasmic functions of the FA pathway and structural data for the FA core complex. First, better studies need to be designed to separate nuclear versus cytoplasmic functions of FA proteins. As outlined in Chapter 1, arguments exist for function in both cellular compartments. The nature of the core complex being at least eight proteins suggests that it may have functions other than simply monoubiquitinating FANCD2, and studies have confirmed this notion $(44,102$, 191). Deletion studies on proteins to determine critical regions for nuclear transport have been performed incompletely and only for FANCA $(40,89)$. Yet, certainly FA proteins defective for nuclear accumulation do not complement function (119). One hypothesis would be that the nuclear role of the core complex is in the monoubiquitination of FANCD2, and the cytoplasmic function is separable. To test this hypothesis, would a 
FANCA mutant defective for nuclear accumulation complement an FA-A cell line expressing a FANCD2-H2B fusion, previously shown by Matsushita et. al. to correct a FANCD2 line (102)?

Secondly, structural data for the FA core complex and FANCD2 could provide insight into FA pathway function. So far, limited structural data has given insight only minimally into protein-protein interactions and not into function $(72,126)$. Studies are underway in our lab and in others to define more and better structures for the FA proteins, and I trust they will, as is the paradigm for structural data, give insight into the function of the proteins.

Finally, I have been fortunate to spend my time working on a human disease and have seen the impact of this disease on the lives of children and families. Moreover, as a disease of cancer predisposition, studying FA allows the chance to impact cancer in a substantial way. As research into the field progresses, my hope is treatment of the patient will be the foremost aim, as I have tried to make it mine. 


\section{References}

1. 1996. Positional cloning of the Fanconi anaemia group A gene. The Fanconi anaemia/breast cancer consortium. Nat Genet 14:324-8.

2. Adachi, D., T. Oda, H. Yagasaki, K. Nakasato, T. Taniguchi, A. D. D'Andrea, S. Asano, and T. Yamashita. 2002. Heterogeneous activation of the Fanconi anemia pathway by patient-derived FANCA mutants. Hum Mol Genet 11:312534.

3. Akkari, Y. M., R. L. Bateman, C. A. Reifsteck, S. B. Olson, and M. Grompe. 2000. DNA replication is required To elicit cellular responses to psoralen-induced DNA interstrand cross-links. Mol Cell Biol 20:8283-9.

4. Alter, B. P. 2003. Cancer in Fanconi anemia, 1927-2001. Cancer 97:425-40.

5. Alter, B. P., P. S. Rosenberg, and L. C. Brody. 2007. Clinical and molecular features associated with biallelic mutations in FANCD1/BRCA2. J Med Genet 44:1-9.

6. Andreassen, P. R., A. D. D'Andrea, and T. Taniguchi. 2004. ATR couples FANCD2 monoubiquitination to the DNA-damage response. Genes Dev 18:195863.

7. Araujo, S. J., and R. D. Wood. 1999. Protein complexes in nucleotide excision repair. Mutat Res 435:23-33.

8. Auerbach, A. D., B. Adler, and R. S. Chaganti. 1981. Prenatal and postnatal diagnosis and carrier detection of Fanconi anemia by a cytogenetic method. Pediatrics 67:128-35.

9. Auerbach, A. D., A. Rogatko, and T. M. Schroeder-Kurth. 1989. International Fanconi Anemia Registry: relation of clinical symptoms to diepoxybutane sensitivity. Blood 73:391-6.

10. Bialojan, C., and A. Takai. 1988. Inhibitory effect of a marine-sponge toxin, okadaic acid, on protein phosphatases. Specificity and kinetics. Biochem J 256:283-90. 
11. Blom, E., H. J. van de Vrugt, Y. de Vries, J. P. de Winter, F. Arwert, and H. Joenje. 2004. Multiple TPR motifs characterize the Fanconi anemia FANCG protein. DNA Repair (Amst) 3:77-84.

12. Bohr, V. A., C. A. Smith, D. S. Okumoto, and P. C. Hanawalt. 1985. DNA repair in an active gene: Removal of pyrimidine dimers from the DHFR gene of CHO cells is much more efficient than in the genome overall. Cell 40:359-369.

13. Bregman, D. B., R. Halaban, A. J. van Gool, K. A. Henning, E. C. Friedberg, and S. L. Warren. 1996. UV-induced ubiquitination of RNA polymerase II: a novel modification deficient in Cockayne syndrome cells. Proc Natl Acad Sci U S A 93:11586-90.

14. Brueckner, F., U. Hennecke, T. Carell, and P. Cramer. 2007. CPD Damage Recognition by Transcribing RNA Polymerase II. Science 315:859-862.

15. Bruun, D., A. Folias, Y. Akkari, Y. Cox, S. Olson, and R. Moses. 2003. siRNA depletion of BRCA1, but not BRCA2, causes increased genome instability in Fanconi anemia cells. DNA Repair (Amst) 2:1007-13.

16. Burkitt, K., and M. Ljungman. 2007. Compromised Fanconi anemia response due to BRCA1 deficiency in cisplatin-sensitive head and neck cancer cell lines. Cancer Lett 23:23.

17. Butturini, A., R. P. Gale, P. C. Verlander, B. Adler-Brecher, A. P. Gillio, and A. D. Auerbach. 1994. Hematologic abnormalities in Fanconi anemia: an International Fanconi Anemia Registry study. Blood 84:1650-5.

18. Calin, G. A., and C. M. Croce. 2006. MicroRNA signatures in human cancers. Nat Rev Cancer 6:857-66.

19. Cantor, S., R. Drapkin, F. Zhang, Y. Lin, J. Han, S. Pamidi, and D. M. Livingston. 2004. The BRCA1-associated protein BACH1 is a DNA helicase targeted by clinically relevant inactivating mutations. PNAS 101:2357-2362.

20. Cheng, N. C., H. J. van de Vrugt, M. A. van der Valk, A. B. Oostra, P. Krimpenfort, Y. de Vries, H. Joenje, A. Berns, and F. Arwert. 2000. Mice with a targeted disruption of the Fanconi anemia homolog Fanca. Hum Mol Genet 9:1805-11. 
21. Cheung, I., M. Schertzer, A. Rose, and P. M. Lansdorp. 2002. Disruption of dog-1 in Caenorhabditis elegans triggers deletions upstream of guanine-rich DNA. Nat Genet 31:405-9.

22. Chirnomas, D., T. Taniguchi, M. de la Vega, A. P. Vaidya, M. Vasserman, A. R. Hartman, R. Kennedy, R. Foster, J. Mahoney, M. V. Seiden, and A. D. D'Andrea. 2006. Chemosensitization to cisplatin by inhibitors of the Fanconi anemia/BRCA pathway. Mol Cancer Ther 5:952-61.

23. Ciccia, A., C. Ling, R. Coulthard, Z. Yan, Y. Xue, A. R. Meetei, E. H. Laghmani, H. Joenje, N. McDonald, J. P. de Winter, W. Wang, and S. C. West. 2007. Identification of FAAP24, a Fanconi Anemia Core Complex Protein that Interacts with FANCM. Molecular Cell 25:331-343.

24. Cleaver, J. E., and K. H. Kraemer. 1995. Xeroderma pigmentosum and Cockayne syndrome, p. 4393-4419. In C. R. Scriver and e. al. (ed.), The Metabolic and Molecular Bases of Inherited Disease. McGraw-Hill, New York.

25. Collins, N., and G. M. Kupfer. 2005. Molecular pathogenesis of Fanconi anemia. Int J Hematol 82:176-83.

26. Couch, F. J., M. R. Johnson, K. Rabe, L. Boardman, R. McWilliams, M. de Andrade, and G. Petersen. 2005. Germ line Fanconi anemia complementation group C mutations and pancreatic cancer. Cancer Res 65:383-6.

27. Cumming, R. C., J. Lightfoot, K. Beard, H. Youssoufian, P. J. O'Brien, and M. Buchwald. 2001. Fanconi anemia group C protein prevents apoptosis in hematopoietic cells through redox regulation of GSTP1. Nat Med 7:814-20.

28. de Lange, T. 2002. Protection of mammalian telomeres. Oncogene 21:532-40.

29. de Winter, J. P., F. Leveille, C. G. van Berkel, M. A. Rooimans, L. van Der Weel, J. Steltenpool, I. Demuth, N. V. Morgan, N. Alon, L. Bosnoyan-Collins, J. Lightfoot, P. A. Leegwater, Q. Waisfisz, K. Komatsu, F. Arwert, J. C. Pronk, C. G. Mathew, M. Digweed, M. Buchwald, and H. Joenje. 2000. Isolation of a cDNA representing the Fanconi anemia complementation group $\mathrm{E}$ gene. Am J Hum Genet 67:1306-8.

30. de Winter, J. P., M. A. Rooimans, L. van Der Weel, C. G. van Berkel, N. Alon, L. Bosnoyan-Collins, J. de Groot, Y. Zhi, Q. Waisfisz, J. C. Pronk, F. Arwert, C. G. Mathew, R. J. Scheper, M. E. Hoatlin, M. Buchwald, and H. Joenje. 2000. The Fanconi anaemia gene FANCF encodes a novel protein with homology to ROM. Nat Genet 24:15-6. 
31. de Winter, J. P., Q. Waisfisz, M. A. Rooimans, C. G. van Berkel, L. Bosnoyan-Collins, N. Alon, M. Carreau, O. Bender, I. Demuth, D. Schindler, J. C. Pronk, F. Arwert, H. Hoehn, M. Digweed, M. Buchwald, and H. Joenje. 1998. The Fanconi anaemia group G gene FANCG is identical with XRCC9. Nat Genet 20:281-3.

32. Degan, P., S. Bonassi, M. De Caterina, L. G. Korkina, L. Pinto, F. Scopacasa, A. Zatterale, R. Calzone, and G. Pagano. 1995. In vivo accumulation of 8hydroxy-2'-deoxyguanosine in DNA correlates with release of reactive oxygen species in Fanconi's anaemia families. Carcinogenesis 16:735-41.

33. Dewannieux, M., C. Esnault, and T. Heidmann. 2003. LINE-mediated retrotransposition of marked Alu sequences. Nat Genet 35:41-8.

34. Donahue, S. L., R. Lundberg, R. Saplis, and C. Campbell. 2003. Deficient regulation of DNA double-strand break repair in Fanconi anemia fibroblasts. J Biol Chem 278:29487-95.

35. Drolet, M., P. Phoenix, R. Menzel, E. Masse, L. F. Liu, and R. J. Crouch. 1995. Overexpression of RNase H partially complements the growth defect of an Escherichia coli delta topA mutant: R-loop formation is a major problem in the absence of DNA topoisomerase I. Proc Natl Acad Sci U S A 92:3526-30.

36. Dronkert, M. L., and R. Kanaar. 2001. Repair of DNA interstrand cross-links. Mutat Res 486:217-47.

37. Dunker, A. K., and R. R. Rueckert. 1969. Observations on Molecular Weight Determinations on Polyacrylamide Gel. J. Biol. Chem. 244:5074-5080.

38. Duquette, M. L., P. Handa, J. A. Vincent, A. F. Taylor, and N. Maizels. 2004. Intracellular transcription of G-rich DNAs induces formation of G-loops, novel structures containing G4 DNA. Genes Dev 18:1618-29.

39. Dutrillaux, B., A. Aurias, A. M. Dutrillaux, D. Buriot, and M. Prieur. 1982. The cell cycle of lymphocytes in Fanconi anemia. Hum Genet 62:327-32.

40. Ferrer, M., J. A. Rodriguez, E. A. Spierings, J. P. de Winter, G. Giaccone, and F. A. Kruyt. 2005. Identification of multiple nuclear export sequences in Fanconi anemia group A protein that contribute to CRM1-dependent nuclear export. Hum Mol Genet 14:1271-81. 
41. Flygare, J., and S. Karlsson. 2006. Diamond-Blackfan anemia: erythropoiesis lost in translation. Blood:blood-2006-09-001222.

42. Foe, J. R., M. A. Rooimans, L. Bosnoyan-Collins, N. Alon, M. Wijker, L. Parker, J. Lightfoot, M. Carreau, D. F. Callen, A. Savoia, N. C. Cheng, C. G. van Berkel, M. H. Strunk, J. J. Gille, G. Pals, F. A. Kruyt, J. C. Pronk, F. Arwert, M. Buchwald, and H. Joenje. 1996. Expression cloning of a cDNA for the major Fanconi anaemia gene, FAA. Nat Genet 14:488.

43. Franklin, A., P. J. Milburn, R. V. Blanden, and E. J. Steele. 2004. Human DNA polymerase-eta, an A-T mutator in somatic hypermutation of rearranged immunoglobulin genes, is a reverse transcriptase. Immunol Cell Biol 82:219-25.

44. Freie, B. W., S. L. Ciccone, X. Li, P. A. Plett, C. M. Orschell, E. F. Srour, H. Hanenberg, D. Schindler, S. H. Lee, and D. W. Clapp. 2004. A role for the Fanconi anemia $\mathrm{C}$ protein in maintaining the DNA damage-induced G2 checkpoint. J Biol Chem 279:50986-93.

45. Futaki, M., T. Igarashi, S. Watanabe, S. Kajigaya, A. Tatsuguchi, J. Wang, and J. M. Liu. 2002. The FANCG Fanconi anemia protein interacts with CYP2E1: possible role in protection against oxidative DNA damage. Carcinogenesis 23:67-72.

46. Ganesan, S., D. P. Silver, R. A. Greenberg, D. Avni, R. Drapkin, A. Miron, S. C. Mok, V. Randrianarison, S. Brodie, J. Salstrom, T. P. Rasmussen, A. Klimke, C. Marrese, Y. Marahrens, C.-X. Deng, J. Feunteun, and D. M. Livingston. 2002. BRCA1 Supports XIST RNA Concentration on the Inactive X Chromosome. Cell 111:393-405.

47. Garcia-Higuera, I., T. Taniguchi, S. Ganesan, M. S. Meyn, C. Timmers, J. Hejna, M. Grompe, and A. D. D'Andrea. 2001. Interaction of the Fanconi anemia proteins and BRCA1 in a common pathway. Mol Cell 7:249-62.

48. Garcia-Higuera, I., T. Taniguchi, S. Ganesan, M. S. Meyn, C. Timmers, J. Hejna, M. Grompe, and A. D. D'Andrea. 2001. Interaction of the Fanconi Anemia Proteins and BRCA1 in a Common Pathway. Molecular Cell 7:249-262.

49. Gazda, H. T., A. Grabowska, L. B. Merida-Long, E. Latawiec, H. E. Schneider, J. M. Lipton, A. Vlachos, E. Atsidaftos, S. E. Ball, K. A. Orfali, E. Niewiadomska, L. Da Costa, G. Tchernia, C. Niemeyer, J. J. Meerpohl, J. Stahl, G. Schratt, B. Glader, K. Backer, C. Wong, D. G. Nathan, A. H. Beggs, and C. A. Sieff. 2006. Ribosomal protein S24 gene is mutated in DiamondBlackfan anemia. Am J Hum Genet 79:1110-8. 
50. Giampietro, P. F., B. Adler-Brecher, P. C. Verlander, S. G. Pavlakis, J. G. Davis, and A. D. Auerbach. 1993. The need for more accurate and timely diagnosis in Fanconi anemia: a report from the International Fanconi Anemia Registry. Pediatrics 91:1116-20.

51. Godthelp, B. C., F. Artwert, H. Joenje, and M. Z. Zdzienicka. 2002. Impaired DNA damage-induced nuclear Rad51 foci formation uniquely characterizes Fanconi anemia group D1. Oncogene 21:5002-5.

52. Gong, X. Q., Y. A. Nedialkov, and Z. F. Burton. 2004. Alpha-amanitin blocks translocation by human RNA polymerase II. J Biol Chem 279:27422-7.

53. Gordon, S. M., and M. Buchwald. 2003. Fanconi anemia protein complex: mapping protein interactions in the yeast 2- and 3-hybrid systems. Blood 102:136-41.

54. Gurtan, A. M., and A. D. D'Andrea. 2006. Dedicated to the core: Understanding the Fanconi anemia complex. DNA Repair 5:1119-1125.

55. Haile, D. T., and J. D. Parvin. 1999. Activation of transcription in vitro by the BRCA1 carboxyl-terminal domain. J Biol Chem 274:2113-7.

56. Hall, P. A., and S. E. H. Russell. 2005. New perspectives on neoplasia and the RNA world. Hematological Oncology 23:49-53.

57. Ho, G. P., S. Margossian, T. Taniguchi, and A. D. D'Andrea. 2006. Phosphorylation of FANCD2 on two novel sites is required for mitomycin C resistance. Mol Cell Biol 26:7005-15.

58. Howlett, N. G., T. Taniguchi, S. Olson, B. Cox, Q. Waisfisz, C. De DieSmulders, N. Persky, M. Grompe, H. Joenje, G. Pals, H. Ikeda, E. A. Fox, and A. D. D'Andrea. 2002. Biallelic inactivation of BRCA2 in Fanconi anemia. Science 297:606-9.

59. Hraiky, C., M. A. Raymond, and M. Drolet. 2000. RNase H overproduction corrects a defect at the level of transcription elongation during rRNA synthesis in the absence of DNA topoisomerase I in Escherichia coli. J Biol Chem 275:1125763.

60. Huertas, P., and A. Aguilera. 2003. Cotranscriptionally Formed DNA:RNA Hybrids Mediate Transcription Elongation Impairment and TranscriptionAssociated Recombination. Molecular Cell 12:711-721. 
61. Hussain, S., J. B. Wilson, A. L. Medhurst, J. Hejna, E. Witt, S. Ananth, A. Davies, J. Y. Masson, R. Moses, S. C. West, J. P. de Winter, A. Ashworth, N. J. Jones, and C. G. Mathew. 2004. Direct interaction of FANCD2 with BRCA2 in DNA damage response pathways. Hum Mol Genet 13:1241-8.

62. Hussain, S., E. Witt, P. A. Huber, A. L. Medhurst, A. Ashworth, and C. G. Mathew. 2003. Direct interaction of the Fanconi anaemia protein FANCG with BRCA2/FANCD1. Hum Mol Genet 12:2503-10.

63. Iakoucheva, L. M., A. L. Kimzey, C. D. Masselon, R. D. Smith, A. K. Dunker, and E. J. Ackerman. 2001. Aberrant mobility phenomena of the DNA repair protein XPA. Protein Sci 10:1353-1362.

64. Ikeda, H., M. Matsushita, Q. Waisfisz, A. Kinoshita, A. B. Oostra, A. W. Nieuwint, J. P. De Winter, M. E. Hoatlin, Y. Kawai, M. S. Sasaki, A. D. D'Andrea, Y. Kawakami, and H. Joenje. 2003. Genetic reversion in an acute myelogenous leukemia cell line from a Fanconi anemia patient with biallelic mutations in BRCA2. Cancer Res 63:2688-94.

65. Inukai, N., Y. Yamaguchi, I. Kuraoka, T. Yamada, S. Kamijo, J. Kato, K. Tanaka, and H. Handa. 2004. A novel hydrogen peroxide-induced phosphorylation and ubiquitination pathway leading to RNA polymerase II proteolysis. J Biol Chem 279:8190-5.

66. Itakura, E., K. Umeda, E. Sekoguchi, H. Takata, M. Ohsumi, and A. Matsuura. 2004. ATR-dependent phosphorylation of ATRIP in response to genotoxic stress. Biochem Biophys Res Commun 323:1197-202.

67. Jackson, J. R., A. Gilmartin, C. Imburgia, J. D. Winkler, L. A. Marshall, and A. Roshak. 2000. An indolocarbazole inhibitor of human checkpoint kinase (Chk1) abrogates cell cycle arrest caused by DNA damage. Cancer Res 60:56672 .

68. Joenje, H., and K. J. Patel. 2001. The emerging genetic and molecular basis of Fanconi anaemia. Nat Rev Genet 2:446-57.

69. Kleiman, F. E., F. Wu-Baer, D. Fonseca, S. Kaneko, R. Baer, and J. L. Manley. 2005. BRCA1/BARD1 inhibition of mRNA 3' processing involves targeted degradation of RNA polymerase II. Genes Dev 19:1227-37.

70. Kloosterman, W. P., and R. H. A. Plasterk. 2006. The Diverse Functions of MicroRNAs in Animal Development and Disease. Developmental Cell 11:441450. 
71. Korkina, L. G., E. V. Samochatova, A. A. Maschan, T. B. Suslova, Z. P. Cheremisina, and I. B. Afanas'ev. 1992. Release of active oxygen radicals by leukocytes of Fanconi anemia patients. J Leukoc Biol 52:357-62.

72. Kowal, P., A. M. Gurtan, P. Stuckert, A. D. D'Andrea, and T. Ellenberger. 2007. Structural determinants of human FANCF protein that function in the assembly of a DNA damage signaling complex. J Biol Chem 282:2047-55.

73. Kruhlak, M., E. E. Crouch, M. Orlov, C. Montano, S. A. Gorski, A. Nussenzweig, T. Misteli, R. D. Phair, and R. Casellas. 2007. The ATM repair pathway inhibits RNA polymerase[thinsp]I transcription in response to chromosome breaks. Nature 447:730-734.

74. Kruyt, F. A., T. Hoshino, J. M. Liu, P. Joseph, A. K. Jaiswal, and H. Youssoufian. 1998. Abnormal microsomal detoxification implicated in Fanconi anemia group $\mathrm{C}$ by interaction of the FAC protein with NADPH cytochrome P450 reductase. Blood 92:3050-6.

75. Kubbies, M., D. Schindler, H. Hoehn, A. Schinzel, and P. S. Rabinovitch. 1985. Endogenous blockage and delay of the chromosome cycle despite normal recruitment and growth phase explain poor proliferation and frequent edomitosis in Fanconi anemia cells. Am J Hum Genet 37:1022-30.

76. Kupfer, G., D. Naf, I. Garcia-Higuera, J. Wasik, A. Cheng, T. Yamashita, A. Tipping, N. Morgan, C. G. Mathew, and A. D. D'Andrea. 1999. A patientderived mutant form of the Fanconi anemia protein, FANCA, is defective in nuclear accumulation. Exp Hematol 27:587-93.

77. Kupfer, G. M., and A. D. D'Andrea. 1996. The effect of the Fanconi anemia polypeptide, FAC, upon p53 induction and G2 checkpoint regulation. Blood 88:1019-25.

78. Kupfer, G. M., D. Naf, A. Suliman, M. Pulsipher, and A. D. D'Andrea. 1997. The Fanconi anaemia proteins, FAA and FAC, interact to form a nuclear complex. Nat Genet 17:487-90.

79. Kupfer, G. M., T. Yamashita, D. Naf, A. Suliman, S. Asano, and A. D. D'Andrea. 1997. The Fanconi anemia polypeptide, FAC, binds to the cyclindependent kinase, cdc2. Blood 90:1047-54.

80. Kutler, D. I., B. Singh, J. Satagopan, S. D. Batish, M. Berwick, P. F. Giampietro, H. Hanenberg, and A. D. Auerbach. 2003. A 20-year perspective on the International Fanconi Anemia Registry (IFAR). Blood 101:1249-56. 
81. Kutler, D. I., B. Singh, J. Satagopan, S. D. Batish, M. Berwick, P. F. Giampietro, H. Hanenberg, and A. D. Auerbach. 2003. A 20-year perspective on the International Fanconi Anemia Registry (IFAR). Blood 101:1249-1256.

82. Kuznetsova, A. V., J. Meller, P. O. Schnell, J. A. Nash, M. L. Ignacak, Y. Sanchez, J. W. Conaway, R. C. Conaway, and M. F. Czyzyk-Krzeska. 2003. von Hippel-Lindau protein binds hyperphosphorylated large subunit of RNA polymerase II through a proline hydroxylation motif and targets it for ubiquitination. PNAS 100:2706-2711.

83. Lehmann, A. R. 2003. DNA repair-deficient diseases, xeroderma pigmentosum, Cockayne syndrome and trichothiodystrophy. Biochimie 85:1101-11.

84. Leveille, F., E. Blom, A. L. Medhurst, P. Bier, H. Laghmani el, M. Johnson, M. A. Rooimans, A. Sobeck, Q. Waisfisz, F. Arwert, K. J. Patel, M. E. Hoatlin, H. Joenje, and J. P. de Winter. 2004. The Fanconi anemia gene product FANCF is a flexible adaptor protein. J Biol Chem 279:39421-30.

85. Levitus, M., M. A. Rooimans, J. Steltenpool, N. F. Cool, A. B. Oostra, C. G. Mathew, M. E. Hoatlin, Q. Waisfisz, F. Arwert, J. P. de Winter, and H. Joenje. 2004. Heterogeneity in Fanconi anemia: evidence for 2 new genetic subtypes. Blood 103:2498-503.

86. Levitus, M., Q. Waisfisz, B. C. Godthelp, Y. de Vries, S. Hussain, W. W. Wiegant, E. Elghalbzouri-Maghrani, J. Steltenpool, M. A. Rooimans, G. Pals, F. Arwert, C. G. Mathew, M. Z. Zdzienicka, K. Hiom, J. P. De Winter, and H. Joenje. 2005. The DNA helicase BRIP1 is defective in Fanconi anemia complementation group J. Nat Genet 37:934-5.

87. Levran, O., C. Attwooll, R. T. Henry, K. L. Milton, K. Neveling, P. Rio, S. D. Batish, R. Kalb, E. Velleuer, S. Barral, J. Ott, J. Petrini, D. Schindler, H. Hanenberg, and A. D. Auerbach. 2005. The BRCA1-interacting helicase BRIP1 is deficient in Fanconi anemia. Nat Genet 37:931-3.

88. Li, X., and J. L. Manley. 2005. Inactivation of the SR protein splicing factor ASF/SF2 results in genomic instability. Cell 122:365-78.

89. Lightfoot, J., N. Alon, L. Bosnoyan-Collins, and M. Buchwald. 1999. Characterization of regions functional in the nuclear localization of the Fanconi anemia group A protein. Hum Mol Genet 8:1007-15.

90. Ling, C., M. Ishiai, A. M. Ali, A. L. Medhurst, K. Neveling, R. Kalb, Z. Yan, Y. Xue, A. B. Oostra, A. D. Auerbach, M. E. Hoatlin, D. Schindler, H. Joenje, 
J. P. de Winter, M. Takata, A. R. Meetei, and W. Wang. 2007. FAAP100 is essential for activation of the Fanconi anemia-associated DNA damage response pathway. Embo J 29:29.

91. Lipton, J. M., E. Atsidaftos, I. Zyskind, and A. Vlachos. 2006. Improving clinical care and elucidating the pathophysiology of Diamond Blackfan anemia: An update from the Diamond Blackfan Anemia Registry. Pediatric Blood \& Cancer 46:558-564.

92. Litman, R., M. Peng, Z. Jin, F. Zhang, J. Zhang, S. Powell, P. R. Andreassen, and S. B. Cantor. 2005. BACH1 is critical for homologous recombination and appears to be the Fanconi anemia gene product FANCJ. Cancer Cell 8:255-65.

93. Liu, N., J. E. Lamerdin, J. D. Tucker, Z. Q. Zhou, C. A. Walter, J. S. Albala, D. B. Busch, and L. H. Thompson. 1997. The human XRCC9 gene corrects chromosomal instability and mutagen sensitivities in CHO UV40 cells. Proc Natl Acad Sci U S A 94:9232-7.

94. Machida, Y. J., Y. Machida, Y. Chen, A. M. Gurtan, G. M. Kupfer, A. D. D'Andrea, and A. Dutta. 2006. UBE2T Is the E2 in the Fanconi Anemia Pathway and Undergoes Negative Autoregulation. Molecular Cell 23:589-596.

95. Mahadevan, M. S., R. S. Yadava, Q. Yu, S. Balijepalli, C. D. FrenzelMcCardell, T. D. Bourne, and L. H. Phillips. 2006. Reversible model of RNA toxicity and cardiac conduction defects in myotonic dystrophy. Nat Genet 38:1066-70.

96. Maizels, N. 2006. Dynamic roles for G4 DNA in the biology of eukaryotic cells. Nat Struct Mol Biol 13:1055-9.

97. Marrone, A., A. Walne, and I. Dokal. 2005. Dyskeratosis congenita: telomerase, telomeres and anticipation. Current Opinion in Genetics \& Development 15:249-257.

98. Marshall, N. F., J. Peng, Z. Xie, and D. H. Price. 1996. Control of RNA polymerase II elongation potential by a novel carboxyl-terminal domain kinase. $\mathrm{J}$ Biol Chem 271:27176-83.

99. Masse, E., and M. Drolet. 1999. Escherichia coli DNA topoisomerase I inhibits R-loop formation by relaxing transcription-induced negative supercoiling. J Biol Chem 274:16659-64. 
100. Masumoto, H., D. Hawke, R. Kobayashi, and A. Verreault. 2005. A role for cell-cycle-regulated histone H3 lysine 56 acetylation in the DNA damage response. Nature 436:294-298.

101. Matsuoka, S., B. A. Ballif, A. Smogorzewska, E. R. McDonald, 3rd, K. E. Hurov, J. Luo, C. E. Bakalarski, Z. Zhao, N. Solimini, Y. Lerenthal, Y. Shiloh, S. P. Gygi, and S. J. Elledge. 2007. ATM and ATR substrate analysis reveals extensive protein networks responsive to DNA damage. Science 316:1160-6.

102. Matsushita, N., H. Kitao, M. Ishiai, N. Nagashima, S. Hirano, K. Okawa, T. Ohta, D. S. Yu, P. J. McHugh, I. D. Hickson, A. R. Venkitaraman, H. Kurumizaka, and M. Takata. 2005. A FancD2-monoubiquitin fusion reveals hidden functions of Fanconi anemia core complex in DNA repair. Mol Cell 19:841-7.

103. McGowan, C. H., and P. Russell. 2004. The DNA damage response: sensing and signaling. Curr Opin Cell Biol 16:629-33.

104. Medhurst, A. L., P. A. Huber, Q. Waisfisz, J. P. de Winter, and C. G. Mathew. 2001. Direct interactions of the five known Fanconi anaemia proteins suggest a common functional pathway. Hum Mol Genet 10:423-9.

105. Medhurst, A. L., E. H. Laghmani, J. Steltenpool, M. Ferrer, C. Fontaine, J. de Groot, M. A. Rooimans, R. J. Scheper, A. R. Meetei, W. Wang, H. Joenje, and J. P. de Winter. 2006. Evidence for subcomplexes in the Fanconi anemia pathway. Blood 108:2072-2080.

106. Meetei, A. R., J. P. de Winter, A. L. Medhurst, M. Wallisch, Q. Waisfisz, H. J. van de Vrugt, A. B. Oostra, Z. Yan, C. Ling, C. E. Bishop, M. E. Hoatlin, H. Joenje, and W. Wang. 2003. A novel ubiquitin ligase is deficient in Fanconi anemia. Nat Genet 35:165-70.

107. Meetei, A. R., M. Levitus, Y. Xue, A. L. Medhurst, M. Zwaan, C. Ling, M. A. Rooimans, P. Bier, M. Hoatlin, G. Pals, J. P. de Winter, W. Wang, and H. Joenje. 2004. X-linked inheritance of Fanconi anemia complementation group B. Nat Genet 36:1219-24.

108. Meetei, A. R., A. L. Medhurst, C. Ling, Y. Xue, T. R. Singh, P. Bier, J. Steltenpool, S. Stone, I. Dokal, C. G. Mathew, M. Hoatlin, H. Joenje, J. P. de Winter, and W. Wang. 2005. A human ortholog of archaeal DNA repair protein Hef is defective in Fanconi anemia complementation group M. Nat Genet 37:95863. 
109. Meetei, A. R., A. L. Medhurst, C. Ling, Y. Xue, T. R. Singh, P. Bier, J. Steltenpool, S. Stone, I. Dokal, C. G. Mathew, M. Hoatlin, H. Joenje, J. P. de Winter, and W. Wang. 2005. A human ortholog of archaeal DNA repair protein Hef is defective in Fanconi anemia complementation group M. Nat Genet 37:958963.

110. Mellon, I., G. Spivak, and P. C. Hanawalt. 1987. Selective removal of transcription-blocking DNA damage from the transcribed strand of the mammalian DHFR gene. Cell 51:241-249.

111. Meyer, S., W. D. Fergusson, A. B. Oostra, A. L. Medhurst, Q. Waisfisz, J. P. de Winter, F. Chen, T. F. Carr, J. Clayton-Smith, T. Clancy, M. Green, L. Barber, O. B. Eden, A. M. Will, H. Joenje, and G. M. Taylor. 2005. A crosslinker-sensitive myeloid leukemia cell line from a 2-year-old boy with severe Fanconi anemia and biallelic FANCD1/BRCA2 mutations. Genes Chromosomes Cancer 42:404-15.

112. Mi, J., and G. M. Kupfer. 2004. The Fanconi Anemia Core Complex Associates with Chromatin During S Phase. Blood.

113. Mi, J., F. Qiao, J. B. Wilson, A. A. High, M. J. Schroeder, P. T. Stukenberg, A. Moss, J. Shabanowitz, D. F. Hunt, N. J. Jones, and G. M. Kupfer. 2004. FANCG is phosphorylated at serines 383 and 387 during mitosis. Mol Cell Biol 24:8576-85.

114. Miglierina, R., M. Le Coniat, and R. Berger. 1991. A simple diagnostic test for Fanconi anemia by flow cytometry. Anal Cell Pathol 3:111-8.

115. Monteiro, A. N., A. August, and H. Hanafusa. 1996. Evidence for a transcriptional activation function of BRCA1 C-terminal region. Proc Natl Acad Sci U S A 93:13595-9.

116. Mosedale, G., W. Niedzwiedz, A. Alpi, F. Perrina, J. B. Pereira-Leal, M. Johnson, F. Langevin, P. Pace, and K. J. Patel. 2005. The vertebrate Hef ortholog is a component of the Fanconi anemia tumor-suppressor pathway. Nat Struct Mol Biol 12:763-771.

117. Moynahan, M. E., T. Y. Cui, and M. Jasin. 2001. Homology-directed dna repair, mitomycin-c resistance, and chromosome stability is restored with correction of a Brca1 mutation. Cancer Res 61:4842-50.

118. Murakami, E., J. Y. Feng, H. Lee, J. Hanes, K. A. Johnson, and K. S. Anderson. 2003. Characterization of novel reverse transcriptase and other RNA- 
associated catalytic activities by human DNA polymerase gamma: importance in mitochondrial DNA replication. J Biol Chem 278:36403-9.

119. Naf, D., G. M. Kupfer, A. Suliman, K. Lambert, and A. D. D'Andrea. 1998. Functional activity of the fanconi anemia protein FAA requires FAC binding and nuclear localization. Mol Cell Biol 18:5952-60.

120. Nakanishi, K., Y. G. Yang, A. J. Pierce, T. Taniguchi, M. Digweed, A. D. D'Andrea, Z. Q. Wang, and M. Jasin. 2005. Human Fanconi anemia monoubiquitination pathway promotes homologous DNA repair. Proc Natl Acad Sci U S A 102:1110-5.

121. Narayan, G., H. Arias-Pulido, S. V. Nandula, K. Basso, D. D. Sugirtharaj, H. Vargas, M. Mansukhani, J. Villella, L. Meyer, A. Schneider, L. Gissmann, M. Durst, B. Pothuri, and V. V. Murty. 2004. Promoter hypermethylation of FANCF: disruption of Fanconi Anemia-BRCA pathway in cervical cancer. Cancer Res 64:2994-7.

122. Nickoloff, J. A. 1992. Transcription enhances intrachromosomal homologous recombination in mammalian cells. Mol Cell Biol 12:5311-8.

123. Niedzwiedz, W., G. Mosedale, M. Johnson, C. Y. Ong, P. Pace, and K. J. Patel. 2004. The Fanconi anaemia gene FANCC promotes homologous recombination and error-prone DNA repair. Mol Cell 15:607-20.

124. Nijman, S. M., T. T. Huang, A. M. Dirac, T. R. Brummelkamp, R. M. Kerkhoven, A. D. D'Andrea, and R. Bernards. 2005. The deubiquitinating enzyme USP1 regulates the Fanconi anemia pathway. Mol Cell 17:331-9.

125. Noll, M., K. P. Battaile, R. Bateman, T. P. Lax, K. Rathbun, C. Reifsteck, G. Bagby, M. Finegold, S. Olson, and M. Grompe. 2002. Fanconi anemia group A and $\mathrm{C}$ double-mutant mice: functional evidence for a multi-protein Fanconi anemia complex. Exp Hematol 30:679-88.

126. Nookala, R. K., S. Hussain, and L. Pellegrini. 2007. Insights into Fanconi Anaemia from the structure of human FANCE. Nucleic Acids Res 35:1638-48.

127. O'Driscoll, M., V. L. Ruiz-Perez, C. G. Woods, P. A. Jeggo, and J. A. Goodship. 2003. A splicing mutation affecting expression of ataxia-telangiectasia and Rad3-related protein (ATR) results in Seckel syndrome. Nat Genet 33:497501. 
128. O'Neill, T., A. J. Dwyer, Y. Ziv, D. W. Chan, S. P. Lees-Miller, R. H. Abraham, J. H. Lai, D. Hill, Y. Shiloh, L. C. Cantley, and G. A. Rathbun. 2000. Utilization of oriented peptide libraries to identify substrate motifs selected by ATM. J Biol Chem 275:22719-27.

129. Ohashi, A., M. Z. Zdzienicka, J. Chen, and F. J. Couch. 2005. FANCD2 functions independently of BRCA2 and RAD51 associated homologous recombination in response to DNA damage. J Biol Chem.

130. Ory, D. S., B. A. Neugeboren, and R. C. Mulligan. 1996. A stable humanderived packaging cell line for production of high titer retrovirus/vesicular stomatitis virus G pseudotypes. Proc Natl Acad Sci U S A 93:11400-6.

131. Otsuki, T., T. Nagashima, N. Komatsu, K. Kirito, Y. Furukawa, S. Kobayashi Si, J. M. Liu, and K. Ozawa. 2002. Phosphorylation of Fanconi anemia protein, FANCA, is regulated by Akt kinase. Biochem Biophys Res Commun 291:628-34.

132. Pace, P., M. Johnson, W. M. Tan, G. Mosedale, C. Sng, M. Hoatlin, J. de Winter, H. Joenje, F. Gergely, and K. J. Patel. 2002. FANCE: the link between Fanconi anaemia complex assembly and activity. Embo J 21:3414-23.

133. Pang, Q., S. Fagerlie, T. A. Christianson, W. Keeble, G. Faulkner, J. Diaz, R. K. Rathbun, and G. C. Bagby. 2000. The Fanconi anemia protein FANCC binds to and facilitates the activation of STAT1 by gamma interferon and hematopoietic growth factors. Mol Cell Biol 20:4724-35.

134. Pang, Q., W. Keeble, J. Diaz, T. A. Christianson, S. Fagerlie, K. Rathbun, G. R. Faulkner, M. O'Dwyer, and G. C. Bagby, Jr. 2001. Role of double-stranded RNA-dependent protein kinase in mediating hypersensitivity of Fanconi anemia complementation group $\mathrm{C}$ cells to interferon gamma, tumor necrosis factor-alpha, and double-stranded RNA. Blood 97:1644-52.

135. Park, W. H., S. Margossian, A. A. Horwitz, A. M. Simons, A. D. D'Andrea, and J. D. Parvin. 2005. Direct DNA binding activity of the fanconi anemia $\mathrm{d} 2$ protein. J Biol Chem 280:23593-8.

136. Payne, J. M., P. J. Laybourn, and M. E. Dahmus. 1989. The transition of RNA polymerase II from initiation to elongation is associated with phosphorylation of the carboxyl-terminal domain of subunit IIa. J Biol Chem 264:19621-9. 
137. Pichierri, P., D. Averbeck, and F. Rosselli. 2002. DNA cross-linkdependent RAD50/MRE11/NBS1 subnuclear assembly requires the Fanconi anemia C protein. Hum Mol Genet 11:2531-46.

138. Pichierri, P., A. Franchitto, and F. Rosselli. 2004. BLM and the FANC proteins collaborate in a common pathway in response to stalled replication forks. Embo $\mathrm{J}$ 23:3154-63.

139. Pichierri, P., and F. Rosselli. 2004. The DNA crosslink-induced S-phase checkpoint depends on ATR-CHK1 and ATR-NBS1-FANCD2 pathways. Embo J 23:1178-87.

140. Qiao, F., J. Mi, J. B. Wilson, G. Zhi, N. R. Bucheimer, N. J. Jones, and G. M. Kupfer. 2004. Phosphorylation of fanconi anemia complementation group $\mathrm{G}$ protein, FANCG, at serine 7 is important for function of the FA pathway. J Biol Chem.

141. Qiao, F., A. Moss, and G. M. Kupfer. 2001. Fanconi anemia proteins localize to chromatin and the nuclear matrix in a DNA damage- and cell cycle-regulated manner. J Biol Chem 276:23391-6.

142. Query, C. C., R. C. Bentley, and J. D. Keene. 1989. A common RNA recognition motif identified within a defined U1 RNA binding domain of the $70 \mathrm{~K}$ U1 snRNP protein. Cell 57:89-101.

143. Rahman, N., S. Seal, D. Thompson, P. Kelly, A. Renwick, A. Elliott, S. Reid, K. Spanova, R. Barfoot, T. Chagtai, H. Jayatilake, L. McGuffog, S. Hanks, D. G. Evans, D. Eccles, D. F. Easton, and M. R. Stratton. 2007. PALB2, which encodes a BRCA2-interacting protein, is a breast cancer susceptibility gene. Nat Genet 39:165-7.

144. Rathbun, R. K., G. R. Faulkner, M. H. Ostroski, T. A. Christianson, G. Hughes, G. Jones, R. Cahn, R. Maziarz, G. Royle, W. Keeble, M. C. Heinrich, M. Grompe, P. A. Tower, and G. C. Bagby. 1997. Inactivation of the Fanconi anemia group $\mathrm{C}$ gene augments interferon-gamma-induced apoptotic responses in hematopoietic cells. Blood 90:974-85.

145. Ratner, J. N., B. Balasubramanian, J. Corden, S. L. Warren, and D. B. Bregman. 1998. Ultraviolet Radiation-induced Ubiquitination and Proteasomal Degradation of the Large Subunit of RNA Polymerase II. IMPLICATIONS FOR TRANSCRIPTION-COUPLED DNA REPAIR. J. Biol. Chem. 273:5184-5189. 
146. Reid, S., D. Schindler, H. Hanenberg, K. Barker, S. Hanks, R. Kalb, K. Neveling, P. Kelly, S. Seal, M. Freund, M. Wurm, S. D. Batish, F. P. Lach, S. Yetgin, H. Neitzel, H. Ariffin, M. Tischkowitz, C. G. Mathew, A. D.

Auerbach, and N. Rahman. 2007. Biallelic mutations in PALB2 cause Fanconi anemia subtype FA-N and predispose to childhood cancer. Nat Genet 39:162-4.

147. Risinger, M. A., and J. Groden. 2004. Crosslinks and crosstalk: Human cancer syndromes and DNA repair defects. Cancer Cell 6:539-545.

148. Rosenberg, P. S., M. H. Greene, and B. P. Alter. 2003. Cancer incidence in persons with Fanconi anemia. Blood 101:822-6.

149. Rothfuss, A., and M. Grompe. 2004. Repair kinetics of genomic interstrand DNA cross-links: evidence for DNA double-strand break-dependent activation of the Fanconi anemia/BRCA pathway. Mol Cell Biol 24:123-34.

150. Saadatzadeh, M. R., K. Bijangi-Vishehsaraei, P. Hong, H. Bergmann, and L. S. Haneline. 2004. Oxidant hypersensitivity of Fanconi anemia type C-deficient cells is dependent on a redox-regulated apoptotic pathway. J Biol Chem 279:16805-12.

151. Sarkaria, J. N., R. S. Tibbetts, E. C. Busby, A. P. Kennedy, D. E. Hill, and R. T. Abraham. 1998. Inhibition of phosphoinositide 3-kinase related kinases by the radiosensitizing agent wortmannin. Cancer Res 58:4375-82.

152. Schindler, D., and H. Hoehn. 1988. Fanconi anemia mutation causes cellular susceptibility to ambient oxygen. Am J Hum Genet 43:429-35.

153. Schneider, J., P. Bajwa, F. C. Johnson, S. R. Bhaumik, and A. Shilatifard. 2006. Rtt109 Is Required for Proper H3K56 Acetylation: A CHROMATIN MARK ASSOCIATED WITH THE ELONGATING RNA POLYMERASE II. J. Biol. Chem. 281:37270-37274.

154. Scully, R., S. F. Anderson, D. M. Chao, W. Wei, L. Ye, R. A. Young, D. M. Livingston, and J. D. Parvin. 1997. BRCA1 is a component of the RNA polymerase II holoenzyme. Proc Natl Acad Sci U S A 94:5605-10.

155. Scully, R., J. Chen, A. Plug, Y. Xiao, D. Weaver, J. Feunteun, T. Ashley, and D. M. Livingston. 1997. Association of BRCA1 with Rad51 in mitotic and meiotic cells. Cell 88:265-75. 
156. Seal, S., D. Thompson, A. Renwick, A. Elliott, P. Kelly, R. Barfoot, T. Chagtai, H. Jayatilake, M. Ahmed, K. Spanova, B. North, L. McGuffog, D. G. Evans, D. Eccles, D. F. Easton, M. R. Stratton, and N. Rahman. 2006. Truncating mutations in the Fanconi anemia J gene BRIP1 are low-penetrance breast cancer susceptibility alleles. Nat Genet 38:1239-41.

157. Sehgal, P. B., J. E. Darnell, Jr., and I. Tamm. 1976. The inhibition by DRB (5,6-dichloro-1-beta-D-ribofuranosylbenzimidazole) of hnRNA and mRNA production in HeLa cells. Cell 9:473-80.

158. Selby, C. P., R. Drapkin, D. Reinberg, and A. Sancar. 1997. RNA polymerase II stalled at a thymine dimer: footprint and effect on excision repair. Nucl. Acids Res. 25:787-793.

159. Shen, S. X., Z. Weaver, X. Xu, C. Li, M. Weinstein, L. Chen, X. Y. Guan, T. Ried, and C. X. Deng. 1998. A targeted disruption of the murine Brcal gene causes gamma-irradiation hypersensitivity and genetic instability. Oncogene 17:3115-24.

160. Shimamura, A. 2006. Shwachman-Diamond syndrome. Semin Hematol 43:17888 .

161. Shimamura, A., R. M. de Oca, J. L. Svenson, N. Haining, L. A. Moreau, D. G. Nathan, and A. D. D'Andrea. 2002. A novel diagnostic screen for defects in the Fanconi anemia pathway. Blood 100:4649-54.

162. Siddique, M. A., K. Nakanishi, T. Taniguchi, M. Grompe, and A. D. D'Andrea. 2001. Function of the Fanconi anemia pathway in Fanconi anemia complementation group F and D1 cells. Exp Hematol 29:1448-55.

163. Sims, A. E., E. Spiteri, R. J. Sims, A. G. Arita, F. P. Lach, T. Landers, M. Wurm, M. Freund, K. Neveling, H. Hanenberg, A. D. Auerbach, and T. T. Huang. 2007. FANCI is a second monoubiquitinated member of the Fanconi anemia pathway. Nat Struct Mol Biol 14:564-567.

164. Smogorzewska, A., S. Matsuoka, P. Vinciguerra, E. R. McDonald, 3rd, K. E. Hurov, J. Luo, B. A. Ballif, S. P. Gygi, K. Hofmann, A. D. D'Andrea, and S. J. Elledge. 2007. Identification of the FANCI protein, a monoubiquitinated FANCD2 paralog required for DNA repair. Cell 129:289-301.

165. Smogorzewska, A., S. Matsuoka, P. Vinciguerra, E. R. McDonald, 3rd, K. E. Hurov, J. Luo, B. A. Ballif, S. P. Gygi, K. Hofmann, A. D. D'Andrea, and S. 
J. Elledge. 2007. Identification of the FANCI Protein, a Monoubiquitinated FANCD2 Paralog Required for DNA Repair. Cell 3:3.

166. Somesh, B. P., J. Reid, W. F. Liu, T. M. Sogaard, H. Erdjument-Bromage, P. Tempst, and J. Q. Svejstrup. 2005. Multiple mechanisms confining RNA polymerase II ubiquitylation to polymerases undergoing transcriptional arrest. Cell 121:913-23.

167. Starita, L. M., A. A. Horwitz, M.-C. Keogh, C. Ishioka, J. D. Parvin, and N. Chiba. 2005. BRCA1/BARD1 Ubiquitinate Phosphorylated RNA Polymerase II. J. Biol. Chem. 280:24498-24505.

168. Storici, F., K. Bebenek, T. A. Kunkel, D. A. Gordenin, and M. A. Resnick. 2007. RNA-templated DNA repair. Nature 447:338-41.

169. Strathdee, C. A., H. Gavish, W. R. Shannon, and M. Buchwald. 1992. Cloning of cDNAs for Fanconi's anaemia by functional complementation. Nature 356:763-7.

170. Takeuchi, T., and K. Morimoto. 1993. Increased formation of 8hydroxydeoxyguanosine, an oxidative DNA damage, in lymphoblasts from Fanconi's anemia patients due to possible catalase deficiency. Carcinogenesis 14:1115-20.

171. Taniguchi, T., and A. D. D'Andrea. 2006. Molecular pathogenesis of Fanconi anemia: recent progress. Blood 107:4223-33.

172. Taniguchi, T., and A. D. D'Andrea. 2002. The Fanconi anemia protein, FANCE, promotes the nuclear accumulation of FANCC. Blood 100:2457-62.

173. Taniguchi, T., I. Garcia-Higuera, P. R. Andreassen, R. C. Gregory, M. Grompe, and A. D. D'Andrea. 2002. S-phase-specific interaction of the Fanconi anemia protein, FANCD2, with BRCA1 and RAD51. Blood 100:2414-20.

174. Taniguchi, T., I. Garcia-Higuera, B. Xu, P. R. Andreassen, R. C. Gregory, S. T. Kim, W. S. Lane, M. B. Kastan, and A. D. D'Andrea. 2002. Convergence of the fanconi anemia and ataxia telangiectasia signaling pathways. Cell 109:459-72.

175. Taniguchi, T., M. Tischkowitz, N. Ameziane, S. V. Hodgson, C. G. Mathew, H. Joenje, S. C. Mok, and A. D. D'Andrea. 2003. Disruption of the Fanconi anemia-BRCA pathway in cisplatin-sensitive ovarian tumors. Nat Med 9:568-74. 
176. Terracciano, A., P. Chiurazzi, and G. Neri. 2005. Fragile X syndrome. Am J Med Genet C Semin Med Genet 137:32-7.

177. Thomas, B. J., and R. Rothstein. 1989. Elevated recombination rates in transcriptionally active DNA. Cell 56:619-630.

178. Thomashevski, A., A. A. High, M. Drozd, J. Shabanowitz, D. F. Hunt, P. A. Grant, and G. M. Kupfer. 2004. The Fanconi anemia core complex forms four complexes of different sizes in different subcellular compartments. J Biol Chem 279:26201-9.

179. Timmers, C., T. Taniguchi, J. Hejna, C. Reifsteck, L. Lucas, D. Bruun, M. Thayer, B. Cox, S. Olson, A. D. D'Andrea, R. Moses, and M. Grompe. 2001. Positional cloning of a novel Fanconi anemia gene, FANCD2. Mol Cell 7:241-8.

180. Tischkowitz, M., N. Ameziane, Q. Waisfisz, J. P. De Winter, R. Harris, T. Taniguchi, A. D'Andrea, S. V. Hodgson, C. G. Mathew, and H. Joenje. 2003. Bi-allelic silencing of the Fanconi anaemia gene FANCF in acute myeloid leukaemia. Br J Haematol 123:469-71.

181. Tischkowitz, M. D., N. V. Morgan, D. Grimwade, C. Eddy, S. Ball, I. Vorechovsky, S. Langabeer, R. Stoger, S. V. Hodgson, and C. G. Mathew. 2004. Deletion and reduced expression of the Fanconi anemia FANCA gene in sporadic acute myeloid leukemia. Leukemia 18:420-5.

182. Trott, D. A., and A. C. Porter. 2006. Hypothesis: transcript-templated repair of DNA double-strand breaks. Bioessays 28:78-83.

183. Ule, J., K. Jensen, A. Mele, and R. B. Darnell. 2005. CLIP: a method for identifying protein-RNA interaction sites in living cells. Methods 37:376-86.

184. van der Heijden, M. S., C. J. Yeo, R. H. Hruban, and S. E. Kern. 2003. Fanconi anemia gene mutations in young-onset pancreatic cancer. Cancer Res 63:2585-8.

185. Venkitaraman, A. R. 2002. Cancer susceptibility and the functions of BRCA1 and BRCA2. Cell 108:171-82.

186. Wang, X., P. R. Andreassen, and A. D. D'Andrea. 2004. Functional interaction of monoubiquitinated FANCD2 and BRCA2/FANCD1 in chromatin. Mol Cell Biol 24:5850-62. 
187. Wang, X., R. Kennedy, K. Ray, P. Stuckert, T. Ellenberger, and A. D. D'Andrea. 2007. Chk1-mediated Phosphorylation of FANCE is Required for the Fanconi Anemia/BRCA Pathway. Mol Cell Biol 12:12.

188. Wang, Y., D. Cortez, P. Yazdi, N. Neff, S. J. Elledge, and J. Qin. 2000. BASC, a super complex of BRCA1-associated proteins involved in the recognition and repair of aberrant DNA structures. Genes Dev 14:927-39.

189. Weinstock, D. M., C. A. Richardson, B. Elliott, and M. Jasin. 2006. Modeling oncogenic translocations: distinct roles for double-strand break repair pathways in translocation formation in mammalian cells. DNA Repair (Amst) 5:1065-74.

190. West, S. C. 2003. Molecular views of recombination proteins and their control. Nat Rev Mol Cell Biol 4:435-45.

191. Whitney, M. A., G. Royle, M. J. Low, M. A. Kelly, M. K. Axthelm, C. Reifsteck, S. Olson, R. E. Braun, M. C. Heinrich, R. K. Rathbun, G. C. Bagby, and M. Grompe. 1996. Germ cell defects and hematopoietic hypersensitivity to gamma-interferon in mice with a targeted disruption of the Fanconi anemia C gene. Blood 88:49-58.

192. Williams, B. R. 1999. PKR; a sentinel kinase for cellular stress. Oncogene 18:6112-20.

193. Wong, J. C., N. Alon, C. McKerlie, J. R. Huang, M. S. Meyn, and M. Buchwald. 2003. Targeted disruption of exons 1 to 6 of the Fanconi Anemia group A gene leads to growth retardation, strain-specific microphthalmia, meiotic defects and primordial germ cell hypoplasia. Hum Mol Genet 12:2063-76.

194. Wu, W., H. Nishikawa, R. Hayami, K. Sato, A. Honda, S. Aratani, T. Nakajima, M. Fukuda, and T. Ohta. 2007. BRCA1 Ubiquitinates RPB8 in Response to DNA Damage. Cancer Res 67:951-958.

195. Xia, B., J. C. Dorsman, N. Ameziane, Y. de Vries, M. A. Rooimans, Q. Sheng, G. Pals, A. Errami, E. Gluckman, J. Llera, W. Wang, D. M. Livingston, H. Joenje, and J. P. de Winter. 2007. Fanconi anemia is associated with a defect in the BRCA2 partner PALB2. Nat Genet 39:159-61.

196. Xia, B., Q. Sheng, K. Nakanishi, A. Ohashi, J. Wu, N. Christ, X. Liu, M. Jasin, F. J. Couch, and D. M. Livingston. 2006. Control of BRCA2 Cellular and Clinical Functions by a Nuclear Partner, PALB2. Molecular Cell 22:719-729. 
197. Yagasaki, H., D. Adachi, T. Oda, I. Garcia-Higuera, N. Tetteh, A. D.

D'Andrea, M. Futaki, S. Asano, and T. Yamashita. 2001. A cytoplasmic serine protein kinase binds and may regulate the Fanconi anemia protein FANCA. Blood 98:3650-7.

198. Yamamoto, K., S. Hirano, M. Ishiai, K. Morishima, H. Kitao, K. Namikoshi, M. Kimura, N. Matsushita, H. Arakawa, J. M. Buerstedde, K. Komatsu, L. H. Thompson, and M. Takata. 2005. Fanconi anemia protein FANCD2 promotes immunoglobulin gene conversion and DNA repair through a mechanism related to homologous recombination. Mol Cell Biol 25:34-43.

199. Yamamoto, K., M. Ishiai, N. Matsushita, H. Arakawa, J. E. Lamerdin, J. M. Buerstedde, M. Tanimoto, M. Harada, L. H. Thompson, and M. Takata. 2003. Fanconi anemia FANCG protein in mitigating radiation- and enzymeinduced DNA double-strand breaks by homologous recombination in vertebrate cells. Mol Cell Biol 23:5421-30.

200. Yamashita, T., G. M. Kupfer, D. Naf, A. Suliman, H. Joenje, S. Asano, and A. D. D'Andrea. 1998. The fanconi anemia pathway requires FAA phosphorylation and FAA/FAC nuclear accumulation. Proc Natl Acad Sci U S A 95:13085-90.

201. Yamashita, T., N. Wu, G. Kupfer, C. Corless, H. Joenje, M. Grompe, and A. D. D'Andrea. 1996. Clinical variability of Fanconi anemia (type C) results from expression of an amino terminal truncated Fanconi anemia complementation group C polypeptide with partial activity. Blood 87:4424-4432.

202. Yamashita, T., N. Wu, G. Kupfer, C. Corless, H. Joenje, M. Grompe, and A. D. D'Andrea. 1996. Clinical variability of Fanconi anemia (type C) results from expression of an amino terminal truncated Fanconi anemia complementation group C polypeptide with partial activity. Blood 87:4424-32.

203. Yang, Y. G., Z. Herceg, K. Nakanishi, I. Demuth, C. Piccoli, J. Michelon, G. Hildebrand, M. Jasin, M. Digweed, and Z. Q. Wang. 2005. The Fanconi anemia group A protein modulates homologous repair of DNA double-strand breaks in mammalian cells. Carcinogenesis.

204. Yu, K., and M. R. Lieber. 2003. Nucleic acid structures and enzymes in the immunoglobulin class switch recombination mechanism. DNA Repair (Amst) 2:1163-74. 
205. Yu, K., D. Roy, F. Huang, M. R. Lieber, J. L. Campbell, and P. Modrich. 2006. Detection and Structural Analysis of R-Loops, p. 316-329, Methods in Enzymology, vol. Volume 409. Academic Press.

206. Zhang, H., K. Somasundaram, Y. Peng, H. Tian, H. Zhang, D. Bi, B. L. Weber, and W. S. El-Deiry. 1998. BRCA1 physically associates with p53 and stimulates its transcriptional activity. Oncogene 16:1713-21.

207. Zhang, X., J. Li, D. P. Sejas, K. R. Rathbun, G. C. Bagby, and Q. Pang. 2004. The Fanconi anemia proteins functionally interact with the protein kinase regulated by RNA (PKR). J Biol Chem 279:43910-9.

208. Zhou, B. B., and S. J. Elledge. 2000. The DNA damage response: putting checkpoints in perspective. Nature 408:433-9.

209. Zunino, A., P. Degan, T. Vigo, and A. Abbondandolo. 2001. Hydrogen peroxide: effects on DNA, chromosomes, cell cycle and apoptosis induction in Fanconi's anemia cell lines. Mutagenesis 16:283-8. 